\title{
Proteasome-dependent truncation of the negative heterochromatin regulator Epe1 mediates antifungal resistance
}

\author{
Imtiyaz Yaseen ${ }^{1,2,5}$, Sharon A. White ${ }^{1,2,5}$, Sito Torres-Garcia ${ }^{1,2}$, Christos Spanos ${ }^{1,2}$, \\ Marcel Lafos ${ }^{1,2}$, Elisabeth Gaberdiel ${ }^{1,2}$, Rebecca Yeboah ${ }^{1,2}$, Meriem El Karoui ${ }^{2,3}$, Juri \\ Rappsilber ${ }^{1,4}$, Alison L. Pidoux ${ }^{1,2}$, and Robin C. Allshire ${ }^{1,2,3^{*}}$.
}

${ }^{1}$ Wellcome Trust Centre for Cell Biology, ${ }^{2}$ Institute of Cell Biology, ${ }^{3}$ SynthSys, School of Biological Sciences, The University of Edinburgh, Edinburgh EH9 3BF, Scotland UK.

${ }^{4}$ Institute of Biotechnology, Technische Universität, Gustav-Meyer-Allee25, 13355 Berlin, Germany.

${ }^{5}$ These authors contributed equally.

* Corresponding author: robin.allshire@ed.ac.uk

Tel: 00-44-7753-741307 


\section{Abstract}

Epe1 histone demethylase restricts H3K9-methylation-dependent heterochromatin, preventing it from spreading over, and silencing, gene-containing regions in fission yeast. External stress induces an adaptive response allowing heterochromatin island formation that confers resistance on surviving wild-type lineages. Here we investigate the mechanism by which Epe1 is regulated in response to stress. Exposure to caffeine or antifungals results in Epe1 ubiquitylation and proteasome-dependent removal of the $\mathrm{N}$-terminal 150 residues from Epe1, generating truncated tEpe1 which accumulates in the cytoplasm. Constitutive tEpe1 expression increases H3K9 methylation over several chromosomal regions, reducing expression of underlying genes and enhancing resistance. Reciprocally, constitutive noncleavable Epe1 expression decreases resistance. tEpe1-mediated resistance requires a functional JmjC demethylase domain. Moreover, caffeine-induced Epe1-to-tEpe1 cleavage is dependent on an intact cell-integrity MAP kinase stress signalling pathway, mutations in which alter resistance. Thus, environmental changes provoke a mechanism that curtails the function of this key epigenetic modifier, allowing heterochromatin to reprogram gene expression, thereby bestowing resistance to some cells within a population. H3K9me-heterochromatin components are conserved in human and crop plant fungal pathogens for which a limited number of antifungals exist. Our findings reveal how transient heterochromatin-dependent antifungal resistant epimutations develop and thus inform on how they might be countered. 


\section{Main}

The overuse in agriculture of antifungal agents, related to those used in treating human fungal infections, has caused progressive increases in resistance in soil-borne fungi ${ }^{1}$. Consequently, clinical treatment of patients exhibiting aspergillosis (Aspergillus), candidiasis (Candida) or cryptococcosis (Cryptococcus) is challenging due to the limited number of effective antifungal drugs and the increasing prevalence of resistance ${ }^{2-4}$. A dilemma exists as widespread use of antifungals in agriculture is required to combat major plant pathogens such as Magnaporthe oryzae (rice; blast fungus) and Zymoseptoria tritici (wheat; leaf blotch) in order to enhance crop yields. Optimised crop production is required to meet the nutritional needs of the human population that is estimated to increase by approximately 2 billion in the next 30 years ${ }^{5}$. It is therefore important to understand the mechanisms that allow fungi to adapt and develop resistance to external insults such as antifungals in order to design more prudent interventions in clinical and agricultural settings.

Throughout their evolutionary history fungi have been exposed to challenging environments ${ }^{6}$. Consequently, fungi have developed robust, intricate systems to sense and adapt to 'new' external insults such as antifungal compounds. Altered environments or manipulations are known to allow transcriptional memory and epigenetic inheritance in single-celled organisms such as fungi ${ }^{7-13}$, and also in multicellular organisms ${ }^{14-17}$ so that resulting DNA and chromatin modifications can persist through cell division, long after the original stimulus has dissipated. Such 'epigenetic memory' encourages heterogeneity with variable persistence in otherwise genetically identical cell populations, providing a bet-hedging strategy that ensures adaptation and survival of a proportion of individual cells upon exposure to new environmental challenges. Thus, transient but metastable epigenetic states can confer a selective advantage to particular cell lineages within a clonal population, while allowing return to the initial normal state once external pressures are relaxed ${ }^{13}$.

The fission yeast Clr4 methyltransferase installs all histone $\mathrm{H} 3 \mathrm{~K} 9$ methylation, triggering heterochromatin formation and transcriptional repression at locations such as centromeres, telomeres, the mating-type locus ${ }^{18-21}$, and facultative heterochromatin islands ${ }^{22-26}$. Heterochromatin assembly is antagonized by the histone acetyltransferase Mst2, which acetylates $\mathrm{H} 3$, preventing $\mathrm{H} 3 \mathrm{~K} 9$ methylation, and the JmjC domain histone demethylase Epe1 that likely removes superfluous $\mathrm{H} 3 \mathrm{~K} 9$ methylation from euchromatic regions and islands ${ }^{22,27-}$ 30. S. pombe lacks DNA methylation ${ }^{31,32}$, thus its heterochromatin-mediated epigenetic regulation relies entirely on histone modification. 
In the absence of Epe1 synthetic heterochromatin induced at ectopic chromosomal locations can be transmitted through multiple cell divisions by a read-write mechanism following the release of the heterochromatin-nucleating activity ${ }^{7,8}$. Recently we demonstrated that heterochromatin redistributes in an acute response to caffeine stress ${ }^{13}$. Caffeine treatment resulted in Epe1 down-regulation, suggesting that this allows heterochromatin assembly at beneficial loci. However, the mechanism of Epe1 regulation in response to caffeine stress remained unexplained.

Here we determine how Epe1 levels are down-regulated in response to external stresses caffeine and antifungal agents. Unexpectedly, we find that the $\mathrm{N}$-terminal region of Epe1 is removed in response to insults, resulting in diminished Epe1 heterochromatin nuclear foci, cytoplasmic accumulation and redistribution of heterochromatin to other locations, including those that confer resistance through resulting gene repression. Epe1 cleavage is mediated by E3 ubiquitin ligases and the proteasome in a process resembling regulated ubiquitin/proteasome-dependent processing (RUP) ${ }^{33,34}$. Constitutive tEpe1 expression results in more $\mathrm{H} 3 \mathrm{~K} 9$ me-heterochromatin, increased associated gene repression and elevated resistance. Epe1 processing is dependent on signalling through the cell integrity MAP kinase stress pathway which therefore modulates heterochromatin-mediated caffeine and antifungal resistance. Epe1-related histone demethylase proteins are broadly conserved, suggesting that similar mechanisms contribute to adaption to external insults and antifungal resistance in pathogenic fungi.

\section{Results}

\section{Epe1 exhibits altered mobility upon exposure to stress}

Exposure of fission yeast expressing $\mathrm{N}$-terminally 3xFLAG-tagged Epe1 to caffeine results in reduced levels of this key negative regulator of heterochromatin ${ }^{13}$. However, caffeine treatment of cells expressing C-terminally 13xMyc-tagged Epe1 (Epe1-Myc) revealed a fastermigrating form (hereafter tEpe1) and reduced levels of full-length Epe1-Myc (Fig.1a,b). This effect was independent of the tag as a faster-migrating form of C-terminally GFP-tagged Epe1 (Epe1-GFP) was also detected upon caffeine exposure (Supp. Fig.1a). tEpe1 also appeared upon osmotic $(1 \mathrm{M} \mathrm{KCl})$ or prolonged oxidative $\left(1 \mathrm{mM} \mathrm{H}_{2} \mathrm{O}_{2}\right)$ stress (Fig.1b). By comparison, neither amount nor mobility of C-terminally TAP-tagged Lid2 JmjC H3K4 demethylase ${ }^{35}$ were altered by caffeine exposure (Fig.1C). Thus, the mobility of a proportion of Epe1-Myc increases in response to several external stresses.

The appearance of tEpe1 was time and concentration dependent, with tEpe1 visible after $7 \mathrm{~h}$ exposure to $14 \mathrm{mM}$ caffeine and increasing steadily thereafter, and upon $16 \mathrm{~h}$ treatment with 
5-15mM caffeine (Fig.1d,e). Upon caffeine removal after 14mM/16h treatment, the proportion of tEpe1 declined with time and was undetectable after $9 \mathrm{~h}$ when levels of normally migrating Epe1-Myc had recovered to those of untreated cells (Fig.1f,g). Cycloheximide prevented recovery, indicating that new protein synthesis is needed to restore Epe1-Myc to the normally migrating form (Fig.1f,h).

\section{Altered Epe1 mobility results from cleavage and loss of its $\mathrm{N}$-terminal region}

Altered protein mobility can result from changes in transcription, translation initiation, posttranslational modifications or protein cleavage. epe1 contains no introns, precluding altered splicing as an explanation (www.pombase.org/gene/SPCC622.16c). RT-qPCR analysis indicated that steady state levels of epe 1 transcript measured either immediately upstream of the initiating AUG or within the coding sequence were unaffected by caffeine (Supp. Fig.1b). Thus, stress-induced tEpe1 is unlikely to result from a downstream transcriptional start site (TSS). Indeed, no change in epe $1^{+}$TSS usage in stress was previously detected ${ }^{36}$.

Mass spectrometry analysis of affinity-selected Epe1-GFP indicated that several residues gained phosphorylation following caffeine treatment (Supp. Fig.1c). However, the mobility of neither normally migrating nor tEpe1 was altered by lambda phosphatase treatment, suggesting that phosphorylation does not cause the stress-mediated increase in Epe1 mobility (Supp. Fig.1d).

To investigate if exposure to caffeine results in post-translational cleavage of Epe1, a strain expressing Epe1 tagged at both the $\mathrm{N}$-terminus (3xMyc) and C-terminus (GFP) from the endogenous locus was constructed (Myc-Epe1-GFP). Anti-GFP westerns following caffeine treatment detected tEpe1-GFP but only the normal, slower-migrating form was detected by anti-Myc western, albeit it at a reduced level (Fig.2a). This observation suggests that in response to stress a region containing the $\mathrm{N}$-terminal $3 \mathrm{xMyc}$ tag is cleaved away from MycEpe1-GFP to leave both full-length (FL-) Epe1-GFP and truncated tEpe1-GFP detectable.

\section{The $\mathbf{N}$-terminal region of Epe1 carries a portable signal for stress-mediated processing}

To investigate the requirements for stress-induced Epe1 cleavage strains expressing a series of $\mathrm{N}$-terminal truncations of Epe1-GFP were generated (Fig.2b). Epe1 $\Delta$ N50-GFP, Epe $1 \Delta$ N100-GFP, Epe1 $\Delta$ N150-GFP, and Epe1 $1 \Delta$ N200-GFP truncated proteins were expressed at similar levels to FL-Epe1-GFP. Following caffeine treatment, cells expressing Epe1-GFP, Epe1 $\Delta$ N50-GFP, or Epe1 $\Delta$ N100-GFP exhibited faster-migrating forms. However, no caffeine-induced change in Epe1 $\Delta$ N150-GFP or Epe1 $\Delta$ N200-GFP mobility was observed 
(Fig.2b), suggesting that a region required for caffeine-induced cleavage resides between Epe1 residues 100 and 150.

Further strains, expressing Epe1-GFP proteins lacking 10 or 20 residues between residues 100 and 210 (Fig.2c; Supp. Fig.2a) were subjected to western analysis following caffeine treatment. Removal of residues 101-110 prevented stress-mediated cleavage of Epe1 101 110-GFP whereas FL-Epe1-GFP, Epe1 $\Delta 111-120-G F P$, Epe1 $\Delta 111-130-G F P$ and Epe1 $1130-$ 150-GFP, Epe1 1 151-170-GFP, Epe1 $\Delta 171-190-G F P$ and Epe1 $\Delta 190-210-G F P$ all exhibited a faster-migrating form. These analyses suggest that residues 101-110 are required for Epe1 cleavage. Direct comparison of caffeine-induced tEpe1 migration with Epe1 $\Delta$ N150-GFP and Epe $1 \Delta$ N200-GFP indicated that, although residues $101-110$ are necessary for Epe1 processing, the new $\mathrm{N}$-terminus resides near residue 150 (Fig.2d,e). A precise cleavage site in Epe1 could not be defined by mass spectrometry. However, after Epe1-Myc immunoprecipitation (three replicates), three peptides (residues: 52-57, 57-67, 83-96) from within the first 150 amino acids of FL-Epe1-Myc were identified in cells grown without caffeine with high confidence (1\% FDR) but were not detectable from tEpe1 following caffeine treatment. In contrast, fifteen peptides beyond residue 150 were detected with high confidence (1\% FDR) from both FL-Epe1-Myc and tEpe1-Myc (Supp. Fig.2b).

To determine if the $\mathrm{N}$-terminal region is sufficient to mediate caffeine-induced cleavage the

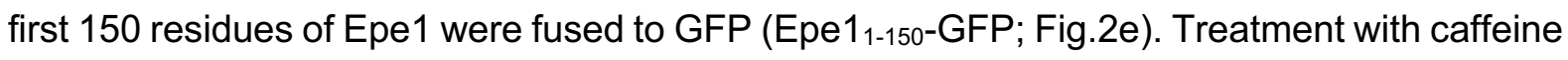

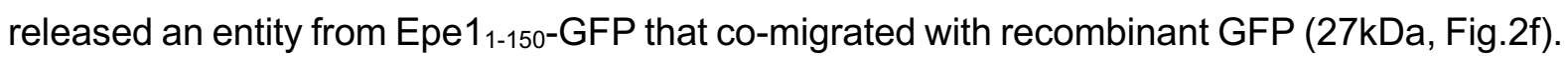
We conclude that the first 150 residues of Epe1 are necessary and sufficient to drive cleavage of a heterologous protein in response to external stress.

\section{Caffeine-induced Epe1 $\mathrm{N}$-terminal removal is proteasome dependent}

To gain insight into the mechanism of Epe1 stress-mediated cleavage we affinity selected Epe1-GFP from cells grown with or without $14 \mathrm{mM}$ caffeine and applied proteomics to identify associated proteins. Notably, caffeine treatment resulted in increased association of 23 of 35 known proteasome subunits ${ }^{38}$, representing components of both the $20 \mathrm{~S}$ core (9) and $19 \mathrm{~S}$ regulatory (14) particles, with Epe1-GFP (Fig.3a). Caffeine-induced cleavage of 3xMyc-Epe1GFP should release an $\mathrm{N}$-terminal product of approximately 180 residues with a predicted mass of $\sim 20 \mathrm{kDa}$ (including $3 \mathrm{xMyc}$ ). However, no such product was detected, suggesting that the $\mathrm{N}$-terminal fragment is rapidly degraded by the proteasome following its initial cleavage (Supp. Fig.3a). To test proteasome involvement in stress-mediated post-translational processing of Epe1 we examined Epe1-13xMyc processing in cells harbouring the $m t s 2-1$ mutation in the Rpt2/ATPase subunit of the 195 proteasome regulatory particle ${ }^{39}$. tEpe1 was 
generated in wild-type but not $m t s 2-1$ cells grown at the permissive temperature, indicating that proteasome function contributes to caffeine-dependent Epe1 cleavage (Fig.3b). A shorter Mst2 histone acetyltransferase (HAT) isoform is made in response to stress by a distinct mechanism involving use of a downstream TSS ${ }^{13,36}$. Production of $\mathrm{N}$-terminally truncated Mst2-13xMyc in caffeine was unaffected by the $m t s 2-1$ mutant: indicating that proteasomemediated processing is Epe1 specific and that $m$ ts2-1 does not prevent other changes in response to caffeine stress (Supp. Fig.3b).

The proteasome inhibitor bortezomib primarily inhibits the Pts $1 / 35$ peptidase of the $20 \mathrm{~S}$ core particle ${ }^{40}$. Addition of bortezomib prevented processing of Epe1-Myc to tEpe1 in the presence of caffeine, and also inhibited caffeine-induced release of GFP from Epe11-150-GFP (Fig.3c,d). In contrast, bortezomib did not inhibit caffeine-induced Mst2/HAT truncation (Supp. Fig.3c), indicating that stress-induced protein truncation is not generally inhibited by defective proteasome function.

Epe1 is a nuclear protein concentrated in 2-4 heterochromatic foci representing clustered centromeres, telomeres and the silent mating type locus ${ }^{28,41}$. Treatment of wild-type cells with caffeine resulted in loss of all major nuclear Epe1-GFP foci but not the distinct centromerespecific histone CENP-A ${ }^{\text {Cnp1 }}$ signal (Supp. Fig.3d,e). Nuclear Epe1-GFP accumulated in proteasome compromised $m t s 2-1$ cells (permissive temperature), consistent with the known Cul4-Ddb1 ${ }^{\text {Cdt2 }}$-mediated ubiquitin-dependent removal of Epe1 from within major blocks of heterochromatin ${ }^{42}$. Although nuclear Epe1 levels were somewhat decreased by addition of caffeine to mts2-1 cells, substantial amounts remained. Thus, proteasome function, and presumably proteasome-dependent Epe1 processing, is required to deplete nuclear Epe1 in response to caffeine stress.

Following caffeine treatment increased ubiquitin associated with affinity-purified Epe1-Myc and Epe1-Myc was enriched on ubiquitin-binding beads (Fig.3e,f). Thus, ubiquitylation of Epe1 is associated with Epe1-to-tEpe1 caffeine-induced proteasome-dependent processing. The Cul4-Ddb1 ${ }^{\text {Cdt2 }}$ E3 ubiquitin ligase targets Epe1 for degradation within major heterochromatin domains ${ }_{2}^{42}$ however, Ddb1 ${ }^{\text {Cdt2 }}$ loss had little impact on Epe1-to-tEpe1 processing (Supp. Fig.3f) suggesting involvement of other E3 ligases. Our proteomics analysis of affinity-selected Epe1-GFP detected enrichment of the Hul5 and Pub3 E3 ubiquitin ligases in the presence or absence of caffeine, respectively (Fig.3a). Cells lacking Hul5 exhibited decreased caffeine-induced Epe1-to-tEpe1 processing, whereas deletion of pub3 ${ }^{+}$had little impact alone or in combination with hul5s. Thus Hul5, but not Pub3, E3 ubiquitin ligase 
contributes to proteasome-mediated Epe1 processing in response to caffeine (Fig. $3 \mathrm{~g}$ ). Consistent with decreased Epe1-to-tEpe1 processing in response to external stress, both hul $5 \Delta$ and hul5 $\Delta$ pub3 $\Delta$ cells, but not pub3 $\Delta$ or $d d b 1 \Delta$ cells, exhibited a lower frequency of caffeine and fluconazole resistant colonies compared to wild-type cells (Fig.3h). We conclude that Hul5 E3 ubiquitin ligase contributes to the removal of the N-terminal region from Epe1 to generate tEpe1 by promoting its ubiquitin-dependent proteasome-mediated processing.

\section{$\mathrm{N}$-terminally truncated Epe1 accumulates in the cytoplasm}

To further investigate the cellular location of processed Epe1-GFP we utilized constitutively expressed $\mathrm{N}$-terminal truncations. Epe $1 \Delta \mathrm{N} 100-\mathrm{GFP}$ gave a similar pattern and nuclear signal intensity to FL-Epe1-GFP. Removal of an additional 50 (Epe1 $\Delta$ N150-GFP) or 100 (Epe1 1 N200-GFP) residues resulted in complete loss of nuclear GFP foci, reduced nuclear signal intensity, with a corresponding increase in cytoplasmic signal intensity (Fig.4a,b). These analyses indicate that the $\mathrm{N}$-terminal 150 residues of Epe1 are required to maintain normal nuclear Epe1 levels and its concentration at heterochromatin domains, and that their removal increases the cytoplasmic location of tEpe1.

Lysates from cells expressing Epe1-Myc grown with or without caffeine were fractionated into soluble cytosolic supernatants and insoluble chromatin-containing pellets (Fig.4c,d). As expected, most $\alpha$-tubulin was released into the supernatant whereas chromatin (histone $\mathrm{H} 3$ ) was retained in the pellet. Without caffeine most Epe1 stayed in the insoluble pellet, as expected for this chromatin-associated protein. Upon caffeine-induced processing, most tEpe1 was present in the soluble fraction whereas unprocessed Epe1-Myc remained in the pellet. This finding indicates that caffeine-induced removal of Epe1's N-terminus results in its loss from chromatin. In agreement with this observation, constitutively truncated Epe $1 \Delta \mathrm{N} 150$ GFP was detected mainly in the soluble fraction and was unaffected by caffeine treatment. Moreover, comparison of full-length Epe1-GFP and Epe1 $\triangle$ N150-GFP-associated proteomes revealed that they occupy distinct cellular compartments (Supp. Fig.4a,b). Epe1-GFP associated with several other chromatin-associated nuclear proteins, including histones, the chromodomain protein Swi6, and the bromodomain proteins Bdc1 and Bdf2. In contrast, constitutively truncated Epe1 $\triangle$ N150-GFP (equivalent to the caffeine-induced tEpe1-GFP) was associated with cytoplasmic proteins, consistent with a more cytosolic location.

To minimize the deleterious effects of caffeine-induced stress on cell morphology and cytology, the location and cytoplasmic/nuclear signal intensity of Epe1-GFP was assessed in the presence and absence of a lower caffeine concentration $(7 \mathrm{mM})$. Under these less stressful conditions less Epe1-to-tEpe1 processing occurs than at higher caffeine concentrations 
(Fig.1e), and most Epe1-GFP remained in the nucleus, nevertheless, cytoplasmic Epe1-GFP signals were elevated (Fig.4e,f). Moreover, employment of the significantly brighter Halo-tag in place of GFP confirmed FL-Epe1-Halo to be primarily nuclear whereas Epe1 $\Delta \mathrm{N} 150-\mathrm{Halo}$ was distributed throughout the nucleus and cytoplasm (Fig.4g). Together these data indicate that stress-mediated Epe1-to-tEpe1 processing, for which Epe1 $\Delta$ N150-GFP and Epe1 $\Delta$ N150Halo provide constitutively expressed proxies, results in loss of tEpe1 from chromatin and its increased presence in the cytoplasm.

\section{Removal of the Epe1 N-terminal region increases heterochromatin formation}

Exposure of fission yeast to caffeine reduces Epe1 association with constitutive heterochromatin regions, alters the distribution of H3K9me-dependent heterochromatin and instigates caffeine resistance through the repression of underlying genes ${ }^{13}$. We next investigated if caffeine-induced $\mathrm{N}$-terminal Epe1 truncation results in changes to its chromatin distribution and that of heterochromatin. Silencing assays at the euchromatin-heterochromatin border on the left side of cen 1 revealed that, as in epe1 $1 \Delta$ cells, repression of the nearby inserted euchromatic ura $4^{+}$marker gene occurred in cells expressing Epe $1 \Delta \mathrm{N} 150$ (growth on counter-selective FOA plates; Supp. Fig.5a). Quantitative ChIP showed that Epe1-GFP was enriched at centromere repeats $(d g)$, a cen1 adjacent boundary region (IRC1-L) and a region near a telomere (t/h2), where Epe1 normally associates ${ }^{22,42}$ (Fig.5a). In contrast, removal of Epe1 N-terminal 150 residues (Epe1 $1 \Delta$ N150-GFP) resulted in loss of association with these regions (Fig 5a). As expected, epe1 $\Delta$ cells exhibit higher $\mathrm{H} 3 \mathrm{~K} 9 \mathrm{me} 2$ levels at known facultative heterochromatin islands ${ }^{22}$ (is/3, is/6; Fig.5b). However, cells expressing only Epe1 $\Delta$ N150-GFP exhibited greater $\mathrm{H} 3 \mathrm{~K} 9 \mathrm{me} 2$ levels at several islands (is/1, is/3, is/6, is/9). Importantly, cells expressing non-cleavable Epe1 $\Delta$ N101-110-GFP exhibited no change in its association with major heterochromatin regions compared to Epe1-GFP before or after caffeine treatment ( $d g$, IRC, tel2R; Fig.5a,c) nor in $\mathrm{H} 3 \mathrm{~K} 9 \mathrm{me} 2$ levels at $d g$ centromere repeats or any island examined (Fig.5b). Thus removal of the Epe1 $\mathrm{N}$-terminal region mimics caffeine treatment ${ }^{13}$ and Epe1 loss $^{22}$ in increasing $\mathrm{H} 3 \mathrm{~K} 9$ methylation-dependent heterochromatin at various chromosomal locations.

ChIP-seq analysis confirmed that $\mathrm{H} 3 \mathrm{~K} 9 \mathrm{me} 2$ levels increase at sub-telomeric and island regions in epe1 $\Delta$ null and Epe $1 \Delta$ N150-GFP expressing cells (Fig.5d,e). Consistent with ChIPqPCR analysis (Fig. 5b), ChIP-seq also shows that at some locations heterochromatin spreads further in Epe1 $\Delta$ N150-GFP cells relative to epe1 $\Delta$ cells, indicating that Epe1 $\Delta$ N150GFP somehow promotes increased heterochromatin formation (tel1L, is/9/mei4; Fig.5d,e). This increased spreading is particularly prominent at sub-telomeric regions and RNA-seq shows that many telomere proximal genes display even greater repression in Epe1 $\Delta \mathrm{N} 150$ - 
GFP cells compared to epe $1 \Delta$ cells (Supp. Figure 5b,c). Therefore, since Epe $1 \Delta$ N150-GFP cells are not equivalent to epe $1 \Delta$ cells, these data reveal that Epe $1 \Delta \mathrm{N} 150-\mathrm{GFP}$, a surrogate for tEpe1, retains functions that can regulate heterochromatin distribution.

\section{Truncated Epe1 and associated catalytic activity enhance caffeine and antifungal resistance through increased heterochromatin formation}

To further explore the influence of Epe1 processing on resistance of fission yeast to caffeine and antifungals we measured the frequency of caffeine resistance amongst viable cells expressing truncated or mutant forms of Epe1. Like epe1 $\Delta$, cells expressing Epe1 $\Delta$ N150-GFP displayed an increased frequency of caffeine-resistant colonies relative to cells expressing wild-type Epe1-GFP or Epe1 $\triangle$ N100-GFP (Fig.6a). In contrast, cells expressing non-cleavable Epe1 10101-110-GFP, which in response to caffeine remains enriched at major heterochromatic regions (dg, IRC-1L, tel2R; Fig.5c), exhibited greater sensitivity to caffeine than wild-type cells (Fig.6b). Removal of Clr4 H3K9 methyltransferase from epe1 $\Delta$, Epe $1 \Delta$ N100-GFP or Epe $1 \Delta$ N150-GFP cells reduced the frequency of caffeine-resistant colonies, demonstrating that heterochromatin is required to confer resistance ${ }^{13}$ (Fig.6a). Thus, Epe1 $\mathrm{N}$-terminal truncation to residue 150 results in its increased cytoplasmic location and phenocopies the $\mathrm{H} 3 \mathrm{~K} 9$ me heterochromatin-dependent resistance phenotype of epe $1 \Delta$ cells. Reciprocally, non-cleavable Epe1 $101-110$-GFP remains chromatin associated in the presence of caffeine, thus the reprogramming required to elicit resistance cannot take place, rendering these cells super-sensitive.

ChIP-qPCR performed on caffeine-resistant isolates from Epe1 $\triangle$ N150-GFP cells revealed significantly higher H3K9me2 levels over the is/14/ncRNA394 locus in eight of ten isolates analyzed (Fig.6c). Previously we showed that caffeine resistance directly results from heterochromatin-associated gene repression over is/14/ncRNA394 $4^{13}$. We therefore conclude that cells expressing constitutively truncated Epe1 $\Delta$ N150-GFP exhibit increased caffeine resistance due to similar heterochromatin-mediated epimutations.

Caffeine resistant epimutants were previously shown to also exhibit resistance to clinical and agricultural crop-plant antifungals ${ }^{13}$. As with caffeine and salt stress (Fig.1b), treatment with a clinical antifungal (fluconazole, FLC), or crop-plant fungicides enilconazole (ENL) or tebuconazole (TEB), induced Epe1-to-tEpe1 processing (Fig.6d). Moreover, N-terminally truncated Epe1 $\Delta$ N150-GFP, but not Epe1 $\Delta$ N100-GFP, increased the frequency of colonies resistant to these antifungals to levels similar to epe1 $1 \Delta$ cells (Fig.6e,f). Removal of Clr4 from epe1 $1 \Delta$, Epe1 $1 \Delta$ N100-GFP or Epe1 $\Delta$ N150-GFP cells reduced the frequency of fluconazole- 
resistant colonies, indicating that this increase in anti-fungal resistance also requires $\mathrm{H} 3 \mathrm{~K} 9 \mathrm{me}-$ dependent heterochromatin (Fig.6g).

The phenotype of cells expressing constitutively truncated Epe1 $\Delta$ N150-GFP appears similar to cells completely lacking Epe1 (epe1 $\Delta$ ) in that heterochromatin accumulates at particular chromosomal locations and both exhibit a Clr4-dependent increase in caffeine and antifungal resistance. However, insult-induced tEpe1 and Epe1 $\Delta \mathrm{N} 150$ retain an intact JmjC demethylase domain and accumulate in the cytoplasm (Fig.4). Moreover, cells expressing Epe1 $\Delta$ N150GFP exhibit elevated H3K9me2 levels at certain locations (Fig.5b,d). To determine if the JmjC domain of Epe $1 \Delta \mathrm{N} 150$ contributes to their resistance we constructed cells expressing a predicted catalytically dead version of FL-Epe1-GFP and Epe1 $\triangle$ N150-GFP bearing H297A and $\mathrm{K} 314 \mathrm{~A}$ substitutions to disrupt iron/Fe(II) and 2-oxoglutarate binding, respectively (Epe1cd-GFP, Epe1 $\Delta$ N150-cd-GFP). Both Epe1-cd-GFP and Epe1 $\Delta$ N150-cd-GFP were expressed from the epe1 locus at similar levels to their catalytically active counterparts (Supp. Fig.6a). However, cells expressing Epe1-cd-GFP (naturally induced tEpe1) or Epe1 $\Delta$ N150-cd-GFP (constitutive tEpe1) displayed reduced frequencies of caffeine and fluconazole resistant colonies relative to Epe1-GFP and Epe1 $\Delta$ N150-GFP cells (Supp. Fig.6b). Since tEpe1/Epe1 $\triangle \mathrm{N} 150$ are more cytoplasmically localized, their intact JmjC demethylase domains may promote heterochromatin-mediated resistance via other, perhaps cytoplasmic, substrates. Detailed future investigation will be required to identify potential additional Epe1 substrates and how they might contribute to resistance phenotypes.

\section{The cell integrity MAP kinase pathway regulates stress-induced proteasome-mediated Epe1 cleavage}

TOR and MAP kinase-dependent signalling pathways sense and mediate adaptation of fission yeast to the external environment. TOR serine/threonine kinase dependent pathways are major regulators of cellular metabolism, growth and cell cycle in response to nutrient availability and other stresses ${ }^{43,44}$. TORC2 signalling acts through the single downstream Gad8 effector kinase which is chromatin-associated and known to influence heterochromatin integrity $^{45,46}$ (Supp. Fig.7a). However, gad8 $\Delta$ cells exhibited relatively normal Epe1-to-tEpe1 processing but a reduced frequency of caffeine resistant colonies, suggesting that TORC2mediated signalling may counteract the effects Epe1 processing has on heterochromatin (Supp. Fig.7b,d). Indeed, TORC2/Gad8 is known to antagonise Epe1 function by promoting heterochromatin formation ${ }^{45}$.

Two fission yeast MAP kinase signalling pathways elicit responses to extracellular changes, resulting in altered gene expression enabling cell adaptation and survival ${ }^{47-49}$. The general 
stress-activated (SAP, Fig.7a) and the cell integrity (CIP, Fig.7b) pathways are interconnected, and signal through Sty1 and Pmk1 MAP kinases, respectively, to activate the key downstream transcription factor Atf1. Loss of Pek1/MAPKK or Pmk1/MAPK, but not Sty1/MAPK, dramatically reduced tEpe1-GFP generation in the presence of caffeine, retaining FL-Epe1GFP levels similar to wild-type (Fig.7c,d). Cells lacking Atf1 also retained high levels of FLEpe1, although some cleavage to tEpe1 was apparent. In contrast, cells lacking the Pmp1 phosphatase, which inhibits Pmk1, displayed even lower levels of FL-Epe1 than wild-type cells because more caffeine-induced tEpe1 was evident (Fig.7d). These results indicate that the CIP pathway is mainly responsible for regulating Epe1 processing in response to external caffeine. Epe1-to-tEpe1 processing in response to fluconazole also required intact CIP/MAPK signalling but in this case Atf1 was required for tEpe1 generation (Supp. Fig.7c); cells lacking Atf1 displayed an equivalent frequency of caffeine-resistant colonies but higher frequency of fluconazole-resistant colonies, compared to wild-type cells (Supp. Fig.7d,e). These observations suggest that caffeine and fluconazole activate Epe1 cleavage through overlapping routes.

Consistent with Pmk1 and Pmp1 promoting and hindering stress-induced Epe1 cleavage respectively, Epe1-GFP association with major heterochromatic regions in response to caffeine decreased similarly in wild-type and $p m p 1 \Delta$ cells (more cleavage), but not pek $1 \Delta$ cells (less cleavage) (cen dg, IRC1-L; Fig.7f). Moreover, as in epe1 $\Delta$ cells, pmp1 $\Delta$ cells exhibited an increased frequency of caffeine and fluconazole resistant colonies compared to wild-type (Fig.7e,h), consistent with increased Epe1-to-tEpe1 processing (Fig.7d; Supp. Fig.7c). Reciprocally, loss of the upstream Pek1/MAPKK resulted in reduced frequencies of caffeineand fluconazole-resistant colonies. Double mutant pek1 $\Delta$ epe1- $\Delta N 150$ cells exhibited a similar frequency of caffeine and fluconazole resistant colonies as epe1- $\Delta N 150$ cells. Thus, Pek1 function is bypassed by constitutive Epe1 truncation, confirming that Pek1 acts to promote resistance through Epe1-to-tEpe1 processing (Fig.7g). We conclude that the CIP/MAPK pathway is required to sense and signal the presence of external stresses that can, in part, be overcome by triggering proteasome-mediated Epe1 processing, its loss from chromatin and thus increased heterochromatin-mediated gene repression which confers resistance ${ }^{13}$ (Fig.8). 


\section{Discussion}

We have uncovered an unusual mechanism by which external stresses alter the location of the pivotal heterochromatin regulator Epe1 by inducing its proteasome-mediated processing to a shorter form lacking the $\mathrm{N}$-terminal 150 residues. As previously demonstrated ${ }^{13}$, epimutations arise due to increased heterochromatin formation over genes at various locations, allowing the survival of cells where reduced expression of underlying genes imparts beneficial resistance phenotypes in the face of external challenges. Such genes include $h b a 1^{+}$, encoding a factor involved in nuclear export of the Pap1 stress-induced transcription factor, and $\operatorname{cup} 1^{+}$, encoding a mitochondrial LYR domain protein.

Proteasome-mediated ubiquitin-dependent protein degradation is well known. However, it is less appreciated that some proteins are subject to proteasome-mediated processing in which only part of a target protein is degraded in a process termed regulated ubiquitin proteasomedependent processing (RUP) $)^{33,50-58}$. Mono-ubiquitylation of target proteins can be sufficient to stimulate such processing events ${ }^{59,60}$ which frequently terminate at nearby tightly folded structural domains ${ }^{37,56}$. Thus, elevated Epe1-Myc associated ubiquitylation and enrichment of 23 proteasome subunits with Epe1-GFP upon caffeine treatment (Fig.3a, Supp. Fig.3d) suggest that the translocating activities of the $19 \mathrm{~S}$ regulatory particle may stall at the JmjC domain. Subsequent cleavage and removal of the $\mathrm{N}$-terminal 150 residues by peptidases within the $20 \mathrm{~S}$ proteasome core would produce truncated tEpe1 (Fig.8). Proteasomedependent processing is known to result in ill-defined cleavage sites in substrate proteins due to bidirectional proteasome processivity following initiating cleavage events in the proteasome's catalytic chamber ${ }^{37}$. Thus, our inability to detect a precise cleavage site is consistent with Epe1 cleavage being mediated by the proteasome. Such proteasomemediated Epe1 processing may be relevant to the observation that 19S AAA-ATPase mutants, that do not affect ubiquitin-dependent proteolysis, exhibit an altered heterochromatin distribution ${ }^{61}$.

Epe1-to-tEpe1 processing requires an intact cell integrity signalling pathway (CIP/MAPK) to communicate the presence of external insults (Fig.7). Both Pmk1/MAPK and Pek1/MAPKK are needed for stress-induced Epe1 truncation whereas the counteracting MAPK phosphatase Pmp1 acts to restrain tEpe1 generation. We conclude that activation of the CIP/MAPK pathway by external insults results in regulated $\mathrm{N}$-terminal truncation of Epe1 by proteasomemediated cleavage (Fig.8). CIP/MAPK may directly phosphorylate Epe1 triggering its ubiquitylation. Alternatively, it might act equivalently to MAPK/SIt2 ${ }^{\mathrm{Mpk} 1}$, its $S$. cerevisiae counterpart, which stimulates the assembly of complete $26 \mathrm{~S}$ proteasomes in response to stress $^{62}$. 
Removal of residues 1-150 from Epe1 reduces its chromatin association and nuclear levels, increasing its presence in the cytoplasm, thereby permitting H3K9-methylation, and thus heterochromatin, to increase at known facultative heterochromatin islands and other locations (Fig. 5). Constitutive tEpe1 (Epe1 $\Delta \mathrm{N} 150$ ) expression also increases the frequency of caffeine and antifungal resistance relative to wild-type cells. The majority of Epe $1 \Delta \mathrm{N} 150$ caffeineresistant isolates examined exhibited high $\mathrm{H} 3 \mathrm{~K} 9 \mathrm{me} 2$ levels at is/14/ncRNA394 (Fig. 6) where reduced expression of the nearby cup $1^{+}$encoded mitochondrial protein confers caffeine and anti-fungal resistance ${ }^{13}$. Mitochondrial dysfunction is known to confer antifungal resistance in fission yeast: resistance may result from increased intracellular oxidative stress and associated Pap1 nuclear import, a key stress-regulated transcription factor which elevates efflux pump expression ${ }^{63-65}$. Moreover, higher mitochondrial membrane potential in $S$. cerevisiae correlates with greater anti-fungal resistance; possibly due to efflux pump upregulation ${ }^{66}$. Thus, pathways that respond to mitochondrial-generated stress appear to confer resistance. Interestingly, the JmjC demethylase domain of constitutively truncated Epe $1 \Delta \mathrm{N} 150$ contributes to resistance since mutants expected to disrupt its catalytic activity display reduced resistance (Supp. Fig.6b). Given the increased cytoplasmic presence of Epe $1 \Delta \mathrm{N} 150$ (Fig.4a,d), it is possible that processed tEpe1 acts through unknown cytoplasmic substrates that perhaps alter metabolism and the levels of metabolites that contribute to heterochromatin regulation via chromatin modifiers, thereby influencing resistance ${ }^{67}$.

Constitutive Epe1 truncation causes $\mathrm{H} 3 \mathrm{~K} 9$ me/heterochromatin to redistribute without any selection imposed by external insults. H3K9me2 increases over genes at various locations including heterochromatin islands and especially telomeres, where gene expression is substantially decreased (Fig.5b,d,e; Supp. Fig.5). We therefore propose that in wild-type cells continual exposure to insults triggers Epe1-to-tEpe1 proteasome-mediated processing and selects for the survival of cells where the resulting heterochromatin-imposed gene repression confers resistance through epimutations such as those at is/14/ncRNA394 that reduce cup $1^{+}$ expression (Fig.6c) ${ }^{13}$. Insults that trigger Epe1-to-tEpe1 processing include caffeine, salt, hydrogen peroxide and several clinical and agricultural azole-based antifungal compounds (Fig.1b; Fig.6d). Hence fission yeast can transiently adapt to, and resist, external insults by altering the properties and location of Epe1.

The results presented identify a route by which wild-type fungal cells use chromatin-based epigenetic reprogramming to generate epimutations that survive environmental challenges such as those posed by antifungals. Unlike genetic mutants, such resistant epimutants remain wild-type and can thus return to the normal baseline wild-type state upon removal of the 
triggering insult. However, long-term exposure to that insult will impose selection amongst surviving epimutants for irreversible genetic mutations which fix the resistant phenotype but may also reduce overall fitness. Thus, insult-triggered proteasome-mediated Epe1 processing provides a bet-hedging strategy by which wild-type cells can develop transient resistance with only temporary fitness impacts. Such epigenetic regulation may explain in part the prevalence and variability of resistance in pathogenic plant and animal fungi and may also contribute to the dearth of available effective antifungal treatments.

Azole-based antifungal overuse has resulted in increasing incidence of resistance in both clinical and agricultural settings. H3K9-methylation-dependent heterochromatin is conserved in human pathogenic fungi such as Cryptococcus ${ }^{68}$ and Aspergillus ${ }^{69}$, which threaten the health of immunocompromised individuals, and in major crop pathogens such as Zymoseptoria tritici ${ }^{70}$ and Magnaporthe oryzae ${ }^{71}$ which regularly and significantly reduce global cereal grain yields. Our findings suggest that the development of fungal-specific inhibitors of processes that regulate or mediate heterochromatin formation, and do not affect related host activities, could increase the sensitivity of pathogenic fungi to antifungal compounds. Such compounds would be expected to improve the prognosis of affected patients and reduce crop destruction. 


\section{Acknowledgements}

We thank D. Kelly (WCB, Edinburgh) for microscopy and instrumentation support; members of the Allshire Lab for valuable discussions and input; T. Urano for the 5.1.1 (H3K9me2) antibody; A. Fellas for GFP expressing and clr4 $\Delta$ strains; K. Gull for $\alpha$-tubulin antibody; K. Sawin for Mto2 antibody; A.L. Marston for the Sgo1-GFP S. cerevisiae strain; J. Svejstrup for provision of the MultiDsk2 expression construct; M.D. Wilson for comments on the manuscript; and colleagues at WCB for support and encouragement during a difficult 2020/21.

Author Contributions: I.Y. and S.A.W. designed and performed experiments. S.T.-G. contributed to ChIP, ChIP-seq and RNA-seq experiments and CRISPR design. M.L. carried out ChIP-seq and RNA-seq analyses and data visualisation. E.G. performed Halo-tag experiments. R.Y. contributed to antifungal resistance experiments. C.S. ran samples and performed mass spectrometry analysis with J.R. A.L.P. advised on experimental design, performed ChIP and constructed strains. I.Y., S.A.W., A.L.P., and R.C.A. prepared figures and wrote the manuscript.

Funding: This research was supported by award of an EMBO Long Term Fellowship to I.Y. (EMBO ALTF 130-2018), Darwin Trust of Edinburgh PhD studentships to S.T.-G. and R.Y., a Wellcome 4 Year iCM programme PhD studentship to E.G. (218470), a Wellcome Instrument grant to J.R. (108504), a Wellcome Investigator award to M.E.K. (205008), a Wellcome Principal Research Fellowship to R.C.A. (095021; 200885), core funding for the Wellcome Centre for Cell Biology (203149). The funders had no role in study design, data collection and analysis, decision to publish, or preparation of the manuscript.

Competing interests: The authors have declared that no competing interests exist.

\section{Open Access:}

This research was funded in whole or in part by the Wellcome Trust [Grant numbers 095021 , $108504,200885,203149,205008,218470$, and 203149]. For the purpose of Open Access, the author has applied a CC-BY public copyright licence to any author-accepted manuscript version arising from this submission. 


\section{Methods}

\section{Yeast strains and manipulations}

S. pombe strains used in this study are described in Supp. Table 1. Oligonucleotide sequences are listed in Supp. Table 2. N-terminus truncated Epe1 mutants, 3xMyc-Epe1 and epe1 deletion strains were constructed by CRISPR/Cas9-mediated genome editing using the SpEDIT system ${ }^{72}$; available on Addgene (\#166698, \#166699, \#166700) with oligonucleotides listed in Supp. Table 2. Epe1-GFP and Epe1-13Myc strains and deletion mutants were generated by using the Bahler tagging and deletion method ${ }^{73}$.

\section{Protein extraction and western analysis}

Cells were treated with $14 \mathrm{mM}$ caffeine, $1 \mathrm{M} \mathrm{KCl}, 1 \mathrm{mM} \mathrm{H}_{2} \mathrm{O}_{2}$ for 16 hours, with fresh $\mathrm{H}_{2} \mathrm{O}_{2}$ added every 2 hours to compensate for its decomposition. Protein samples were prepared essentially as previously detailed in Braun, et al, 2011. Briefly, a $10 \mathrm{ml}$ culture of log phase cells was harvested, resuspended in $1 \mathrm{ml}$ of cold water and transferred to an eppendorf tube. Cells were pelleted and resuspended in $775 \mu \mathrm{l}$ water. $150 \mu \mathrm{l} 1.85 \mathrm{M} \mathrm{NaOH}$ and $\beta-$ mercaptoethanol $7.5 \%$ were added and the samples incubated on ice for 15 minutes. $150 \mu \mathrm{l}$ $55 \%$ TCA was added and incubated for a further 10 minutes on ice. Samples were centrifuged at 15,000 rpm for 10 minutes and pellets were resuspended in HU-buffer (8M urea, 5\% SDS, 200mM Tris pH 6.8, 1mM EDTA, with bromo-phenol blue, 1.5 DTT).

Samples were run on a 4-12\% NuPAGE Bis-Tris gel (ThermoFisher) and blotted using the MiniBlot Module (Life Technologies) 20V for 1 hour. Western blotting detection was performed using anti-myc 9B11 (Cell Signalling) 1:1000, anti GFP (Roche) 1:1000 and anti-Mouse IgG (whole molecule)-Peroxidase antibody (Sigma) 1:10000. Gels were visualised using the ChemiDoc imaging system (BioRad) and analysed with ImageJ. Where quantified, levels of full-length (FL) Epe1 and truncated tEpe1 were normalised to no treatment and adjusted relative to the $\alpha$-tubulin loading control. Resulting numbers are an average of 3 biological replicates.

\section{Ubiquitin assay}

Harvested cells were washed with PBS and frozen in liquid nitrogen. Frozen cell pellets were ground using a Retsch MM400 mill. Ground cells were resuspended in lysis buffer (10 mM Tris pH7.4, $5 \mathrm{mM} \mathrm{CaCl}_{2}, 5 \mathrm{mM} \mathrm{MgCl} 2,50 \mathrm{mM} \mathrm{NaCl}, 0.1 \%$ IGEPAL-CA630, $20 \mu \mathrm{M} \mathrm{MG} 132,50$ $\mu \mathrm{M}$ PR-619 supplemented with protease inhibitor (Merck Life Sciences) and thawed for 30' on ice. After centrifugation at high speed, supernatants were subjected to immunoprecipitation with anti-Myc antibody crosslinked to Protein G Dynabeads beads (ThermoFisher) for $2 \mathrm{hrs}$. After three washes with lysis buffer, beads were resuspended in NuPage LDS sample buffer 
(ThermoFisher), separated on 4-12\% NuPAGE Bis-Tris gel (ThermoFisher) and probed with anti-Myc (9B11; Cell Signalling) and anti-ubiquitin (BML-PW8810; Enzo) antibodies.

\section{MultiDsk2 Pull Down assay}

MultiDsk2 pull-down assays were performed as previously described with slight modifications $^{74}$. Ground cell power was resuspended in D-buffer (150 mM Tris-Acetate $\mathrm{pH} 7.4$, $100 \mathrm{mM}$ potassium acetate, $1 \mathrm{mM}$ EDTA, 0.1\% Triton X-100, 10\% glycerol, $20 \mu \mathrm{M}$ MG132 and 50 MM PR-619 Protease Inhibitor (Merck Life Sciences)) and incubated 30' on ice. After centrifugation, $5 \mathrm{mg}$ of protein from each sample was incubated for two hours with purified Multidsk2 recombinant protein bound to glutathione agarose magnetic beads (Sigma G0924). After incubation beads were washed four times with D-buffer and resuspended in NuPage LDS sample buffer (ThermoFisher) and subjected to western analysis as described above.

\section{Serial dilution and colony count assays}

Equal amounts of cells were grown in YES without agents then serially diluted five-fold and then spotted onto appropriate media. Cells were grown at $30-32^{\circ} \mathrm{C}$ for 7 days and then imaged. For resistance assays agents were added at the following concentrations; $16 \mathrm{mM}$ caffeine (Merck Life Sciences), $1.8 \mathrm{M} \mathrm{KCl}, 0.5 \mathrm{mM}$ and $0.75 \mathrm{mM}$ Fluconazole (Merck Life Sciences), $0.0016 \mathrm{mM}$ Tebuconazole (Merck Life Sciences) and $0.006 \mathrm{mM}$ Enilconazole (Merck Life Sciences). $10^{4}$ cells were plated on 8 plates per strain in triplicate (three independent cultures) biological replicates and resistant colonies that formed after seven to ten days were counted. Significance of the difference between samples was evaluated using Student's $t$-test. $\left(^{*}\right) P$ $\left.\left.<0.033,\left({ }^{* *}\right) P<0.002 ;{ }^{* * *}\right) P<0.0002 ;{ }^{* * * *}\right) P<0.0001$; (n.s). not significant.

\section{Immunoprecipitation and mass spectrometry analysis}

IP and mass spectrometry were performed as previously described ${ }^{75}$. Cell were grown in $4 \mathrm{X}-$ YES and $2 \times 10^{10}$ cells were used per immunoprecipitation experiment. After harvesting, cells were washed twice with water and frozen in liquid nitrogen. Frozen cell pellets were ground using Retsch MM400 mill. Ground cells were resuspended in lysis buffer (10 mM Tris pH7.4, $5 \mathrm{mM} \mathrm{CaCl}_{2}, 5 \mathrm{mM} \mathrm{MgCl}_{2}, 50 \mathrm{mM} \mathrm{NaCl}, 0.1 \%$ IGEPAL-CA630 and supplemented with protease inhibitor (Merck Life Sciences) and 2 mM PMSF (Merck Life Sciences) and thawed for 30 minutes on ice. Chromatin and its associated proteins were solubilized by incubation with 420 units of Micrococcal nuclease (MNase; Merck Life Sciences) for 10 minutes at $37^{\circ} \mathrm{C}$. MNase digestion was stopped by adding EGTA to $20 \mathrm{mM}$ and lysates were rotated at $4^{\circ} \mathrm{C}$ for 1 hour to ensure chromatin solubilization. Supernatant was separated from lysates by centrifugation at $20,000 \mathrm{xg}$ for 10 minutes and used for immunoprecipitation using $20 \mu \mathrm{g}$ of antiGFP antibody (Roche) coupled to $50 \mu$ l of Protein G Dynabeads (Life Technologies) using 
dimethyl pimelimidate (DMP; Life Technologies). Bead-bound affinity-selected proteins were washed three times with lysis buffer. Elution was performed with $0.1 \%$ RapiGest SF (Waters) in $50 \mathrm{mM}$ Tris- $\mathrm{HCl} \mathrm{pH} 8$ by incubating at $50^{\circ} \mathrm{C}$ for 10 minutes.

RapiGest-eluted samples were denatured by adding final $25 \mathrm{mM}$ DTT to the and incubated at $95^{\circ} \mathrm{C}$ for 5 minutes. Samples were cooled at room temperature and $200 \mu$ of $8 \mathrm{M}$ Urea in $100 \mathrm{mM}$ Tris- $\mathrm{HCl} \mathrm{pH} 8$ was added and passed through Vivacon 500 column (Sartorius Vivacon 500, 30,000 MWCO Hydrosart) by centrifugation at 14,000xg for 30 minutes. Cysteine residues were alkylated to prevent free sulfhydryls from reforming disulfide bonds by incubation with $100 \mu \mathrm{l}$ of $0.05 \mathrm{M}$ lodoacetamide (Sigma) in $8 \mathrm{M}$ urea for 20 minutes at $27^{\circ} \mathrm{C}$ in the dark and centrifuged at $14,000 x g$ to remove the supernatant. Columns were then washed once with $100 \mu \mathrm{l}$ of $8 \mathrm{M}$ urea and twice with $100 \mu \mathrm{l}$ of $0.05 \mathrm{M}$ ammonium bicarbonate (Sigma). Proteins were digested by addition of $100 \mu$ l of $0.05 \mathrm{M} \mathrm{ABC}$ containing $0.3 \mu \mathrm{g}$ of trypsin (90057, Thermo Scientific) at $37^{\circ} \mathrm{C}$ for 16 hours. Columns were spun at $14,000 x g$ to collect the digested peptides and washed again with $100 \mu$ of 0.05 M ABC. Trypsinization was stopped by addition of $10 \mu \mathrm{l}$ of $10 \%$ trifluoroacetic acid (TFA) to bring the $\mathrm{pH}$ to below 2. C18 reversephase resin (Sigma) was used to desalt peptide samples prior to LC-MS/MS. StageTips were packed tightly with 2 layers of $\mathrm{C} 18$ resin. The resin was conditioned with $30 \mu \mathrm{l}$ of $100 \%$ methanol, washed with $30 \mu \mathrm{l}$ of $80 \%$ acetonitrile to remove impurities and finally equilibrated by passing $30 \mu \mathrm{l}$ of $0.1 \%$ TFA. The trypsinized peptide solution was passed through the stage tip by centrifugation at $2600 \mathrm{rpm}$ for binding.

Following digestion, samples were diluted with equal volume of $0.1 \%$ TFA and spun onto StageTips ${ }^{76}$. Peptides were eluted in $40 \mu$ l of $80 \%$ acetonitrile in $0.1 \%$ TFA and concentrated down to $1 \mu \mathrm{l}$ by vacuum centrifugation (Concentrator 5301, Eppendorf, UK). The peptide sample was then prepared for LC-MS/MS analysis by diluting it to $5 \mu$ by $0.1 \%$ TFA.

LC-MS analyses were performed on an Orbitrap Fusion ${ }^{\mathrm{TM}}$ Lumos $^{\mathrm{TM}}$ Tribrid $^{\mathrm{TM}}$ Mass Spectrometer (Thermo Fisher Scientific, UK) both coupled on-line, to an Ultimate 3000 HPLC (Dionex, Thermo Fisher Scientific, UK). Peptides were separated on a $50 \mathrm{~cm}(2 \mu \mathrm{m}$ particle size) EASY-Spray column (Thermo Scientific, UK), which was assembled on an EASY-Spray source (Thermo Scientific, UK) and operated constantly at $50^{\circ} \mathrm{C}$. Mobile phase A consisted of $0.1 \%$ formic acid in LC-MS grade water and mobile phase B consisted of $80 \%$ acetonitrile and $0.1 \%$ formic acid. Peptides were loaded onto the column at a flow rate of $0.3 \mu \mathrm{min}^{-1}$ and eluted at a flow rate of $0.25 \mu \mathrm{min}^{-1}$ according to the following gradient: 2 to $40 \%$ mobile phase $\mathrm{B}$ in $150 \mathrm{~min}$ and then to $95 \%$ in $11 \mathrm{~min}$. Mobile phase $\mathrm{B}$ was retained at $95 \%$ for $5 \mathrm{~min}$ and returned back to $2 \%$ a minute after until the end of the run (190 $\mathrm{min})$. 
Survey scans were recorded at 120,000 resolution (scan range $350-1500 \mathrm{~m} / \mathrm{z}$ ) with an ion target of $4.0 \mathrm{e} 5$, and injection time of $50 \mathrm{~ms}$. MS2 was performed in the ion trap at a rapid scan mode, with ion target of 2.0E4 and HCD fragmentation ${ }^{77}$ with normalized collision energy of 27. The isolation window in the quadrupole was 1.4 Thomson. Only ions with charge between 2 and 7 were selected for MS2. Dynamic exclusion was set at $60 \mathrm{~s}$.

The MaxQuant software platform ${ }^{78}$ version 1.6.1.0 was used to process the raw files and search was conducted against Schizosaccharomyces pombe complete/reference proteome set of PomBase database (released in July 2017), using the Andromeda search engine ${ }^{79}$ For the first search, peptide tolerance was set to $20 \mathrm{ppm}$ while for the main search peptide tolerance was set to $4.5 \mathrm{pm}$. Isotope mass tolerance was $2 \mathrm{ppm}$ and maximum charge to 7 . Digestion mode was set to specific with trypsin allowing maximum of two missed cleavages. Carbamidomethylation of cysteine was set as fixed modification. Oxidation of methionine, phosphorylation of serine, threonine and tyrosine and ubiquitination of lysine were set as variable modifications. Additionally, methylation of lysine and arginine, di- and tri-methylation of lysine were also set as variable modifications. Label-free quantitation analysis was performed by employing the MaxLFQ algorithm as described ${ }^{80}$. Absolute protein quantification was performed as described previously ${ }^{81}$. Peptide and protein identifications were filtered to $1 \%$ FDR.

\section{Cytology}

Cells were fixed with $3.7 \%$ formaldehyde (Sigma) for 10 minutes at room temperature. Immunolocalization staining was performed as described previously ${ }^{82}$. The following antibodies were used; anti-CENP-A ${ }^{\text {Cnp1 }}$ (sheep in-house, 1:3000), anti-GFP (ThermoFisher Scientific, 1:200), Alexa 594 and 488 labelled secondary antibodies at 1:1000 dilution (Life Technologies). Images were acquired with Zeiss Axioplan, using a 100X/1.40 NA PlanApochromat Oil DIC M27 objective lens and processed using Metamorph acquisition and processing software (Zeiss Microlmaging) or FIJI.

For imaging cells with Halo tagged proteins, 250 to 500nM of HaloTag ligand JF646 dye was added to $400 \mu \mathrm{l}$ of log phase cells and incubated at $32^{\circ} \mathrm{C}$ for 3 hours. Cells were washed with PMG and plated on a PMG agarose pad, dried before addition of a coverslip. Images were taken with an inverted microscope (Nikon TiE) equipped with an EMCCD Camera (iXion Ultra 897, Andor), a SpectraX Line engine (Lumencor) and a 100X Nikon objective (NA 1.45, oil immersion). For HaloTag ligand JF646, a red LED and a CY5 filter cube were used. Images were taken with an EM Gain of 300 and exposure times between 20 and 200ms per frame. 
For all colour channels, a series of $11 \mathrm{z}$ slices (step size $0.2 \mu \mathrm{m}$ ) were taken to cover the entire depth of the cells. Live cells were kept at $32^{\circ} \mathrm{C}$ during imaging. All image analysis was performed in FIJI as follows: a region of interest was manually selected (nuclear/cytoplasmic spot). Background intensity for each cell was subtracted from the mean intensity measurement. Significance of the difference between samples was evaluated using Student's t-test. $\left({ }^{*}\right) P<0.0 .33,\left({ }^{* *}\right) P<0.002 ;\left({ }^{* * *}\right) P<0.0002$; $\left(^{* * * *}\right) P<0.0001$; (n.s). not significant.

\section{qRT-PCR}

Total RNA was extracted using $5 \times 10^{7}$ cells and Monarch Total RNA Miniprep Kit (NEB) as per manufacturer's instructions. Samples were treated with Turbo DNase (Ambion) to remove contaminating DNA. Reverse transcription was performed using LunaScript RT SuperMix Kit (NEB). Oligonucleotides used for qRT-PCR are listed in Supp. Table 1. qRT-PCR histograms represent 3 technical replicates; error bars correspond to standard error of the mean.

\section{Fractionation}

Cells were grown in 4xYES and harvested by centrifugation at $3500 \times \mathrm{g}$, washed twice with water and flash frozen in liquid nitrogen. Frozen cell pellets were ground using Retsch MM400 mill. Ground cells were resuspended in lysis buffer $(10 \mathrm{mM}$ Tris pH7.4, 5mM CaCl2, 5mM $\mathrm{MgCl}$, $50 \mathrm{mM} \mathrm{NaCl}, 0.1 \%$ IGEPAL-CA630 and supplemented with protease inhibitor (P8215, Sigma) and 2 mM PMSF After thawing on ice for 30 minutes, sample were vortexed 15 times for 30", with one minute on ice between each wash. After centrifugation at 5,000xg, supernatant was collected as soluble fraction, pellet was washed twice with same lysis buffer and then collected as insoluble fraction.

\section{ChIP}

ChIP experiments were performed as previously described ${ }^{83}$ using anti-H3K9me2 (5.1.1, a kind gift from Takeshi Urano) or anti-GFP (Life Technologies). Immunoprecipitated DNA was recovered with Chelex-100 resin. qChIPs were analysed by real-time PCR using Lightcycler 480 SYBR Green (Roche) Oligonucleotides are listed in Supp. Table 1. ChIP enrichments were calculated as \% DNA immunoprecipitated at the locus of interest relative to the corresponding input samples. For H3K9me2 ChIP, formaldehyde fixed Schizosaccharomyces octosporus cells were added at the cell lysis stage for spike-in control. For Epe1-GFP ChIP, formaldehyde-fixed Sgo1-GFP Saccharomyces cerevisiae cells ${ }^{84}$ were added at the cell lysis stage for spike-in control. Histograms represent data averaged from three biological replicates; error bars represent standard deviations. Significance of the difference between samples was evaluated using Student's $t$-test. $\quad\left(^{*}\right) P<0.0 .33,\left({ }^{* *}\right) P<0.002 ;\left(^{* * *}\right) P<0.0002$; $\left(^{* * * *}\right) P<0.0001$; (n.s). not significant. 


\section{ChIP-seq, RNA-seq and Bioinformatic analyses}

Samples were prepared as previously described ${ }^{13}$. ChIP-seq and RNA-seq samples were compared using DESeq2 statistics of read counts per feature, accessed by HTSeq-count and genomic $1 \mathrm{~kb}$ bins for ChIP-seq or by Salmon-quant and annotated genes for RNA-seq analyses. Features with adjusted $p$-values $<0.1$ were selected as significantly changed. Features with log2 (Fold Change) values $>1$ (RNA-seq) or $>2$ (ChIP-seq) are presented in figures. 
a

b

Epe1-13xMyc

\section{C}

$14 \mathrm{mM}$ CAF

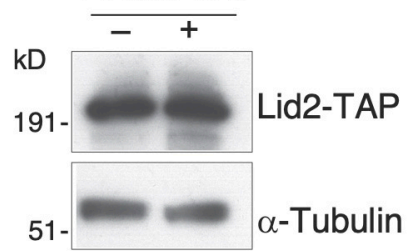

d

Tagged Epe1

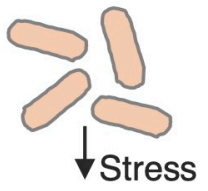

Epe1 western

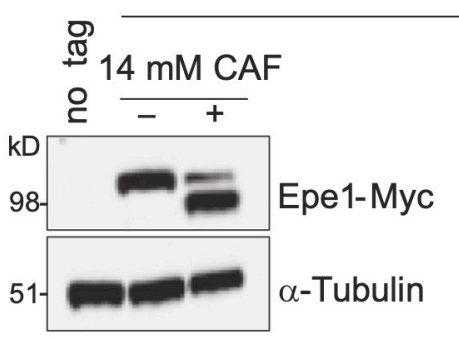

Time (hrs) in $14 \mathrm{mM}$ caffeine
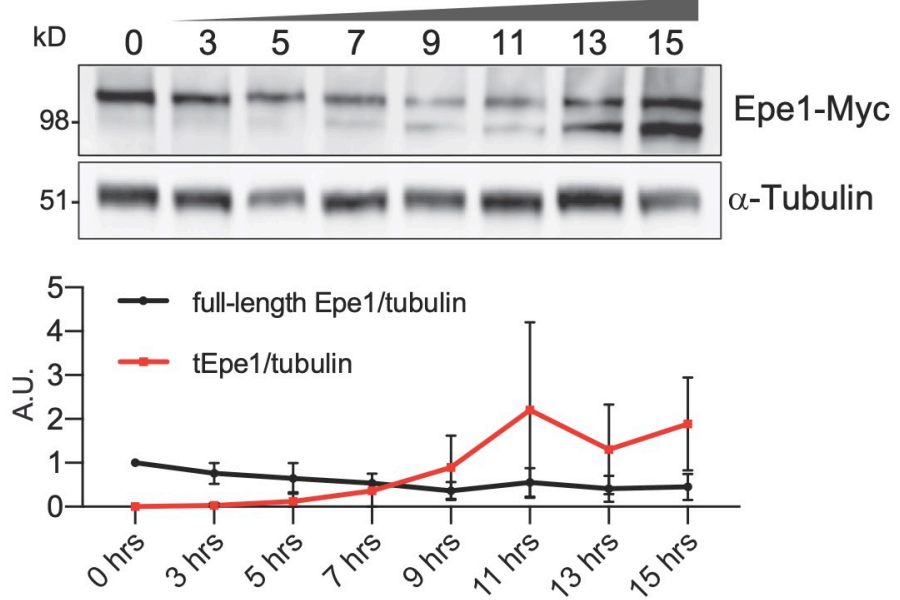

e Concentration (mM) caffeine

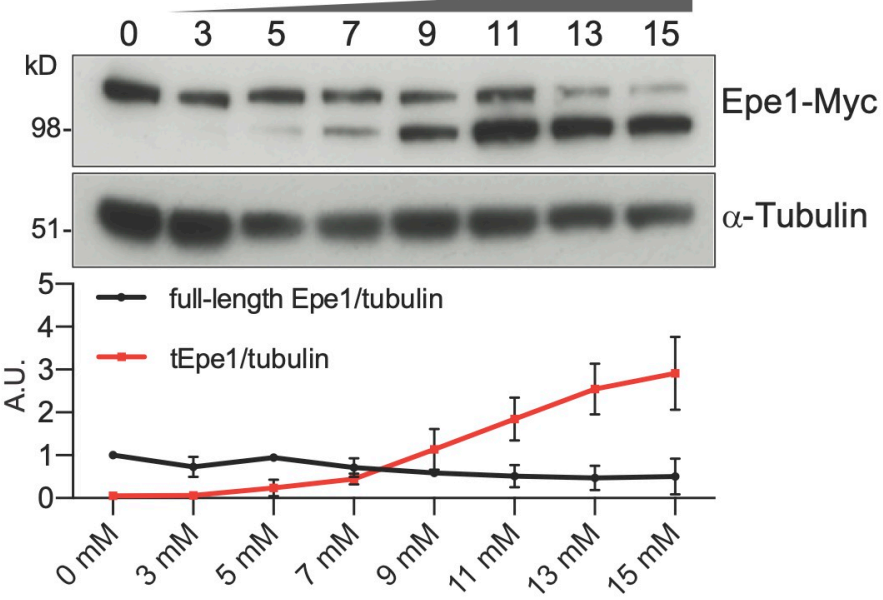

Epe1-13xMyc<smiles>Cc1ccccc1</smiles>

$\stackrel{+14 \mathrm{mM} \mathrm{CAF}}{\underset{16 \mathrm{hrs}}{\longrightarrow}}$

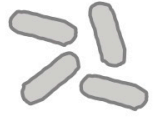

$\underset{+/-\mathrm{CHX}}{\stackrel{\text { CAF recovery }}{\longrightarrow}}$
Epe1-Myc western
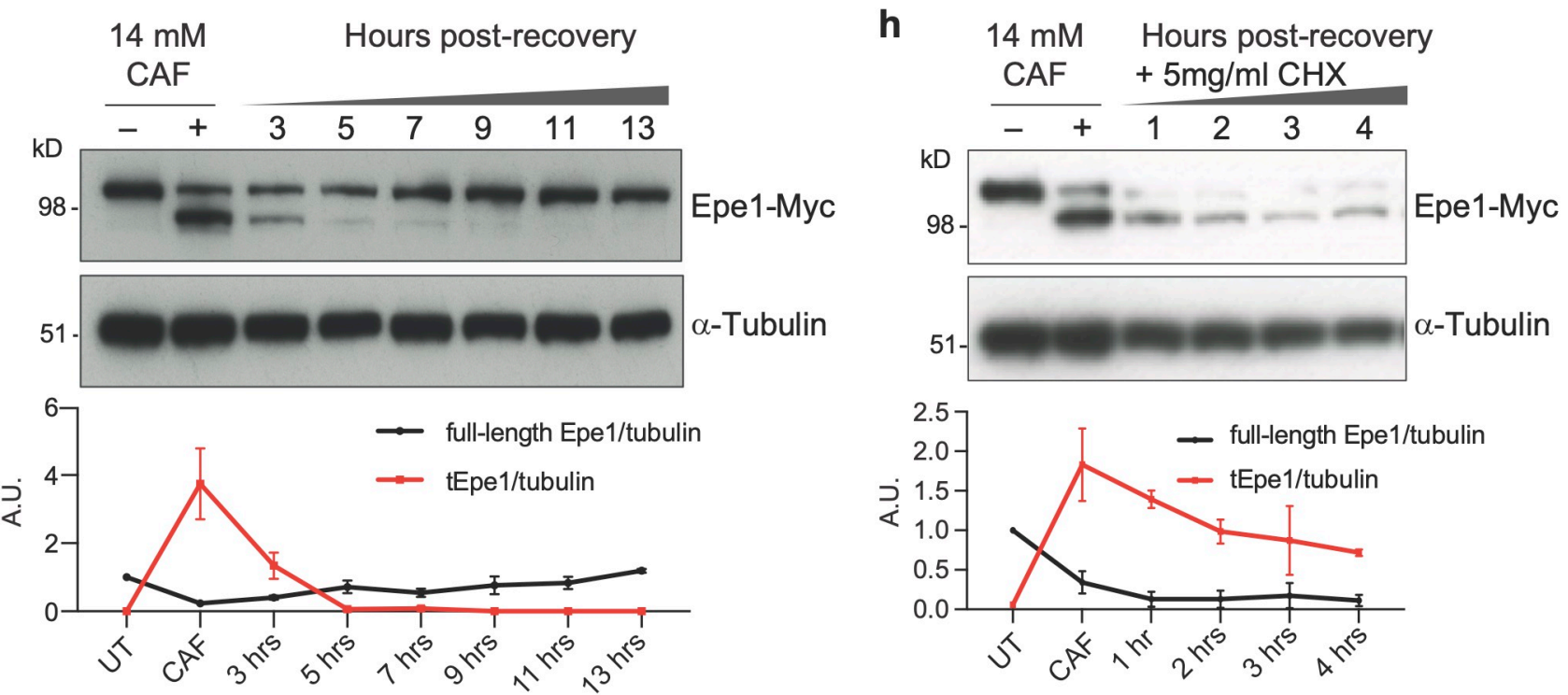

Figure 1. Yaseen, et al. 


\section{Main Figure Legends}

\section{Fig. 1: Epe1 migrates faster after caffeine stress and requires protein synthesis for}

\section{recovery}

a. Schematic of cells expressing tagged Epe1 from endogenous promoter exposed to various stresses followed by western.

b. C-terminally tagged Epe1-13xMyc or $\alpha$-tubulin western from cells untreated (-)/treated $(+)$ with $14 \mathrm{mM}$ caffeine, $1 \mathrm{M} \mathrm{KCl}$ or $1 \mathrm{mM} \mathrm{H}_{2} \mathrm{O}_{2}$ for $16 \mathrm{~h}$.

c. Lid2-TAP or $\alpha$-tubulin western from cells untreated(-)/treated(+) with $14 \mathrm{mM}$ caffeine.

d. Epe1-13xMyc or $\alpha$-tubulin western from cells incubated for indicated times in $14 \mathrm{mM}$ caffeine.

e. Epe1-13xMyc or $\alpha$-tubulin western from cells incubated with indicated caffeine concentrations for $16 \mathrm{~h}$.

f. Cycloheximide block-recovery scheme performed on Epe1-13xMyc cells.

g. Epe1-13xMyc or $\alpha$-tubulin western from cells untreated(-)/treated(+) with $14 \mathrm{mM}$ caffeine for $16 \mathrm{~h}$, following caffeine wash-out and cell recovery in absence of caffeine for indicated times. h. As $\mathrm{g}$. but recovery in $5 \mathrm{mg} / \mathrm{ml}$ cycloheximide.

Plots d,e,g,h: full-length (FL-Epe1) and truncated (tEpe1) levels relative to $\alpha$-tubulin loading control. 
bioRxiv preprint doi: https://doi.org/10.1101/2021.12.20.473483; this version posted December 20, 2021. The copyright holder for this preprint (which was not certified by peer review) is the author/funder, who has granted bioRxiv a license to display the preprint in perpetuity. It is made available under aCC-BY 4.0 International license.

a

$$
\text { myc }-1 \quad 243 \mathrm{JmjC}^{402} \quad 948-\text { GFP }
$$

Myc-Epe1-GFP $\downarrow+14 \mathrm{mM}$ caffeine

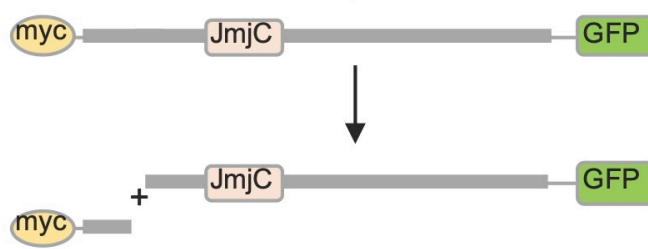

b

Epe1-GFP

Epe1 $\Delta$ N50

Epe1 $1 \Delta$ N100

Epe1 $\Delta \mathrm{N} 150$

Epe1 $1 \Delta 200$

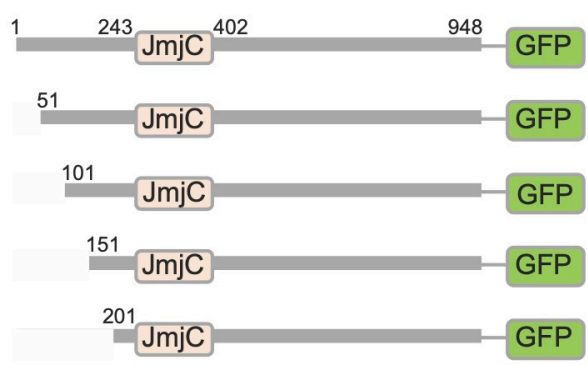

C

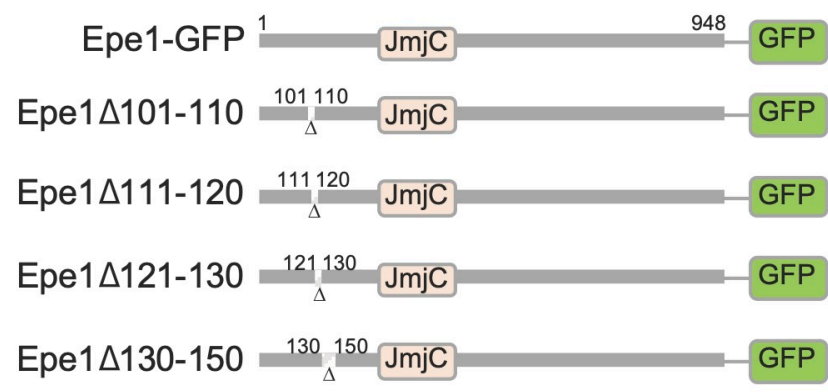

d

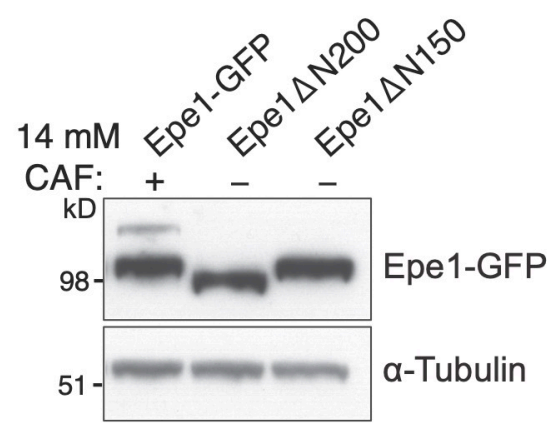

e

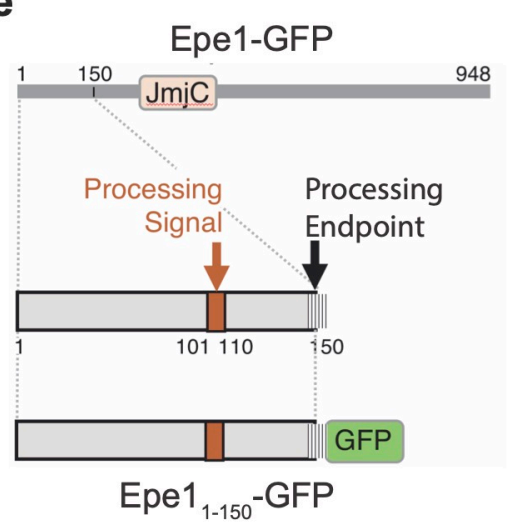

f

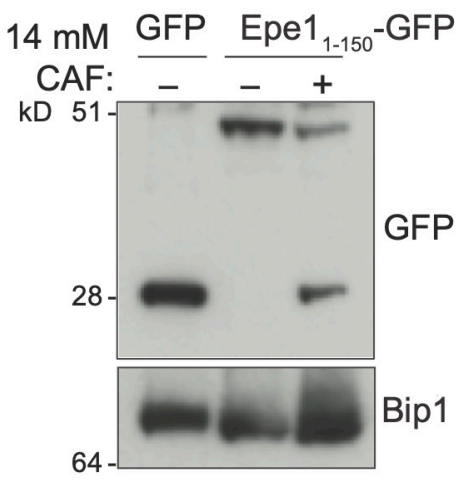

Figure 2. Yaseen, et al. 


\section{Fig. 2: Epe1 altered mobility results from cleavage and release of the $\mathrm{N}$-terminal} region

a. Schematic of 3xMyc-Epe1-GFP: cleavage in $\mathrm{N}$-terminal region would release $\mathrm{N}$-terminal 3xMyc from C-terminal GFP-tagged Epe1 of reduced size relative to full length 3xMyc-Epe1GFP (left). Myc or GFP-tagged 3xMyc-Epe1-GFP, or $\alpha$-tubulin westerns from cells untreated $(-) /$ treated $(+)$ with $14 \mathrm{mM}$ caffeine (right).

b. Schematic of indicated Epe1 N-terminal truncation mutants expressed as GFP fusions from the endogenous epe1 locus (left). N-terminal Epe1 truncation-GFP fusion proteins or $\alpha$-tubulin westerns from cells untreated (-)/treated $(+)$ with $14 \mathrm{mM}$ caffeine (right).

c. Schematic of indicated 10 or 20 residue deletion mutants in the $\mathrm{N}$-terminal coding region of the endogenous epe1 gene expressed as GFP fusions (left). Western detecting indicated mutant Epe1-GFP fusion proteins or $\alpha$-tubulin from cells untreated $(-) /$ treated $(+)$ with $14 \mathrm{mM}$ caffeine (right).

d. Western comparing Epe1-GFP migration following $14 \mathrm{mM} / 16 \mathrm{~h}$ caffeine treatment with constitutively truncated Epe1 and $\alpha$-tubulin loading control.

e. Schematic of proposed Epe1 N-terminal processing signal and endpoint.

f. Epe1N150-GFP (N-terminal 150 residues of Epe1 fused to GFP) or Bip1 loading control western from cells untreated $(-) /$ treated $(+)$ with $14 \mathrm{mM}$ caffeine. 
bioRxiv preprint doi: https://doi.org/10.1101/2021.12.20.473483; this version posted December 20, 2021. The copyright holder for this

a preprint (which was not certified by peer review) is the author/funder, who has granted bioRxiv a license to display the preprint in

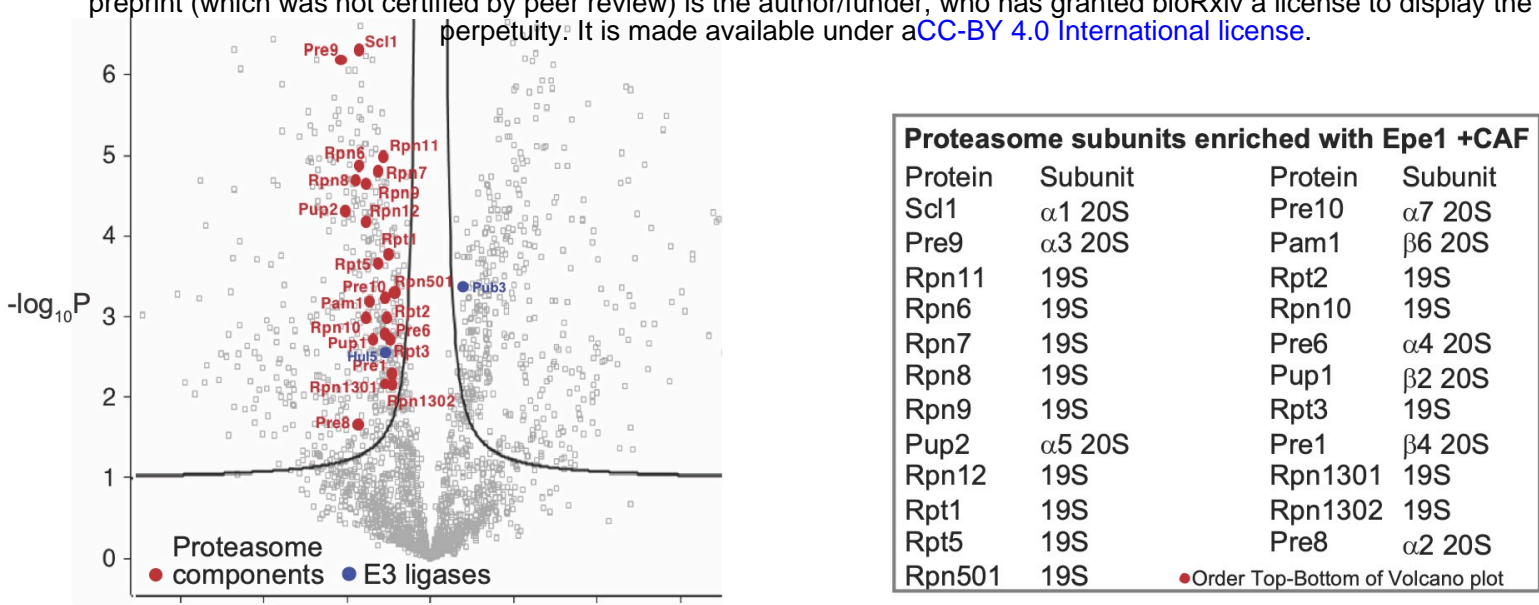

b

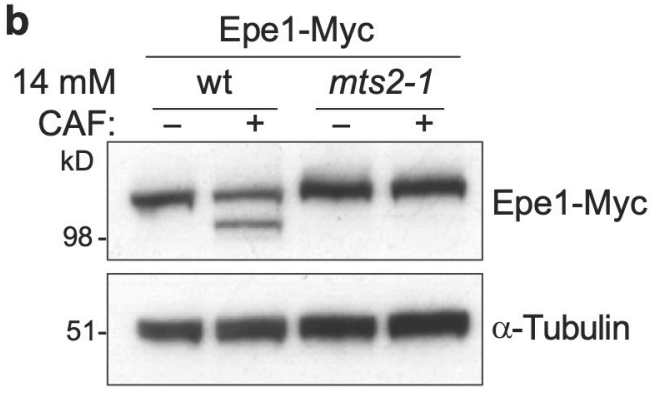

e

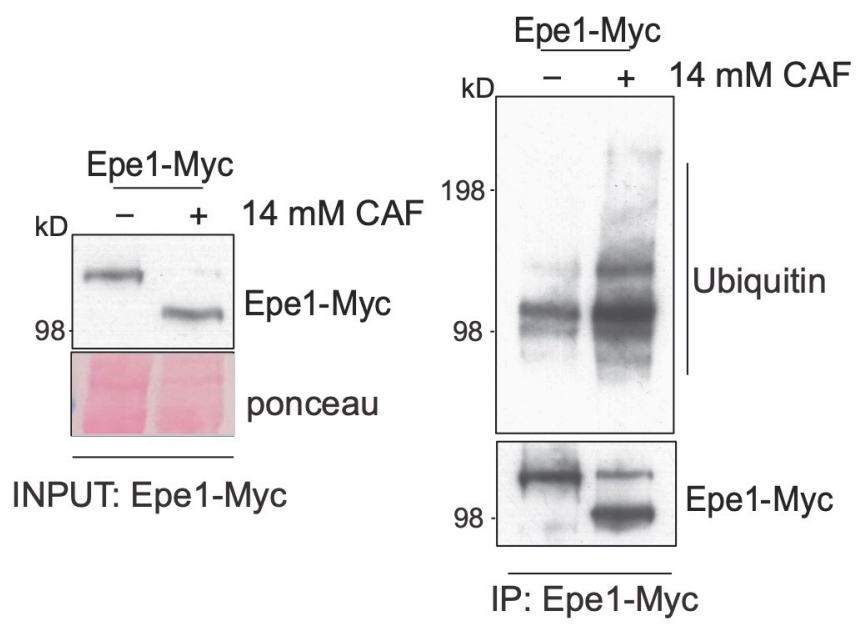

g

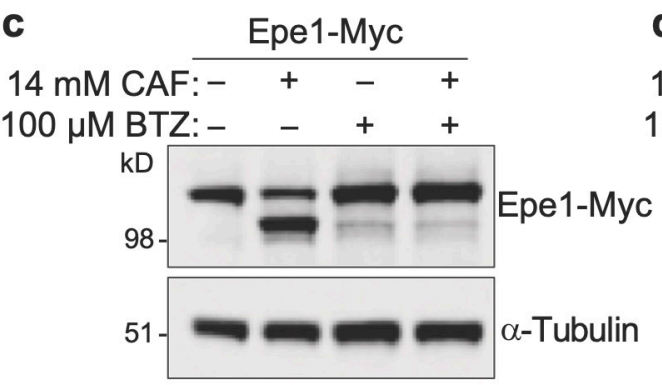

h

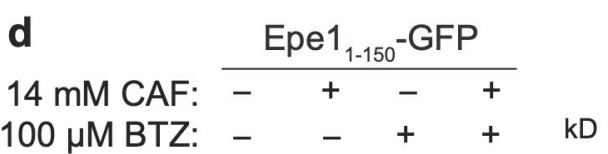

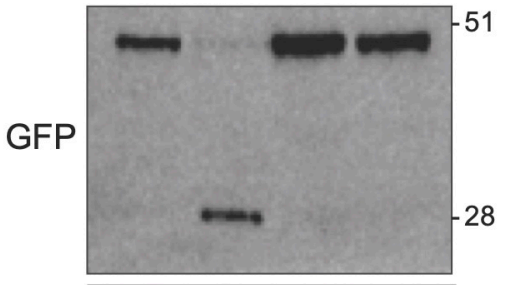

Bip1
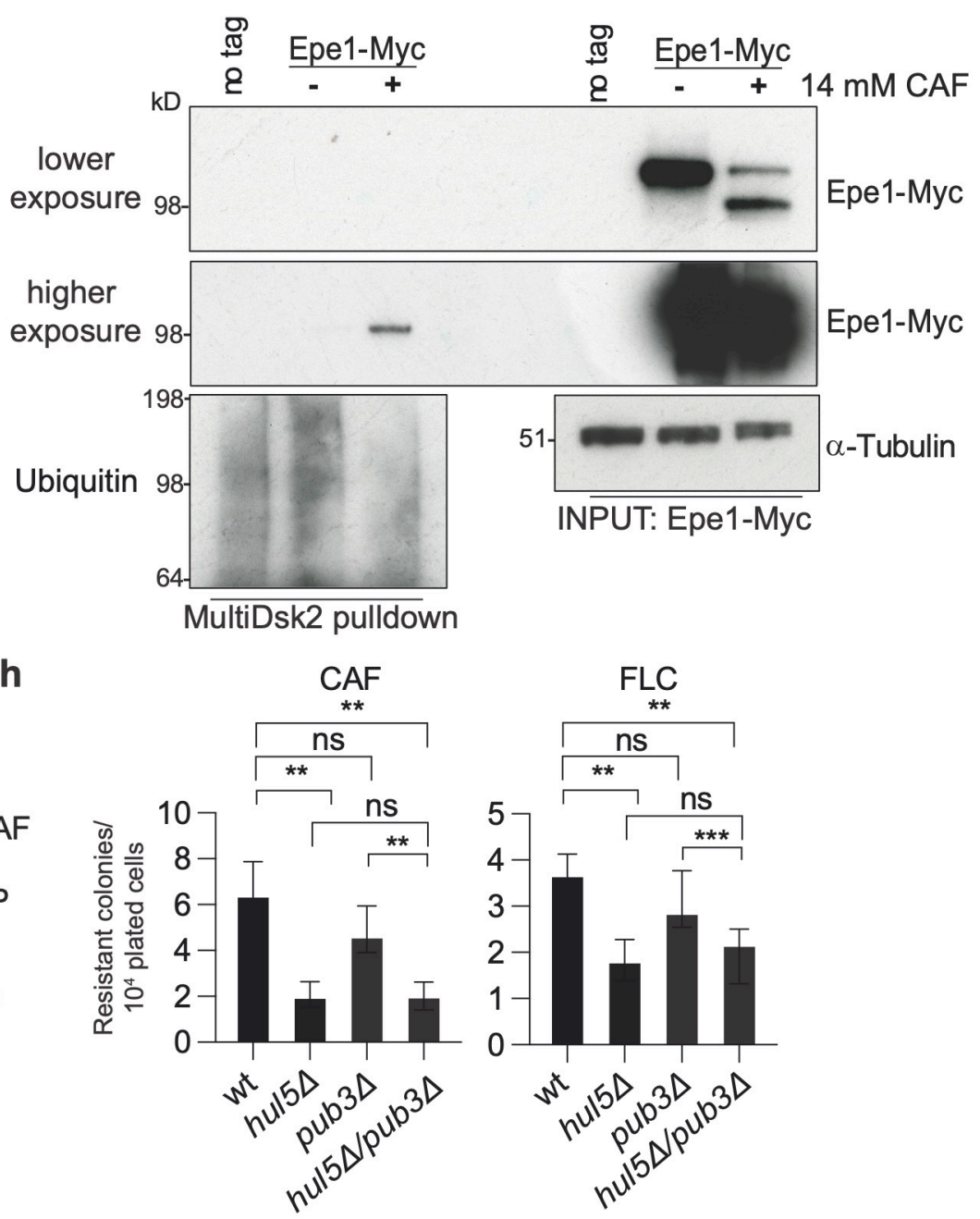

Figure 3. Yaseen, et al. 
Fig. 3: The Epe1 $\mathrm{N}$-terminal region is sufficient for caffeine-induced cleavage that is dependent on proteasome function

a. Volcano plot showing proteins enriched with Epe1-GFP by proteomic analysis of extracts from cells untreated or treated with $14 \mathrm{mM} / 16 \mathrm{~h}$ caffeine. Red dots: $26 \mathrm{~S}$ proteasome components enriched with Epe1-GFP after caffeine treatment named in table (right). Blue dots: enriched E3 ubiquitin ligases. Full data, Supp. Table 3.

b. Epe1-GFP western from wild-type (wt) or proteasome defective cells (mts2-1) untreated ()/treated $(+)$ with $14 \mathrm{mM}$ caffeine.

c. Epe1-Myc western from cells untreated $(-) /$ treated $(+)$ with $14 \mathrm{mM}$ caffeine and/or proteasome inhibitor bortezomib (BTZ).

d. Western detecting Epe11-150-GFP following treatments as in c, or recombinant GFP.

e. Western of immunoprecipitated Epe1-13xMyc probed with anti-Myc or anti-ubiquitin antibodies in absence (-)/presence(+) of $14 \mathrm{mM}$ caffeine.

f. Western of Multidsk2 affinity resin enriched proteins probed with anti-Myc or anti-ubiquitin antibodies in absence (-)/presence $(+)$ of $14 \mathrm{mM}$ caffeine.

g. Western detecting Epe1-GFP or $\alpha$-tubulin in wild-type, hul5 $\Delta$, pub3 $\Delta$ or hul $5 \Delta$ pub3 $\Delta$ cells untreated $(-) /$ treated $(+)$ with $14 \mathrm{mM}$ caffeine for $16 \mathrm{~h}$.

h. Number of resistant colonies formed $/ 1 \times 10^{4}$ viable cells by wild-type, hul $5 \Delta$, pub3 $\Delta$ or hul5 $\Delta$ pub3 $\Delta$ cells plated on caffeine or fluconazole plates.

Statistical analysis of three biological replicates performed as in Methods. 
a

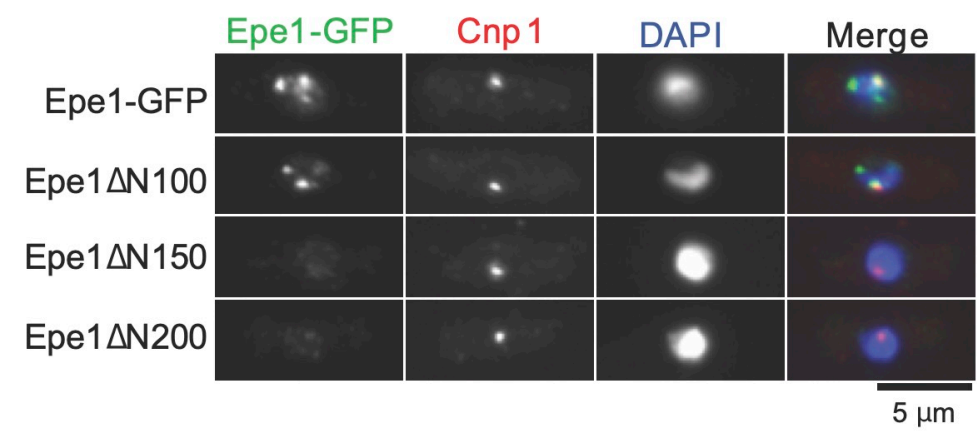

C

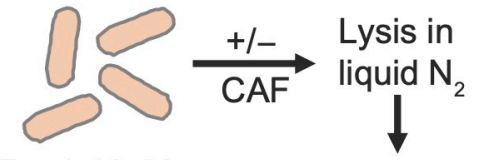

Epe1-13xMyc

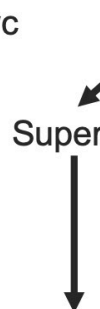

Spin 5000g

Soluble

Fraction

e

$7 \mathrm{mM}$ CAF: Epe1-GFP

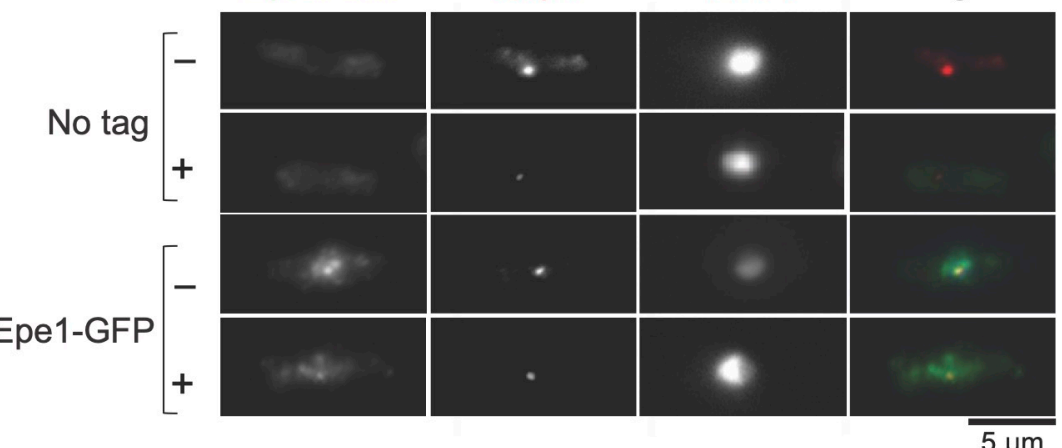

g b Nuclear Intensity A.U. Cytoplasmic Intensity A.U.

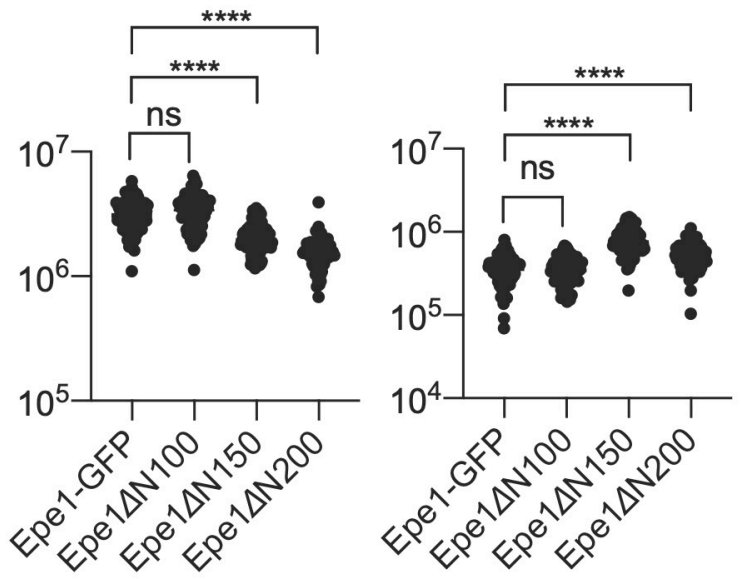

d

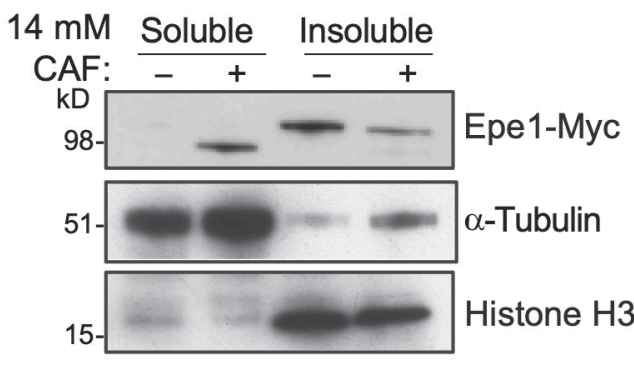

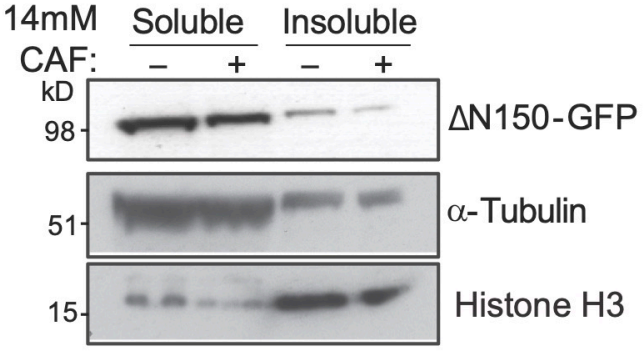

f

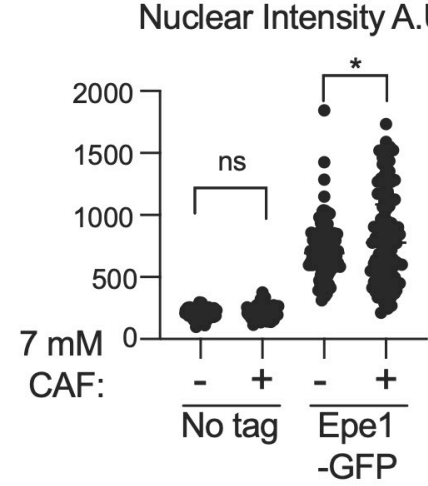

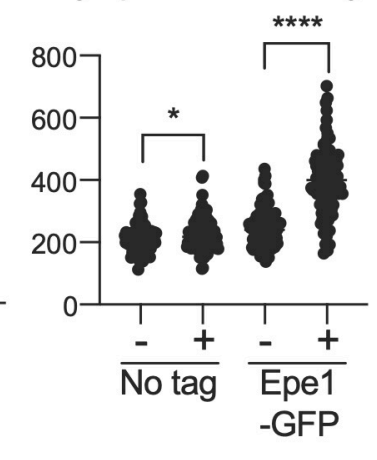

Nuclear Intensity A.U. Cytoplasmic Intensity A.U.
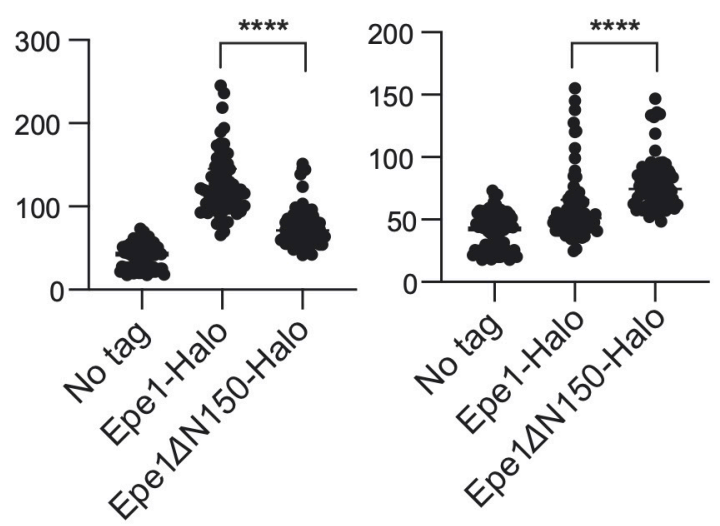
Fig. 4: N-terminally truncated Epe1 and caffeine-processed Epe1 lose association with chromatin

a. Immunolocalization of Epe1-GFP, indicated N-terminal Epe1 truncation-GFP fusion proteins (green) and CENP-A ${ }^{\text {Cnp1 }}$ control (red) in DAPI stained (blue) cells. Scale bar, $5 \mu \mathrm{m}$.

b. Quantification of anti-GFP nuclear and cytoplasmic signals for cells from a. 100 cells analysed per sample.

c. Schematic of insoluble chromatin and soluble cytoplasmic fractionation.

d. Epe1-13xMyc (left) or Epe1 $\Delta$ N150-GFP (right), histone H3 or $\alpha$-tubulin westerns on soluble and insoluble fractions from cells untreated $(-) /$ treated $(+)$ with $14 \mathrm{mM}$ caffeine.

e. Immunolocalization as in a. of Epe1-GFP in cells untreated (-)/treated (+) with $7 \mathrm{mM}$ caffeine compared with control untagged cells.

f. Quantification of anti-GFP nuclear or cytoplasmic signals for cells from e. 100 cells analysed per sample.

g. Images of untagged, Epe1-Halo and Epe1 $\Delta$ N150-Halo cells exposed to the JF646 fluorescent dye (left) and quantification of nuclear or cytoplasmic signals (right). 100 cells analysed/sample.

Statistical analysis of three biological replicates performed as in Methods. 

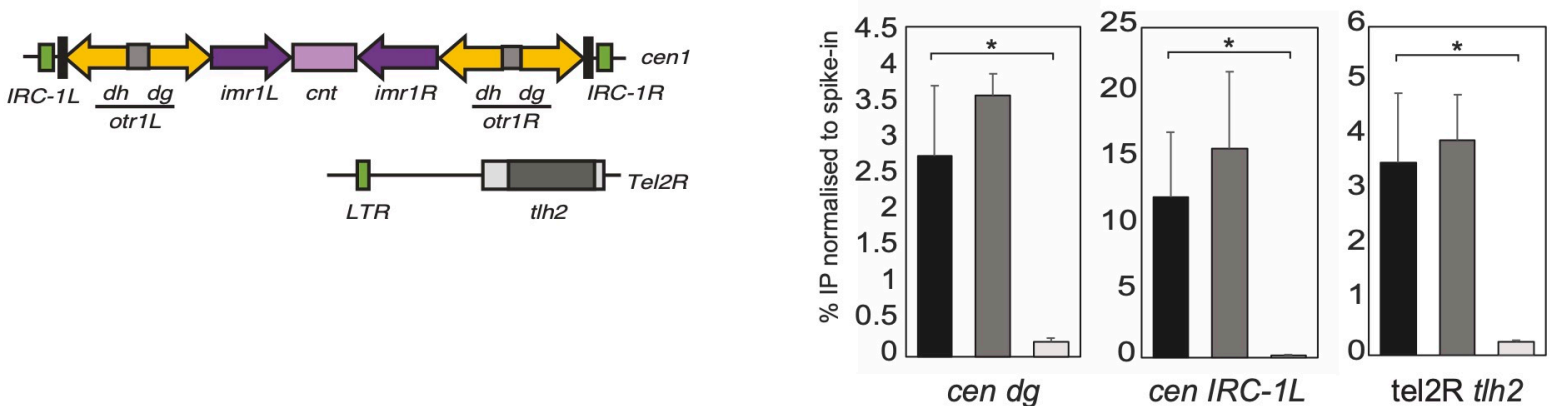

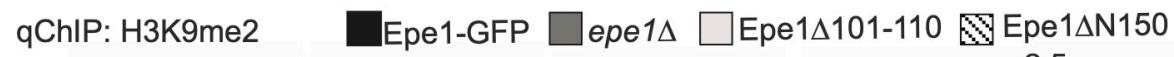
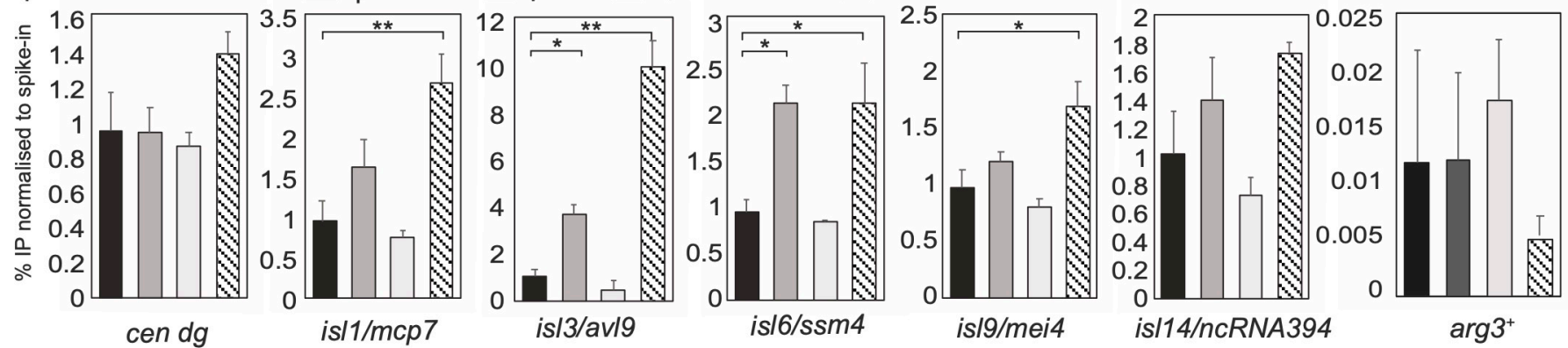

heterochromatin islands

qChIP: Epe1-GFP $\square$ Epe1-GFP $\square$ Epe1 10101-110 $\square$ Epe1 1111-120
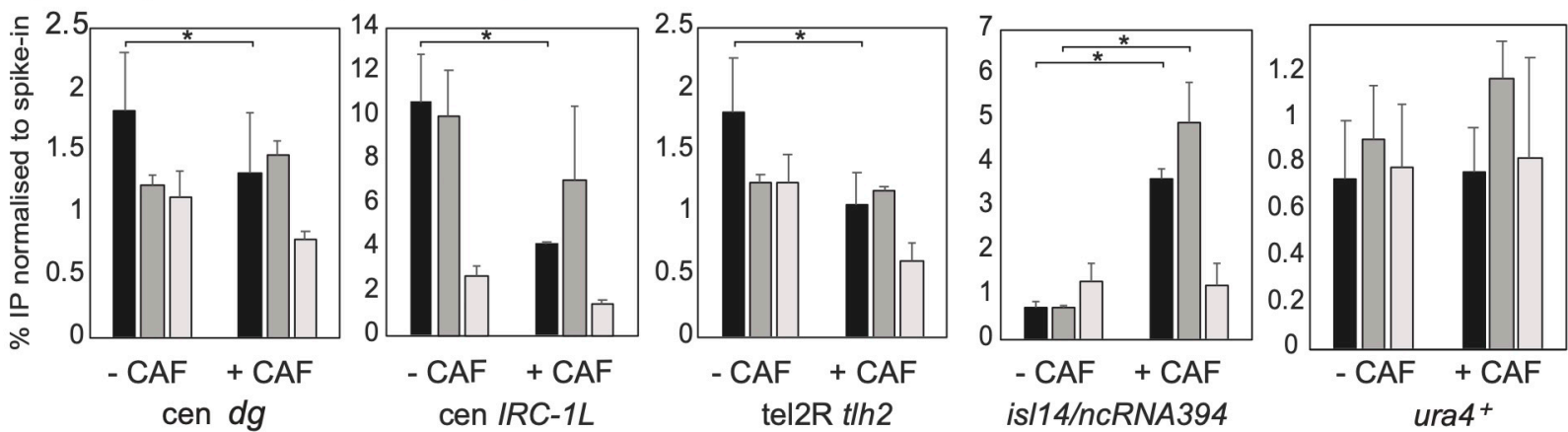

d

\section{ChIP-seq: H3K9me2}
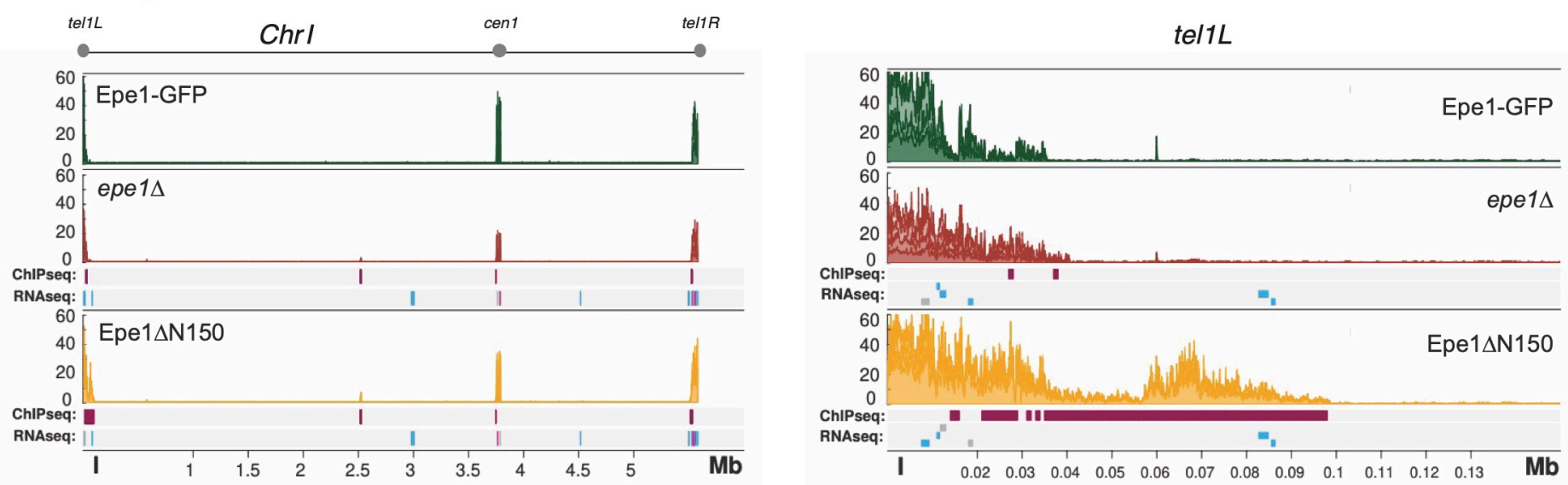

e ChIP-seq: H3K9me2

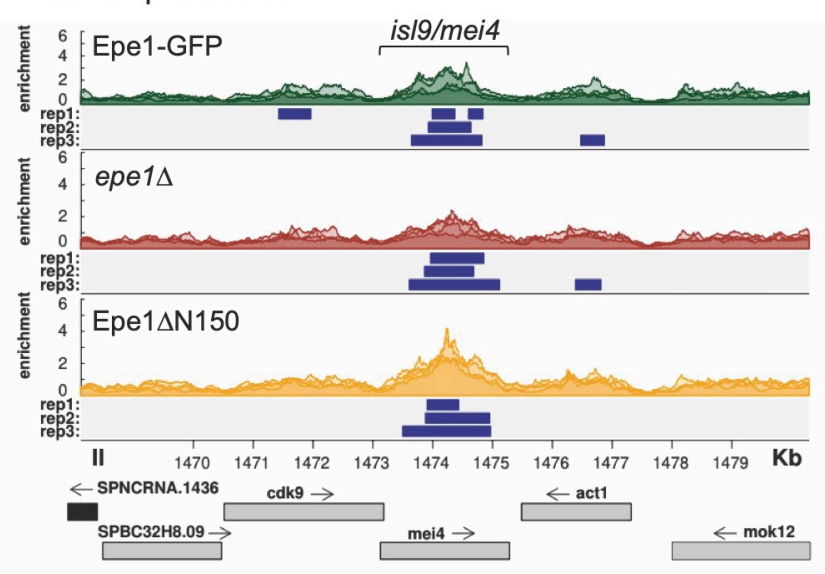

Figure 5. Yaseen, et al. 
Fig. 5: Loss of Epe1 nuclear foci coincides with reduced heterochromatin association, increased H3K9 methylation and associated gene expression changes.

a. Diagram of centromere and telomere heterochromatin regions (left). ChIP-qPCR for Epe1GFP, Epe1 $\Delta$ N100-GFP, Epe1 $\Delta$ N101-110-GFP or Epe1 $\Delta$ N150-GFP levels at centromeric outer repeats $(d g)$, a boundary region (IRC1-L) and telomere (t/h2). Epe1-GFP protein levels were normalised to $S$. cerevisiae Sgo1-GFP spike-in control-

b. ChIP-qPCR for H3K9me2 levels at $d g$ centromere repeats, known heterochromatin islands (is/1, is/3, is/6, is/9, is/14) and euchromatic gene $\left(\arg 3^{+}\right)$in cells with the indicated manipulations at epe1. H3K9me2 levels were normalised to an S. octosporus spike-in control. c. ChIP-qPCR for Epe1-GFP, Epe1 $\Delta$ N101-110-GFP or Epe1 $\Delta$ N111-120-GFP levels at $d g$ centromere repeats, cen1 boundary region (IRC1-L), telomere adjacent th2, is/14/ncRNA.394, and a euchromatic gene $\left(\right.$ ura $\left.^{+}\right)$.

d. ChIP-seq showing H3K9me2 distribution in Epe1-GFP, epe1 1 , and Epe1 $\Delta$ N150-GFP cells across chromosome 1 (Chr1, left) and adjacent to the left telomere (tel1L, right). Three colour shades represent each biological replicate. H3K9me2 ChIP-seq or RNA-seq reads in epe1 $\Delta$ or Epe1 $\Delta$ N150-GFP cells relative to wild-type Epe1-GFP are shown in tracks below. Features, genomic bins (ChIP-seq) or annotated genes (RNA-seq) with significantly (pvalue <0.1; $\log _{2}$ fold change $>2$ ) increased (magenta) or decreased (cyan) read counts are indicated.

e. Three ChIP-seq biological replicates show variable expansion of H3K9me2 over island is/9/mei4 locus of epe1 $\Delta$ and Epe1 $\Delta$ N150-GFP cells relative to wild-type Epe1-GFP. MACS2 detected peaks with enrichments $>2$ are shown (blue).

For ChIP-qPCR a-c: Mean, 3 biological replicates; error bars, standard deviations. Significance of the difference between samples was evaluated using Student's $t$-test. $\left(^{*}\right) P$ $<0.0 .33,\left({ }^{* *}\right) P<0.002$; $\left.{ }^{* \star *}\right) P<0.0002$; $\left.{ }^{* * * *}\right) P<0.0001$; (n.s). not significant. 
bioRxiv preprint doi: https://doi.org/10.1101/2021.12.20.473483; this version posted December 20, 2021. The copyright holder for this perpetuity. It is made avaibble under aCC-BY 4.0 International license.

C
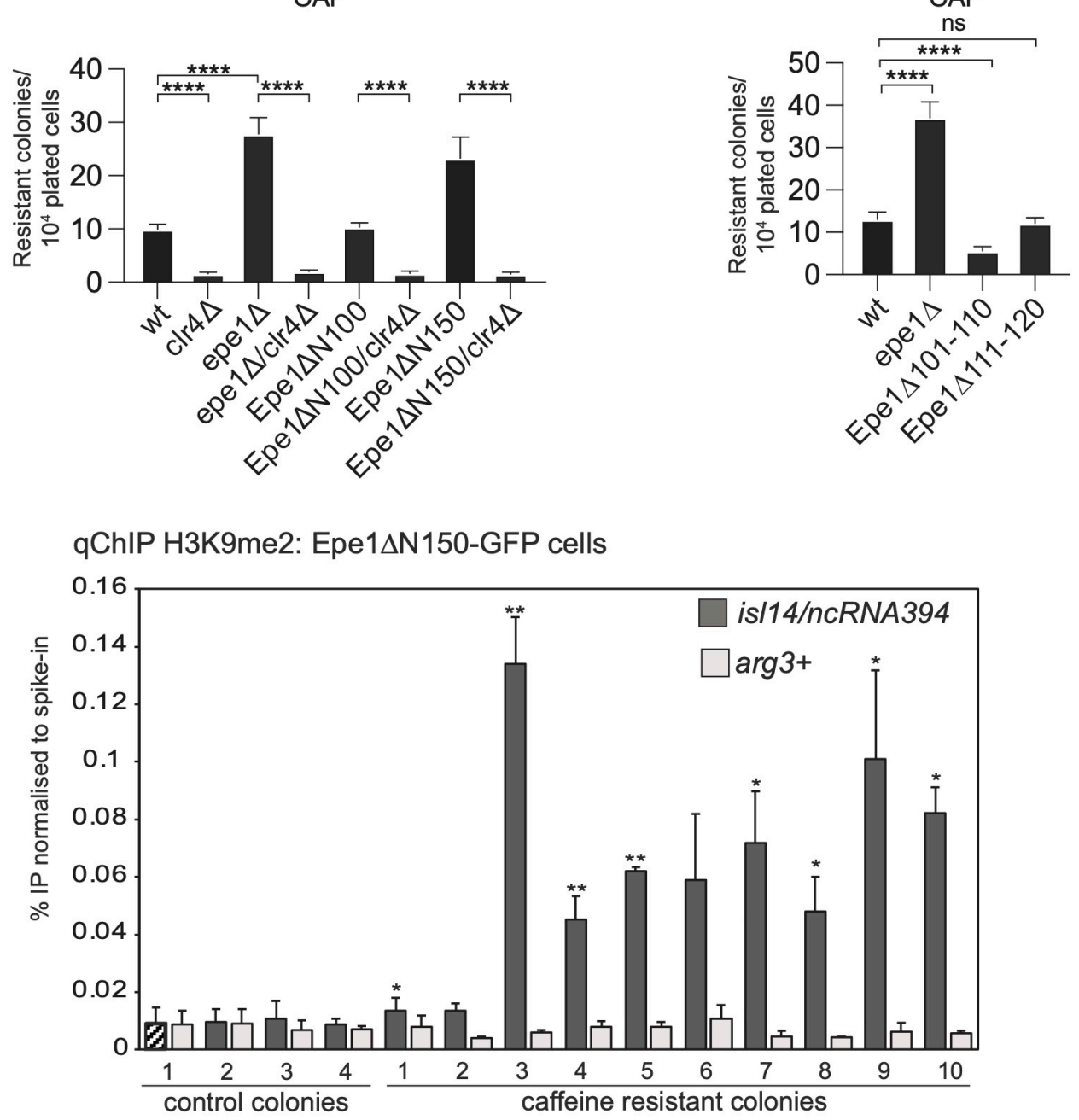

d

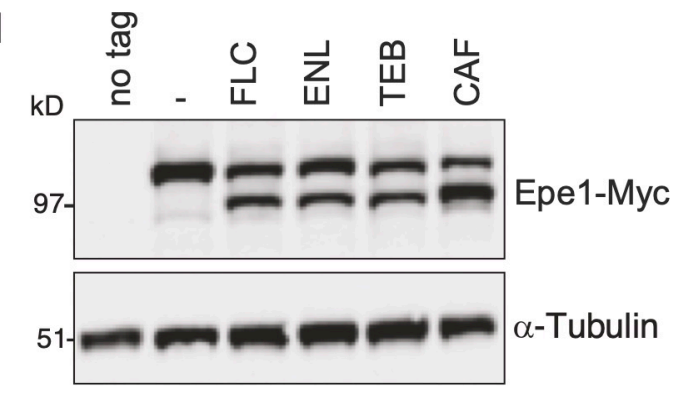

e

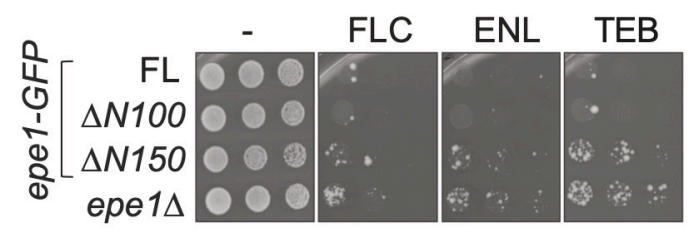

f

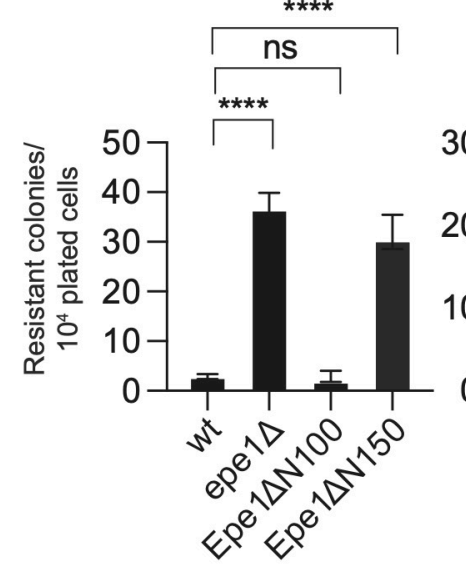

ENL

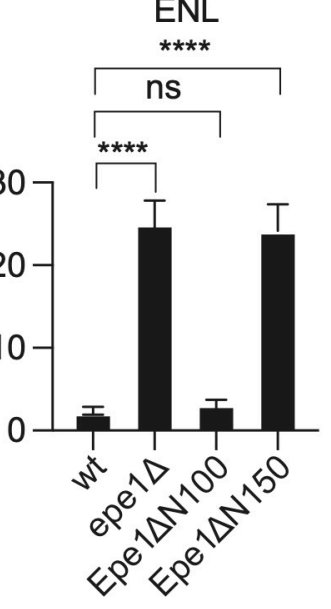

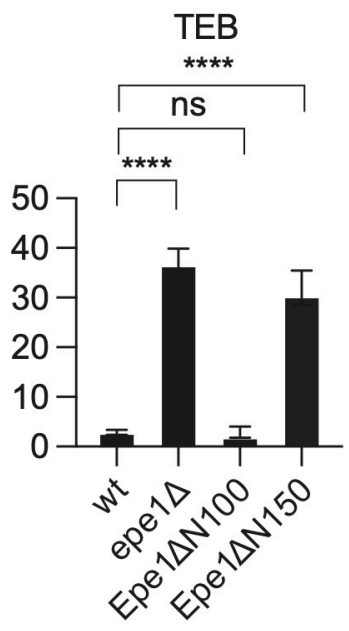

g

FLC

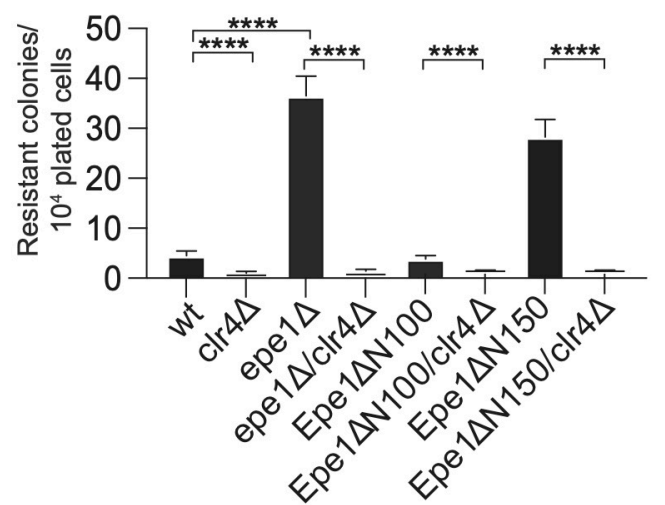

Figure 6. Yaseen et al., 
Fig. 6. Clr4-dependent H3K9 methylation mediates caffeine and antifungal resistance, and is enhanced by Epe1 truncation

a. Number of resistant colonies formed $/ 1 \times 10^{4}$ viable cells plated by wild-type, epe1 $\Delta$, epe $1 \Delta / c / r 4 \Delta$, Epe1 $\Delta$ N100-GFP, Epe1 $1 \Delta$ 50-GFP/clr4 4 , Epe1 $1 \Delta$ N150-GFP and Epe1 $\Delta$ N150GFP/clr4 $\Delta$ on plates containing $16 \mathrm{mM}$ caffeine (CAF).

b. Number of resistant colonies formed $/ 1 \times 10^{4}$ viable cells plated by wild-type, epe $1 \Delta$ Epe1 $1 \Delta 101-110-G F P$ and Epe1 $1111-120-G F P$ cells on plates containing $16 \mathrm{mM}$ caffeine (CAF).

c. ChIP-qPCR for H3K9me2 at the island 14/ncRNA394 or arg3 ${ }^{+}$loci on ten caffeine-resistant and four control colonies (from no caffeine) formed by Epe1 $\Delta$ N150-GFP cells. Signals were normalised to an S. octosporus spike-in control and significance calculated to control colony 1 (cross-hatched). Mean, 3 biological replicates; error bars indicate standard deviation.

d. Epe1-13xMyc or $\alpha$-tubulin westerns from cells untreated $(-) /$ treated $(+)$ with $0.5 \mathrm{mM}$ fluconazole (FLC), $6 \mu \mathrm{M}$ enilconazole (ENL), 16 $\mu \mathrm{M}$ tebuconazole (TEB) or $14 \mathrm{mM}$ CAF

e. Serial dilution growth assay of cells with indicated manipulation at epe1 on plates containing no antifungal (-), FLC, ENL, or TEB.

f. Number of resistant colonies formed $/ 1 \times 10^{4}$ viable cells with indicated manipulation at epe1 on plates containing FLC, ENL or TEB.

g. Number of resistant colonies formed $/ 1 \times 10^{4}$ viable cells plated by wild-type, $c / r 4 \Delta$, epe $1 \Delta$ epe $1 \Delta / c / r 4 \Delta$, Epe $1 \Delta$ N100-GFP, Epe1 $\Delta$ N50-GFP/clr4 $\Delta$, Epe1 $\Delta$ N150-GFP and Epe1 $1 \Delta 150-$ GFP/clr4 $\Delta$ on plates containing $0.5 \mathrm{mM}$ fluconazole (FLC). 
bioRxiv preprint doi: https://doi.org/10.1101/2021.12.20.473483; this version posted December 20, 2021. The copyright holder for this preprint (which was not certified by peer review) is the author/funder, who has granted bioRxiv a license to display the preprint in

a

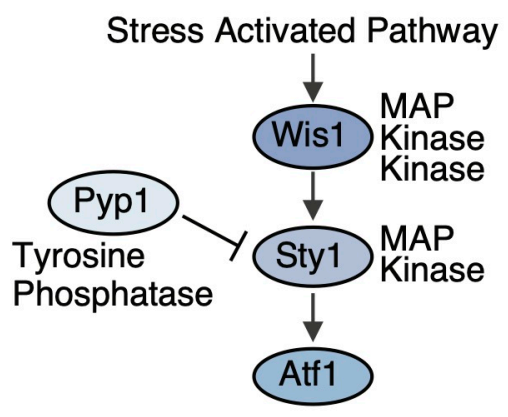
perpetuity. It is made available under aCC-BY 4.0 International license.

d

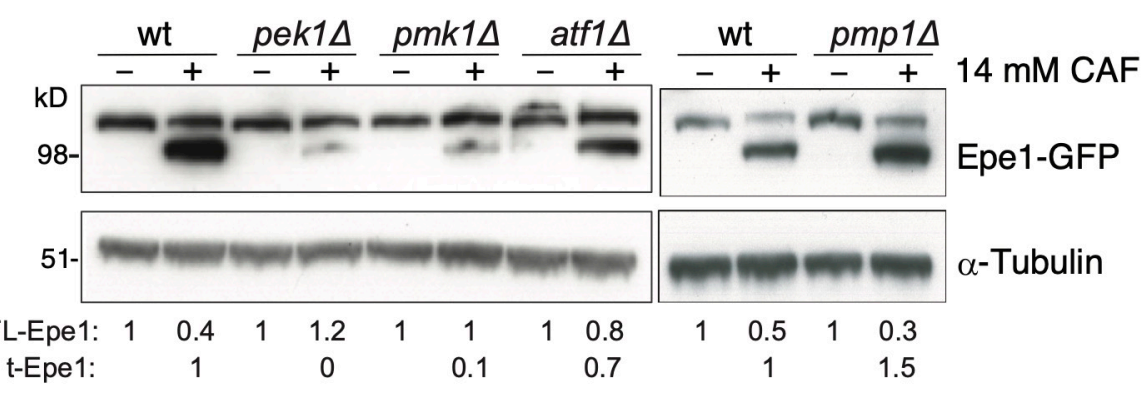

C

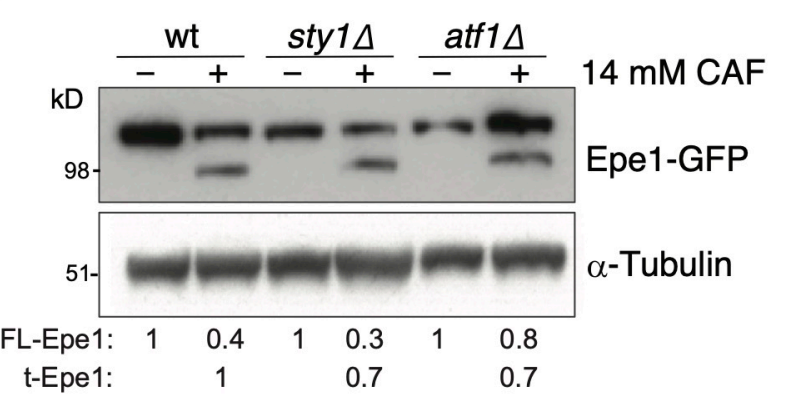

e

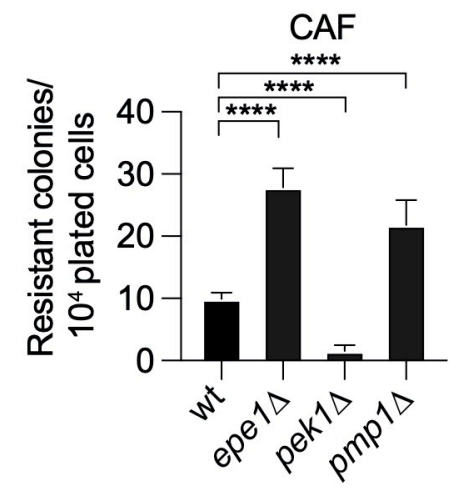

$\mathbf{f}$

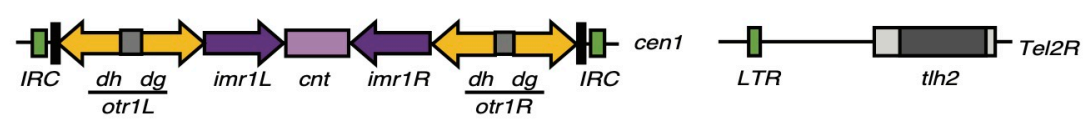

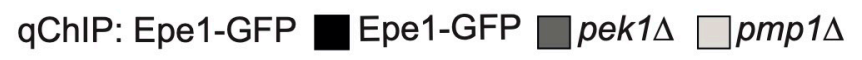
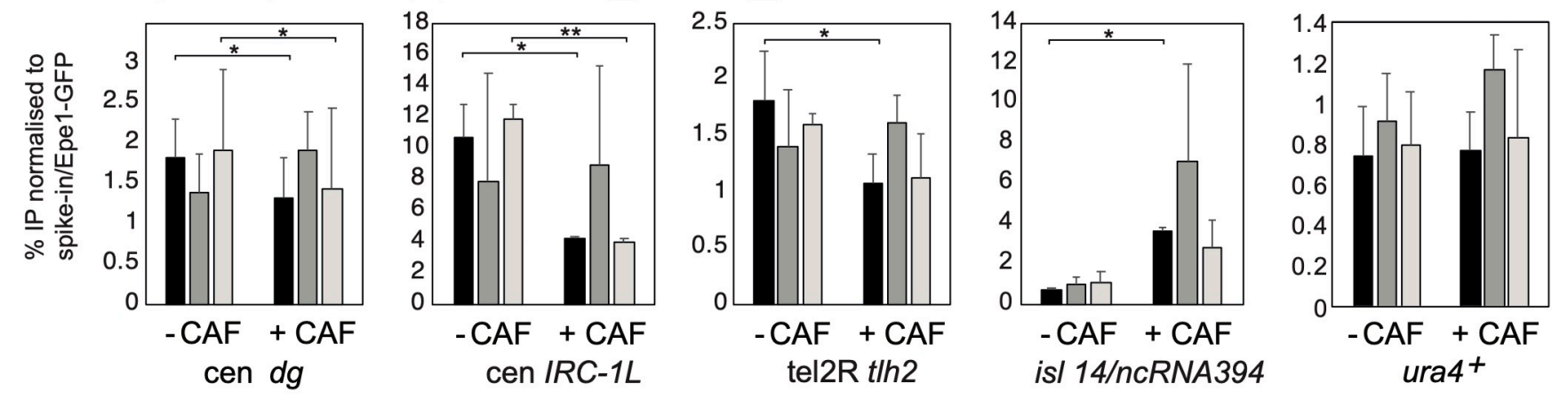

g
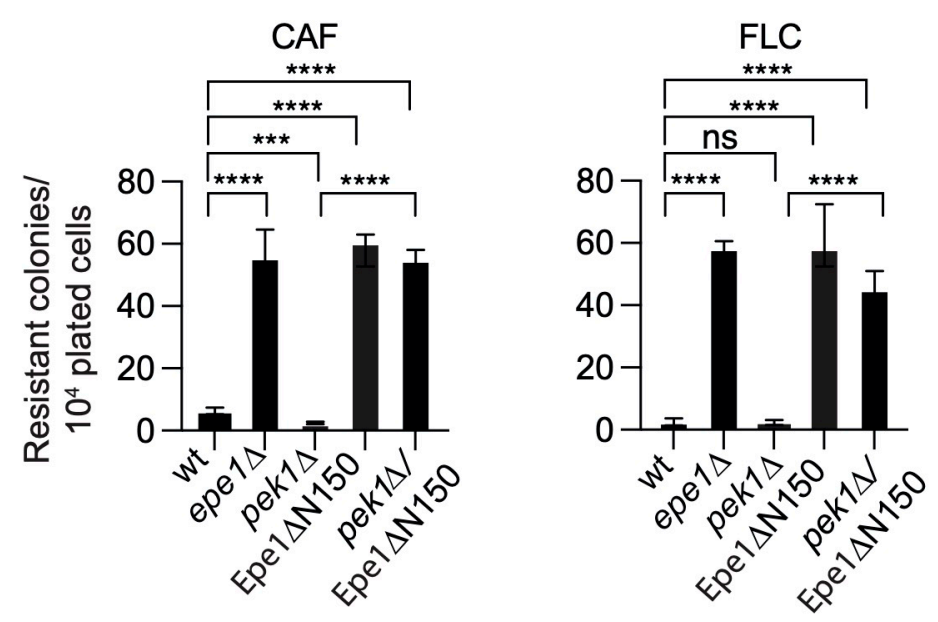

h

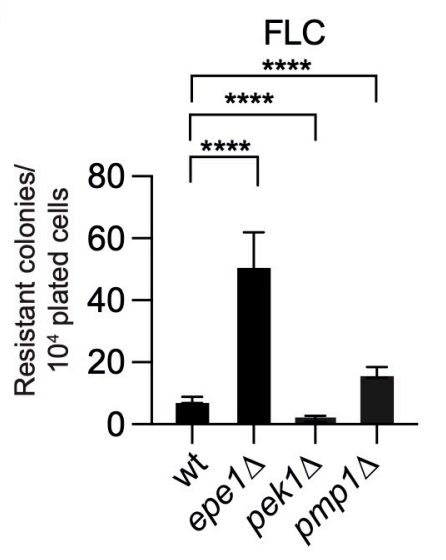

Figure 7. Yaseen, et al. 
Fig. 7: The cell integrity stress pathway regulates Epe1 processing via Pek1 MAPKK, Pmk1 MAPK and Pmp1 MAPK phosphatase

a. Diagram of the $S$. pombe stress-activated signalling pathway (SAP) end point.

b. Diagram of $S$. pombe cell integrity signalling pathway (CIP) end point.

c. Epe1-GFP or $\alpha$-tubulin western from wild-type, sty1 $\Delta$, or atf1 $\Delta$ cells untreated (-)/treated (+) with $14 \mathrm{mM}$ caffeine.

d. Epe1-GFP or $\alpha$-tubulin western from wild-type, pek1 1 , pmk1 1 , atf1 $\Delta$ or pmp1 $\Delta$ cells untreated $(-) /$ treated $(+)$ with $14 \mathrm{mM}$ caffeine.

e. Number of resistant colonies formed $/ 1 \times 10^{4}$ viable cells by wild-type, epe $1 \Delta$, pek $1 \Delta$ and pmp1 $1 \Delta$ cells on caffeine plates.

f. ChIP-qPCR for Epe1-GFP at the indicated locations in wild-type, pek1 1 , or pmp1 $\Delta$ cells cells untreated $(-) /$ treated $(+)$ with $14 \mathrm{mM}$ caffeine. Epe1-GFP levels normalised to S.cerevisiae Sgo1-GFP spike-in control. Mean, 3 biological replicates; error bars, standard deviations.

g. Number of resistant colonies formed $/ 1 \times 10^{4}$ viable cells by wild-type, epe $1 \Delta$, pek1 $\Delta$, Epe $1 \Delta \mathrm{N} 150$ and pek1 $\mathrm{Epe} 1 \Delta \mathrm{N} 150$ cells plated on caffeine or fluconazole plates.

h. Number of resistant colonies formed $/ 1 \times 10^{4}$ viable cells plated by wild-type, epe $1 \Delta$, pek1 $\Delta$ and pmp $1 \Delta$ on plates containing $0.5 \mathrm{mM}$ fluconazole (FLC).

Statistical analysis of three biological replicates performed as in Methods.

Fig. 8: Model for induction of heterochromatin-mediated gene silencing and resulting resistance

External insults (i.e. caffeine, antifungals) detected by the CIP MAPK pathway result in increased Epe1 ubiquitylation (Ub) and proteasome-mediated processing of Epe1 to tEpe1. Loss of the Epe1 $\mathrm{N}$-terminal region results in reduced Epe1 demethylase chromatin association, increased soluble and cytosolic Epe1 and accumulation of Hek9me/heterochromatin over various location, including facultative islands where resulting repression of embedded genes can confer resistance. 
bioRxiv preprint doi: https://doi.org/10.1101/2021.12.20.473483; this version posted December 20, 2021. The copyright holder for this preprint (which was not certified by peer review) is the author/funder, who has granted bioRxiv a license to display the preprint in perpetuity. It is made available under aCC-BY 4.0 International license.

$\begin{array}{cccc}\begin{array}{c}\text { Cell integrity } \\ \text { stress signalling } \\ \text { pathway }\end{array} & \begin{array}{c}\text { Proteasome- } \\ \text { mediated Epe1 } \\ \text { cleavage }\end{array} & \begin{array}{c}\text { tEpe1 lost } \\ \text { from } \\ \text { chromatin }\end{array} & \begin{array}{c}\text { Gene silencing } \\ \text { for antifungal } \\ \text { resistance }\end{array}\end{array}$

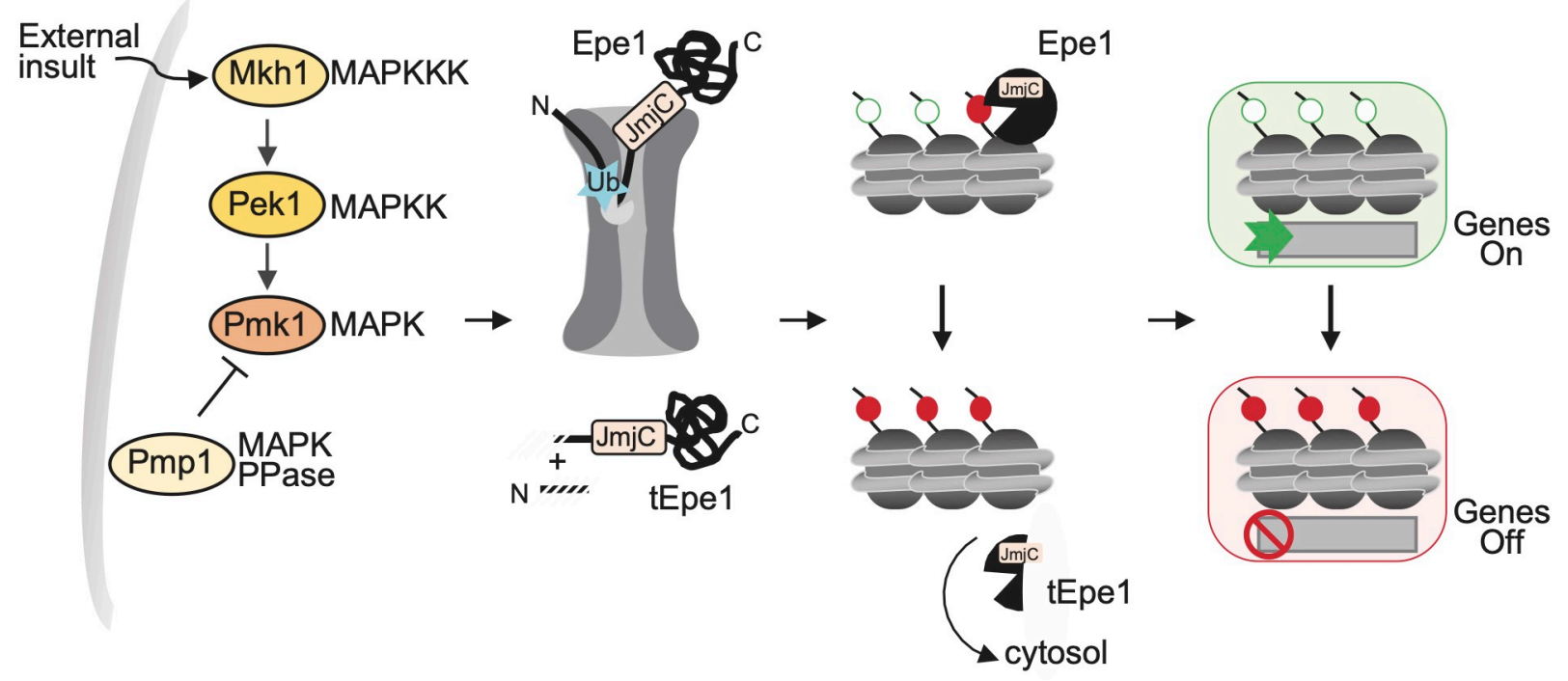

Figure 8. Yaseen, et al. 


\section{References}

1. Fisher, M. C., Hawkins, N. J., Sanglard, D. \& Gurr, S. J. Worldwide emergence of resistance to antifungal drugs challenges human health and food security. Science 360, 739-742 (2018).

2. Perlin, D. S., Rautemaa-Richardson, R. \& Alastruey-Izquierdo, A. The global problem of antifungal resistance: prevalence, mechanisms, and management. Lancet Infect Dis. 17, e383-e392 (2017).

3. Robbins, N., Caplan, T. \& Cowen, L. E. Molecular Evolution of Antifungal Drug Resistance. Annu. Rev. Microbiol. 71, 753-775 (2017).

4. Editorial. Stop neglecting fungi. Nat. Microbiol. 2, 17120 (2017).

5. Godfray, H. C. J. et al. Food security: The challenge of feeding 9 billion people. Science 327, 812-818 (2010).

6. Fisher, M. C. et al. Threats posed by the fungal kingdom to humans, wildlife, and agriculture. mBio 11, e00449-20 (2020).

7. Audergon, P. N. C. B. et al. Restricted epigenetic inheritance of H3K9 methylation. Science. 348, 132-135 (2015).

8. Ragunathan, K., Jih, G. \& Moazed, D. Epigenetic inheritance uncoupled from sequence-specific recruitment. Science 348, 1258699 (2015).

9. Cerulus, B., New, A. M., Pougach, K. \& Verstrepen, K. J. Noise and Epigenetic Inheritance of Single-Cell Division Times Influence Population Fitness. Curr. Biol. 26, 1138-1147 (2016).

10. Hall, I. M. et al. Establishment and maintenance of a heterochromatin domain. Science 297, 2232-2237 (2002).

11. Calo, S. et al. Antifungal drug resistance evoked via RNAi-dependent epimutations. Nature 513, 555-558 (2014).

12. Bheda, P. et al. Single-Cell Tracing Dissects Regulation of Maintenance and Inheritance of Transcriptional Reinduction Memory. Mol. Cell 78, 915-925 (2020).

13. Torres-Garcia, S. et al. Epigenetic gene silencing by heterochromatin primes fungal resistance. Nature 585, 453-458 (2020).

14. Heard, E. \& Martienssen, R. A. Transgenerational epigenetic inheritance: Myths and mechanisms. Cell 157, 95-109 (2014).

15. Whittaker, C. \& Dean, C. The FLC locus: A platform for discoveries in epigenetics and adaptation. Annu. Rev. Cell Dev. Biol. 33, 555-575 (2017).

16. Miska, E. A. \& Ferguson-Smith, A. C. Transgenerational inheritance: Models and mechanisms of non-DNA sequence-based inheritance. Science 354, 59-63 (2016).

17. Duempelmann, L., Skribbe, M. \& Bühler, M. Small RNAs in the Transgenerational Inheritance of Epigenetic Information. Trends Genet. 36, 203-214 (2020). 
18. Allshire, R. C., Nimmo, E. R., Ekwall, K., Javerzat, J. P. \& Cranston, G. Mutations derepressing silent centromeric domains in fission yeast disrupt chromosome segregation. Genes Dev. 9, 218-233 (1995).

19. Nakayama, J., Rice, J. C., Strahl, B. D., Allis, C. D. \& Grewal, S. I. S. Role of histone H3 lysine 9 methylation in epigenetic control of heterochromatin assembly. Science 292, 110-113 (2001).

20. Wang, J. et al. The proper connection between shelterin components is required for telomeric heterochromatin assembly. Genes Dev. 30, 827-839 (2016).

21. Kanoh, J., Sadaie, M., Urano, T. \& Ishikawa, F. Telomere binding protein Taz1 establishes Swi6 heterochromatin independently of RNAi at telomeres. Curr. Biol. 15, 1808-1819 (2005).

22. Zofall, M. et al. RNA elimination machinery targeting meiotic mRNAs promotes facultative heterochromatin formation. Science. 335, 96-100 (2012).

23. Sugiyama, T. et al. Enhancer of Rudimentary Cooperates with Conserved RNAProcessing Factors to Promote Meiotic mRNA Decay and Facultative Heterochromatin Assembly. Mol. Cell 61, 747-759 (2016).

24. Yamanaka, S. et al. RNAi triggered by specialized machinery silences developmental genes and retrotransposons. Nature 493, 557-560 (2013).

25. Zofall, M., Smith, D. R., Mizuguchi, T., Dhakshnamoorthy, J. \& Grewal, S. I. S. Taz1Shelterin Promotes Facultative Heterochromatin Assembly at Chromosome-Internal Sites Containing Late Replication Origins. Mol. Cell 62, 862-874 (2016).

26. Gallagher, P. S. et al. Iron homeostasis regulates facultative heterochromatin assembly in adaptive genome control. Nat. Struct. Mol. Biol. 25, 372-383 (2018).

27. Wang, J., Reddy, B. D. \& Jia, S. Rapid epigenetic adaptation to uncontrolled heterochromatin spreading. Elife 2015, e06179 (2015).

28. Trewick, S. C., Minc, E., Antonelli, R., Urano, T. \& Allshire, R. C. The JmjC domain protein Epe1 prevents unregulated assembly and disassembly of heterochromatin. EMBO J. 26, 4670-4682 (2007).

29. Roguev, A. et al. Conservation and rewiring of functional modules revealed by an epistasis map in fission yeast. Science 322, 405-410 (2008).

30. Wang, J., Lawry, S. T., Cohen, A. L. \& Jia, S. Chromosome boundary elements and regulation of heterochromatin spreading. Cell. Mol. Life Sci. 71 4841-4852 (2014).

31. Antequera, F., Tamame, M., Villanueva, J. R. \& Santos, T. DNA methylation in the fungi. J. Biol. Chem. 259, 8033-8036 (1984).

32. Capuano, F., Mülleder, M., Kok, R., Blom, H. J. \& Ralser, M. Cytosine DNA methylation is found in drosophila melanogaster but absent in saccharomyces cerevisiae, schizosaccharomyces pombe, and other yeast species. Anal. Chem. 86, 
3697-3702 (2014).

33. Rape, M. \& Jentsch, S. Productive RUPture: Activation of transcription factors by proteasomal processing. Biochim. Biophys. Acta 1695, 209-213 (2004).

34. Tian, L. \& Matouschek, A. Where to start and when to stop. Nat. Struct. Mol. Biol. 13, 668-670 (2006).

35. Li, F. et al. Lid2 Is Required for Coordinating H3K4 and H3K9 Methylation of Heterochromatin and Euchromatin. Cell 135, 272-283 (2008).

36. Thodberg, M. et al. Comprehensive profiling of the fission yeast transcription start site activity during stress and media response. Nucleic Acids Res. 47, 1671-1691 (2019).

37. Piwko, W. \& Jentsch, S. Proteasome-mediated protein processing by bidirectional degradation initiated from an internal site. Nat. Struct. Mol. Biol. 13, 691-697 (2006).

38. Bohn, S. et al. Structure of the $26 \mathrm{~S}$ proteasome from Schizosaccharomyces pombe at subnanometer resolution. Proc. Natl. Acad. Sci. U. S. A. 107, 20992-20997 (2010).

39. Gordon, C., McGurk, G., Dillon, P., Rosen, C. \& Hastie, N. D. Defective mitosis due to a mutation in the gene for a fission yeast $26 \mathrm{~S}$ protease subunit. Nature $366,355-357$ (1993).

40. Manasanch, E. E. \& Orlowski, R. Z. Proteasome inhibitors in cancer therapy. Nat. Rev. Clin. Oncol. 14, 417-433 (2017).

41. Zofall, M. \& Grewal, S. I. S. Swi6/HP1 Recruits a JmjC Domain Protein to Facilitate Transcription of Heterochromatic Repeats. Mol. Cell 22, 681-692 (2006).

42. Braun, S. et al. The Cul4-Ddb1Cdt2 ubiquitin ligase inhibits invasion of a boundaryassociated antisilencing factor into heterochromatin. Cell 144, 41-54 (2011).

43. Nicholas Laribee, R. \& Weisman, R. Nuclear functions of TOR: Impact on transcription and the epigenome. Genes. 11, 1-24 (2020).

44. Weisman, R. Target of Rapamycin (TOR) Regulates Growth in Response to Nutritional Signals. Microbiol. Spectr. (2016). doi:10.1128/microbiolspec.funk-00062016.

45. Cohen, A. et al. TOR complex 2 in fission yeast is required for chromatin-mediated gene silencing and assembly of heterochromatic domains at subtelomeres. J. Biol. Chem. 293, 8138-8150 (2018).

46. Oya, E. et al. Leo1 is essential for the dynamic regulation of heterochromatin and gene expression during cellular quiescence. Epigenetics Chromatin 12, 45 (2019). doi: 10.1186/s13072-019-0292-7.

47. Papadakis, M. A. \& Workman, C. T. Oxidative stress response pathways: Fission yeast as archetype. Crit. Rev. Microbiol.. 41, 520-535 (2015).

48. Perez, P. \& Cansado, J. Cell Integrity Signaling and Response to Stress in Fission Yeast. Curr. Protein Pept. Sci. 11, 680-692 (2011). 
49. Pérez, P., Cortés, J. C. G., Cansado, J. \& Ribas, J. C. Fission yeast cell wall biosynthesis and cell integrity signalling. Cell Surf. 4, 1-9 (2018).

50. Heusch, M., Lin, L., Geleziunas, R. \& Greene, W. C. The generation of nfkb2 p52: Mechanism and efficiency. Oncogene 18, 6201-6208 (1999).

51. Palombella, V. J., Rando, O. J., Goldberg, A. L. \& Maniatis, T. The ubiquitinproteasome pathway is required for processing the NF-kB1 precursor protein and the activation of NF-kB. Cell 78, 773-785 (1994).

52. Rape, M. \& Jentsch, S. Taking a bite: Proteasomal protein processing. Nat. Cell Biol. 4, E113-6 (2002).

53. Jiang, J. \& Struhl, G. Regulation of the Hedgehog and Wingless signalling pathways by the F- box/WD40-repeat protein Slimb. Nature 391, 493-496 (1998).

54. Pan, Y., Bai, C. B., Joyner, A. L. \& Wang, B. Sonic hedgehog Signaling Regulates Gli2 Transcriptional Activity by Suppressing Its Processing and Degradation. Mol. Cell. Biol. 26, 3365-3377 (2006).

55. Sato, K., Ito, H., Yokoyama, A., Toba, G. \& Yamamoto, D. Partial proteasomal degradation of Lola triggers the male-to-female switch of a dimorphic courtship circuit. Nat. Commun. 10, 166 (2019).

56. Tian, L., Holmgren, R. A. \& Matouschek, A. A conserved processing mechanism regulates the activity of transcription factors Cubitus interruptus and NF-kB. Nat. Struct. Mol. Biol. 12, 1045-1053 (2005).

57. Sha, Z. \& Goldberg, A. L. Proteasome-mediated processing of Nrf1 is essential for coordinate induction of all proteasome subunits and p97. Curr. Biol. 24, 1573-1583 (2014).

58. Wilson, M. D. et al. Proteasome-mediated processing of Def1, a critical step in the cellular response to transcription stress. Cell 154, 983-995 (2013).

59. Hoppe, T. et al. Activation of a membrane-bound transcription factor by regulated ubiquitin/proteasome-dependent processing. Cell 102, 577-586 (2000).

60. Kravtsova-Ivantsiv, Y., Cohen, S. \& Ciechanover, A. Modification by Single Ubiquitin Moieties Rather Than Polyubiquitination Is Sufficient for Proteasomal Processing of the p105 NF-kB Precursor. Mol. Cell 33, 496-504 (2009).

61. Seo, H. D. et al. The $19 \mathrm{~S}$ proteasome is directly involved in the regulation of heterochromatin spreading in fission yeast. J. Biol. Chem.. 292, 17144-17155 (2017).

62. Rousseau, A. \& Bertolotti, A. An evolutionarily conserved pathway controls proteasome homeostasis. Nature 536, 184-189 (2016).

63. Liu, Q. et al. Dysfunction of prohibitin 2 results in reduced susceptibility to multiple antifungal drugs via activation of the oxidative stress-responsive transcription factor Pap1 in fission yeast. Antimicrob. Agents Chemother. 62, e00860-18. (2018). 
64. Fang, Y. et al. A genomewide screen in Schizosaccharomyces pombe for genes affecting the sensitivity of antifungal drugs that target ergosterol biosynthesis.

Antimicrob. Agents Chemother. 56, 1949-1959. (2012).

65. Calvo, I. A., García, P., Ayté, J. \& Hidalgo, E. The transcription factors Pap1 and Prr1 collaborate to activate antioxidant, but not drug tolerance, genes in response to $\mathrm{H} 2 \mathrm{O}$ 2. Nucleic Acids Res. 40, 4816-4824 (2012).

66. Dhar, R., Missarova, A. M., Lehner, B. \& Carey, L. B. Single cell functional genomics reveals the importance of mitochondria in cell-to-cell phenotypic variation. Elife $\mathbf{8}$, e38904 (2019).

67. Kaelin, W. G. \& McKnight, S. L. Influence of metabolism on epigenetics and disease. Cell 153, 56-69 (2013).

68. Dumesic, P. A. et al. Product binding enforces the genomic specificity of a yeast Polycomb repressive complex. Cell 160, 204-218 (2015).

69. Palmer, J. M., Perrin, R. M., Dagenais, T. R. T. \& Keller, N. P. H3K9 methylation regulates growth and development in Aspergillus fumigatus. Eukaryot. Cell 7, 20522060 (2008).

70. Möller, M. et al. Destabilization of chromosome structure by histone H3 lysine 27 methylation. PLoS Genet. 15, e1008093 (2019).

71. Elías-Villalobos, A., Barrales, R. R. \& Ibeas, J. I. Chromatin modification factors in plant pathogenic fungi: Insights from Ustilago maydis. Fungal Genet. Biol. 129, 52-64 (2019).

72. Torres-Garcia, S. et al. SpEDIT: A fast and efficient CRISPR/Cas9 method for fission yeast. Wellcome Open Res. 5, 274 (2020).

73. Sato, M., Dhut, S. \& Toda, T. New drug-resistant cassettes for gene disruption and epitope tagging in Schizosaccharomyces pombe. Yeast 22, 583-591 (2005).

74. Wilson, M. D., Saponaro, M., Leidl, M. A. \& Svejstrup, J. Q. MultiDsk: A UbiquitinSpecific Affinity Resin. PLoS One 7, e46398 (2012).

75. Singh, P. P. et al. Hap2-Ino80-facilitated transcription promotes de novo establishment of CENP-A chromatin. Genes Dev. 34, 226-238 (2020).

76. Rappsilber, J., Ishihama, Y. \& Mann, M. Stop And Go Extraction tips for matrixassisted laser desorption/ionization, nanoelectrospray, and LC/MS sample pretreatment in proteomics. Anal. Chem. 75, 663-670 (2003).

77. Olsen, J. V et al. Higher-energy C-trap dissociation for peptide modification analysis. Nat. Methods 4, 709-712 (2007).

78. Cox, J. \& Mann, M. MaxQuant enables high peptide identification rates, individualized p.p.b.-range mass accuracies and proteome-wide protein quantification. Nat.

Biotechnol. 26, 1367-1372 (2008). 
79. Cox, J. et al. Andromeda: A peptide search engine integrated into the MaxQuant environment. J. Proteome Res. 10, 1794-1805 (2011).

80. Cox, J. et al. Accurate proteome-wide label-free quantification by delayed normalization and maximal peptide ratio extraction, termed MaxLFQ. Mol. Cell. Proteomics 13, 2513-2526 (2014).

81. Schwanhüusser, B. et al. Global quantification of mammalian gene expression control. Nature 473, 337-342 (2011).

82. Shukla, M. et al. Centromere DNA Destabilizes H3 Nucleosomes to Promote CENP-A Deposition during the Cell Cycle. Curr. Biol. 28, 3924-3936 (2018).

83. Tong, P. et al. Interspecies conservation of organisation and function between nonhomologous regional centromeres. Nat. Commun. 10, 2343 (2019).

84. Nerusheva, O. O., Galander, S., Fernius, J., Kelly, D. \& Marston, A. L. Tensiondependent removal of pericentromeric shugoshin is an indicator of sister chromosome biorientation. Genes Dev. 28, 1291-309 (2014). 


\section{Supplementary Information}

\section{List:}

Supplemental Fig 1 and legend

Supplemental Fig 2 and legend

Supplemental Fig 3 and legend

Supplemental Fig 4 and legend

Supplemental Fig 5 and legend

Supplemental Fig 6 and legend

\section{Supplemental Fig 7 and legend}

Supplemental Table 1 - available as Excel file (Dataset 1) on request

Supplemental Table 2 - available as Excel file (Dataset 2) on request

Supplemental Table 3 - available as Excel file (Dataset 3 ) on request

Supplemental Table 4 - available as Excel file (Dataset 4) on request

Supplemental Table 5 - available as Excel file (Dataset 5) on request

Supplemental Table 6 - available as Excel file (Dataset 6) on request

Supplemental Table 7 - available as Excel file (Dataset 7) on request 


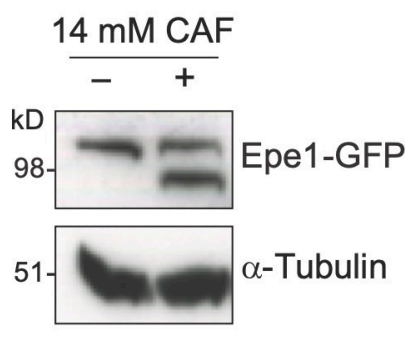

C

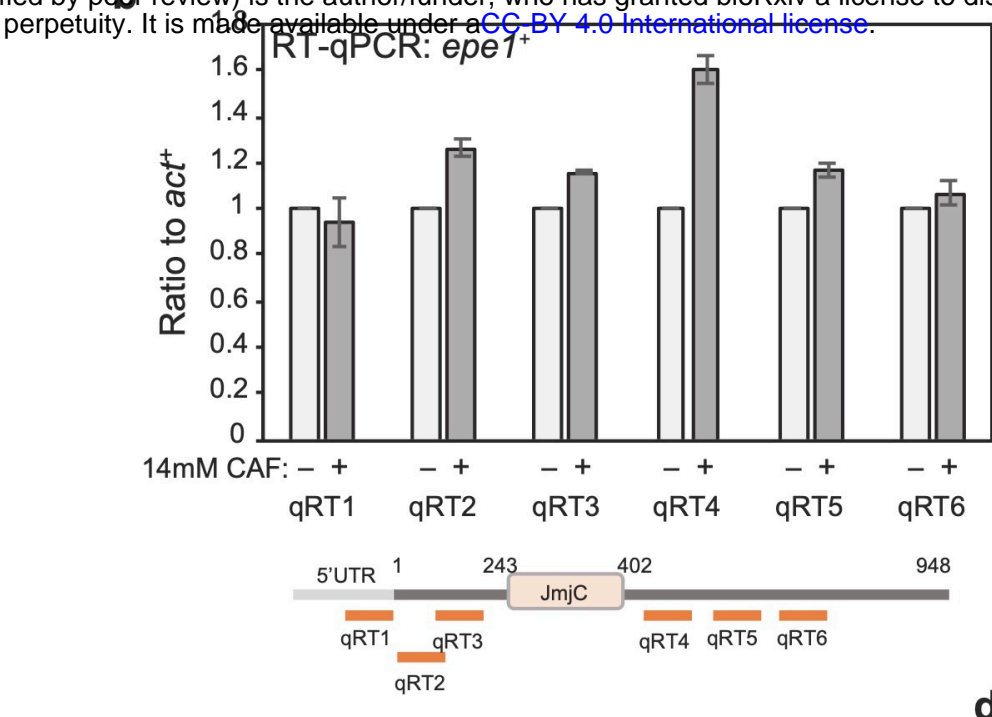

Tagged Epe1

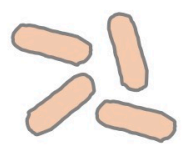

+/- 14mM CAF anti-Myc-IP $\longrightarrow$ hours anti-GFP-IP $\rightarrow \begin{gathered}\text { Phospho site ID } \\ \text { LC-MS-MS }\end{gathered}$ +14 mM caffeine

untreated

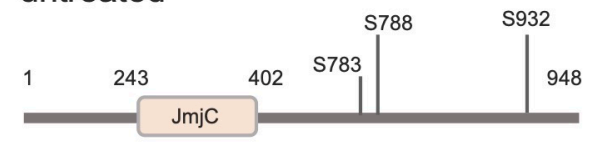

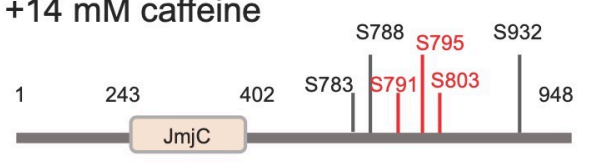

d
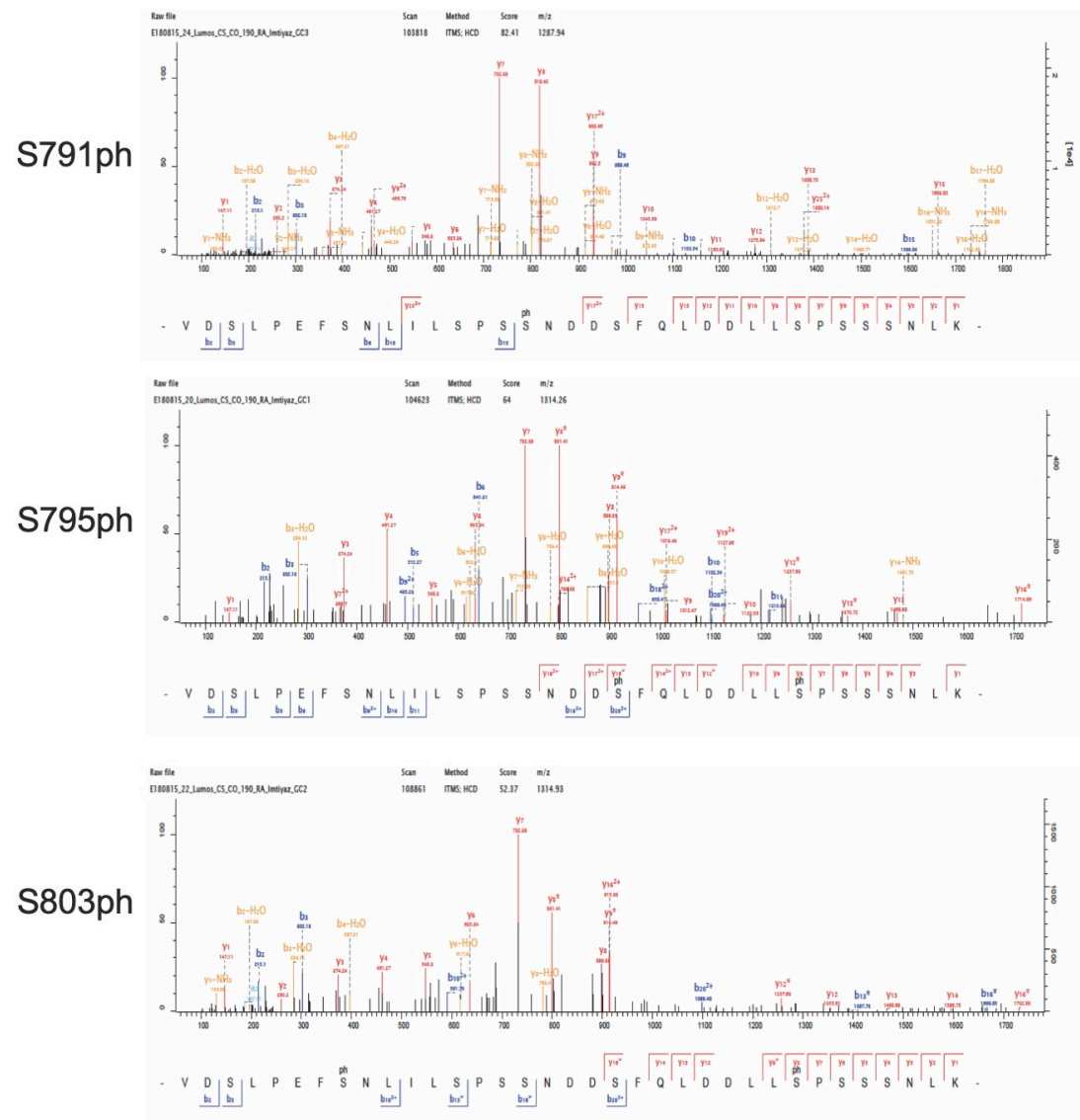


\section{Supplementary Figures and Legends}

Supplemental Fig. 1. Caffeine-induced alteration in Epe1-GFP mobility does not result from transcriptional changes in $5^{\prime}$ region of epe ${ }^{+}$gene or Epe1-Myc phosphorylation

a. Epe1-GFP or $\alpha$-tubulin western from cells untreated (-)/treated $(+)$ with $14 \mathrm{mM}$ caffeine for $16 \mathrm{~h}$.

b. qRT-PCR measurement of steady-state Epe1 transcript levels in cells untreated (-)/treated

$(+)$ with $14 \mathrm{mM}$ caffeine for $16 \mathrm{~h}$. Locations of primers used indicated.

c. Scheme to detect caffeine-induced Epe1-GFP phosphorylation by mass spectrometry (top).

Representation of phosphorylated residues detected on Epe1-GFP from cells untreated or treated with $14 \mathrm{mM}$ caffeine for $16 \mathrm{~h}$ (middle). Spectra showing detection of phosphorylated serine S791, S795 and S803 residues after caffeine treatment (bottom). Full data, Supplementary Table 4.

d. Epe1-Myc and Mto2 westerns from cells treated with $14 \mathrm{mM}$ caffeine for $16 \mathrm{~h}$ before (-)/after (+) lambda protein phosphatase addition. Mto2 mobility is known to be Lambda Phosphatase sensitive ${ }^{1}$. 
bioRxiv preprint doi: https://doi.org/10.1101/2021.12.20.473483; this version posted December 20, 2021. The copyright holder for this

preprint (which was not certified by peer review) is the author/funder, who has granted bioRxiv a license to display the preprint in perpetuity. It is made available under aCC-BY 4.0 International license.

a

$$
\text { Epe1-GFP }
$$$$
\text { JmjC }
$$

Epe1 $\Delta 150-170 \quad \Delta_{\Delta}^{170} \mathrm{JmjC}$

Epe1 $\Delta 171-190 \quad 171190 \mathrm{JmjC} \quad$ GFP

Epe1 $\Delta 191-210 \quad 191219 \overline{\mathrm{mjC}}$

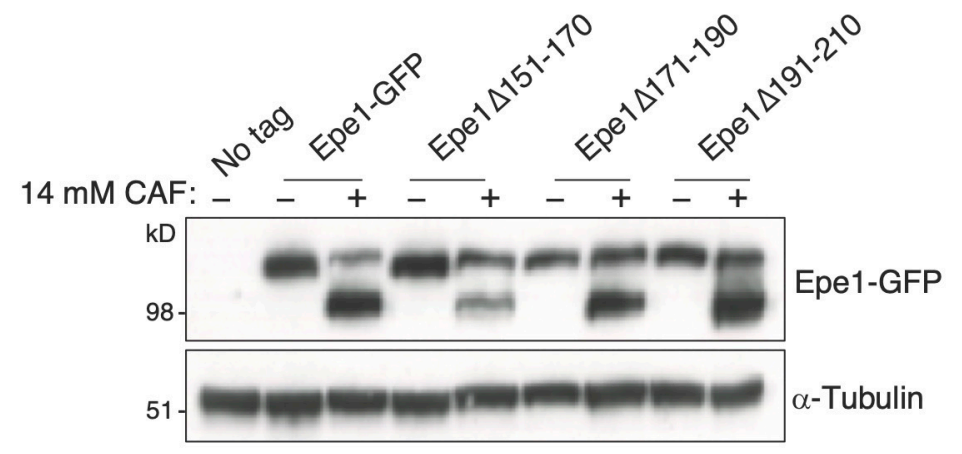

b

\begin{tabular}{|c|c|c|c|c|}
\hline \multirow{2}{*}{ 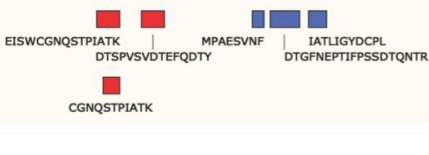 } & AVUTPCDTISAGGNELTF & \multicolumn{3}{|c|}{ 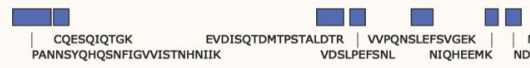 } \\
\hline & & $14 \mathrm{mM} \mathrm{CAF}$ & + & - \\
\hline \multirow{6}{*}{$\bigcap_{-1+C A F}^{\text {Epe1-Myc }}$} & Sequence & Position & & \\
\hline & EEISWCGNQSTPIATK & $52-57$ & n.d. & $\checkmark$ \\
\hline & CGNQSTPIATK & $57-67$ & n.d. & $\checkmark$ \\
\hline & DTSPVSVDTEFQDTY & $82-96$ & n.d. & $\checkmark$ \\
\hline & MPAESVNF & $154-161$ & $\sqrt{ }$ & $\checkmark$ \\
\hline & DTGFNEPTIFPSSDTQNTR & $166-184$ & $\checkmark$ & $\checkmark$ \\
\hline$\nabla$ & IATLIGYDCPL & 191-201 & $\checkmark$ & $\mathrm{v}$ \\
\hline \multirow{2}{*}{ Protein Extraction } & ALGEYPHVDTY & 274-284 & $\checkmark$ & $\checkmark$ \\
\hline & AVVTPCDTISIAGNFLTF & $371-388$ & $\checkmark$ & $\sqrt{2}$ \\
\hline \multirow{3}{*}{ IP Epe1-Myc } & DGIDDIIAEYETGR & $437-450$ & $\sqrt{ }$ & $\sqrt{ }$ \\
\hline & DCDIIIDIYNEPVK & $481-494$ & $\checkmark$ & $\checkmark$ \\
\hline & PANNSYQHQSNFIGVVISTNHNIIK & $557-581$ & $\checkmark$ & $\checkmark$ \\
\hline \multirow{3}{*}{$\stackrel{\nabla}{\text { Digestion }}$} & CQESQIQTGK & 583-592 & $\checkmark$ & $\checkmark$ \\
\hline & EVDISQTDMTPSTALDTR & 754-771 & $\checkmark$ & $\checkmark$ \\
\hline & VDSLPEFSNL & $776-785$ & $\checkmark$ & $\checkmark$ \\
\hline \multirow{4}{*}{ MS Analysis } & VVPQNSLEFSVGEK & $816-829$ & $\checkmark$ & $\checkmark$ \\
\hline & NIQHEEMK & $864-871$ & $\checkmark$ & $\checkmark$ \\
\hline & NDLEYIDQHF & $877-886$ & $\checkmark$ & $\checkmark$ \\
\hline & NENNIYDFEDHSPVR & $921-935$ & $\checkmark$ & $\checkmark$ \\
\hline
\end{tabular}




\section{Supplemental Fig. 2.}

\section{Deletions beyond residue 150 in Epe1-GFP do not hinder caffeine-induced and} peptides within the first 100 residues are not detected following caffeine treatment

a. Schematic of indicated 20 residue deletion mutants in the $\mathrm{N}$-terminal coding region of the endogenous epe1 gene expressed as GFP fusions (Epe1 $150-170-G F P$, Epe1 $\Delta 171-190$ GFP, Epe1 $191-210-G F P ;$ left). Western detecting indicated mutant Epe1-GFP fusion proteins or $\alpha$-tubulin from cells untreated (-) or treated (+) with $14 \mathrm{mM}$ caffeine; right).

b. Epe1-Myc peptides detected following immunoprecipitation from cells untreated (-) or treated $(+)$ with $14 \mathrm{mM}$ caffeine and analysis by mass spectrometry. Top: schematic showing position of peptides detected relative to Epe1 (residues 1-948). Bottom: Epe1 peptides detected in Epe1-Myc immunoprecipitates from treated $(+)$ or untreated $(-)$ with $14 \mathrm{mM}$ caffeine. Of the eighteen peptides detected from Epe1-Myc in untreated (-) samples three were not detected (n.d.; red) in the caffeine-treated sample. The three peptides not detected in the presence of caffeine are derived from within the first 100 residues on the $\mathrm{N}$-terminus. Analysis was performed on three independent immunoprecipitates. Full data, Supplementary Table 5. 
bioRxiv preprint doi: https://doi.org/10.1101/2021.12.20.473483; this version posted December 20, 2021. The copyright holder for this

a preprint (which was not certified by peer review) is the authm(fwad 3xMyc-Epe1-GFP not certified by perpetulty. It is made available under aCC-BY 4 .0 Internatiofial license.
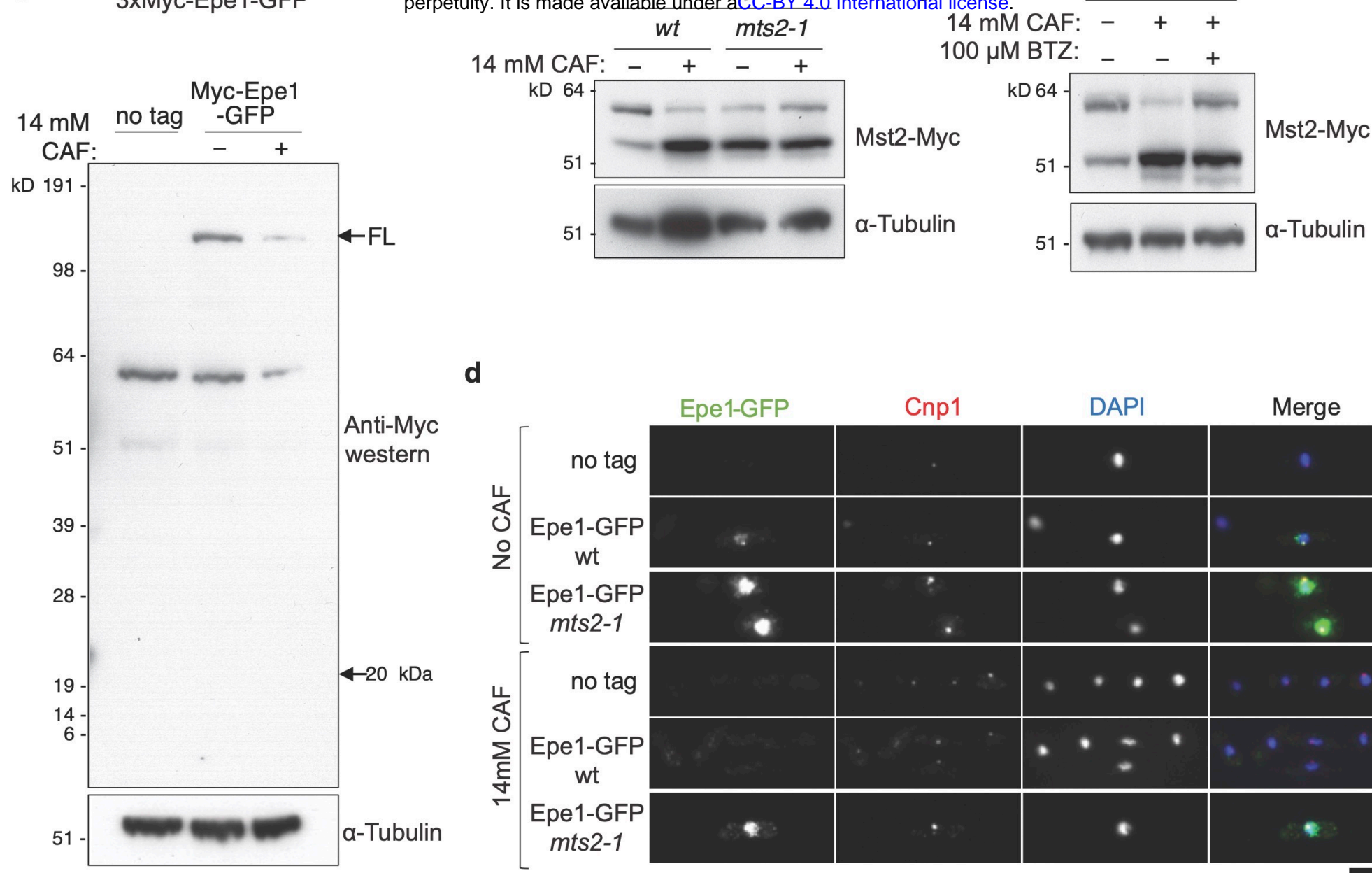

d
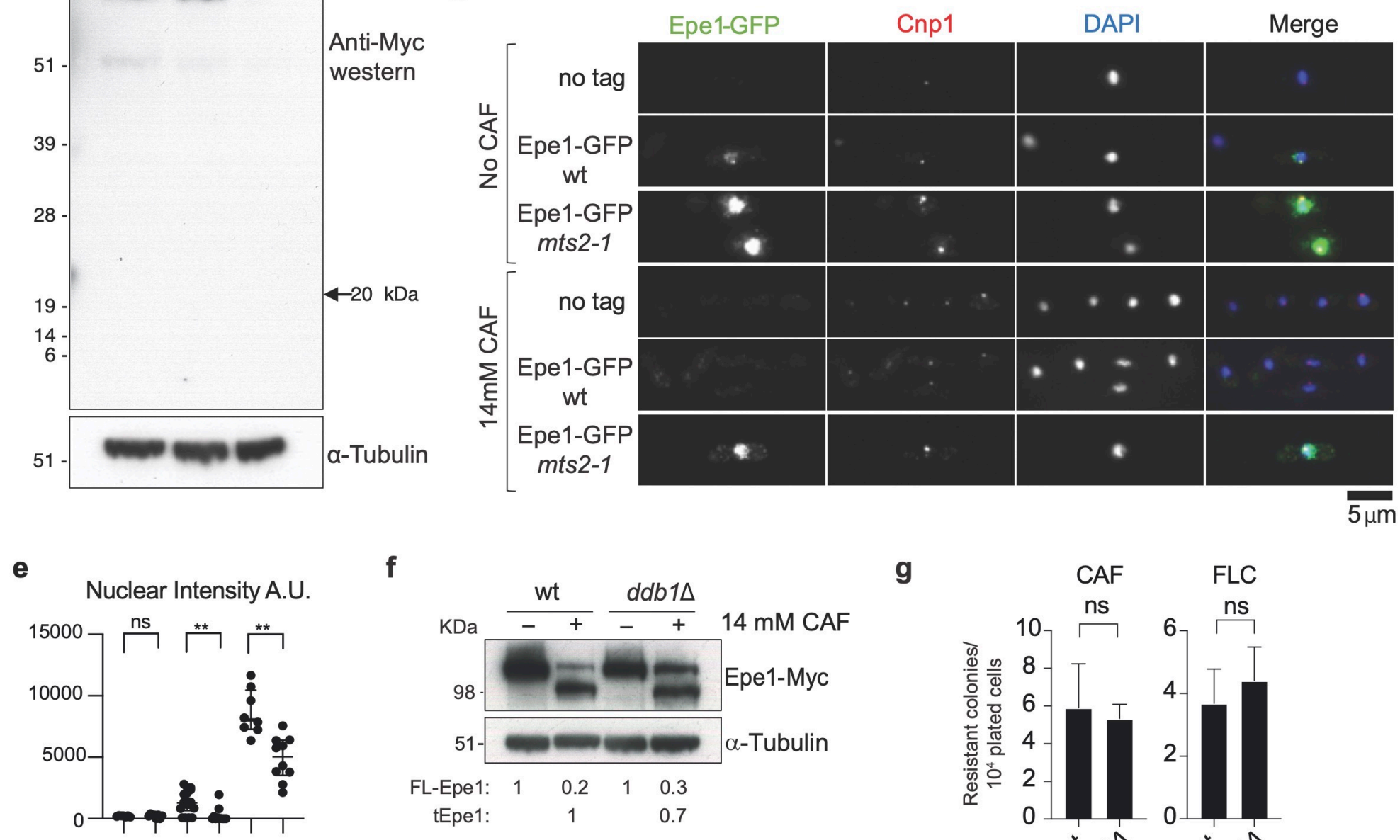

f

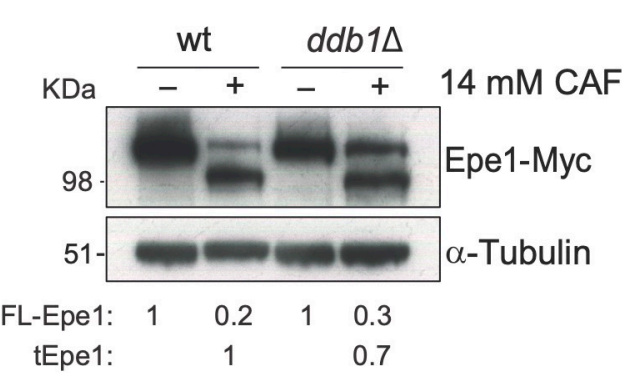

g

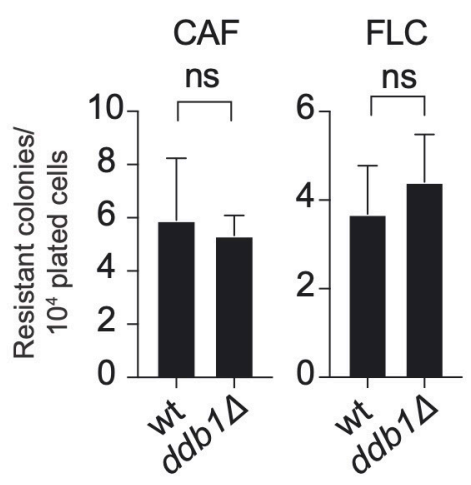




\section{Supplemental Fig. 3. A caffeine-induced N-terminal processing product is not detectable but Epe1-associated ubiquitination increases and Epe1 processing is sensitive to loss of specific E3 ligases which influence resistance}

a. Anti-Myc western of cells untreated (-)/treated (+) with $14 \mathrm{mM}$ caffeine showing that a predicted $\mathrm{N}$-terminal $20 \mathrm{kDa}$ Myc-Epe1 $1_{1-150}$ processing product is not detectable.

b. Western showing detection of both isoforms of the histone acetyltransferase Mst2-Myc or $\alpha$-tubulin from wild-type or mst2-1 proteasome defective cells untreated (-)/treated $(+)$ with $14 \mathrm{mM}$ caffeine for $16 \mathrm{~h}$. This control demonstrates that other known stress-induced changes still occur in mst2-1 cells.

c. Western showing detection of both isoforms of the histone acetyltransferase Mst2-Myc or $\alpha$-tubulin from wild-type cells incubated without (-)/with (+) with the $26 \mathrm{~S}$ proteasome inhibitor Bortezomib (BTZ) prior to no caffeine $(-) / 14 \mathrm{mM}$ caffeine $(+)$ treatment for $16 \mathrm{~h}$. This control demonstrates that other known stress-induced changes still occur in the presence of BTZ.

d. Immunolocalization of Epe1-GFP in wild-type or $m t s 2-1$ cells untreated $(-) /$ treated $(+)$ with $14 \mathrm{mM} / 16 \mathrm{~h}$ caffeine. No tag, negative control.

e. Quantification of anti-GFP/Epe1-GFP nuclear signals of cells in d.

f. Western detecting Epe1-GFP or $\alpha$-tubulin in wild-type or $d d b 1 \Delta$, cells untreated (-)/treated $(+)$ with $14 \mathrm{mM}$ caffeine for $16 \mathrm{~h}$. Numbers below tracks: levels of full-length FL-Epe1 and truncated tEpe 1 normalised to no treatment and adjusted relative to $\alpha$-tubulin loading control, measurement average of 2 biological replicates.

g. Number of resistant colonies formed $/ 1 \times 10^{4}$ viable cells by wild-type or ddb1 $\Delta$ cells plated on caffeine or fluconazole plates.

Statistical analysis of three biological replicates performed as in Materials and Methods. 
bioRxiv preprint doi: https://doi.org/10.1101/2021.12.20.473483; this version posted December 20, 2021. The copyright holder for this

preprint (which was not certified by peer review) is the author/funder, who has granted bioRxiv a license to display the preprint in perpetuity. It is made available under aCC-BY 4.0 International license.

a

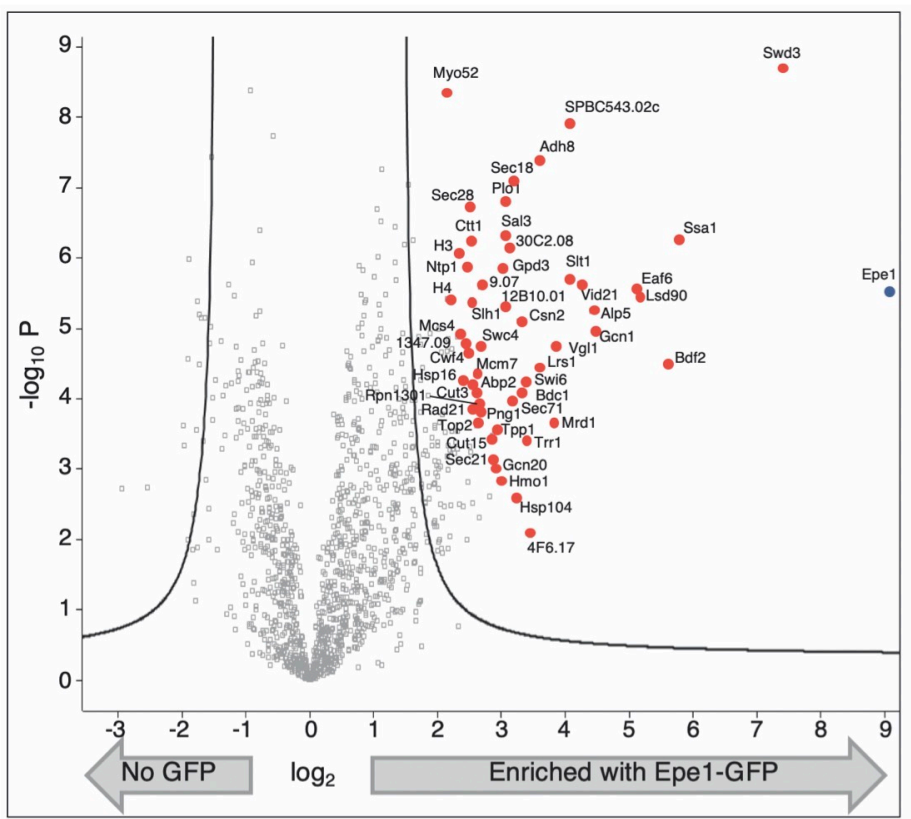

\begin{tabular}{|c|c|c|}
\hline \multicolumn{3}{|c|}{ Proteins enriched with Epe1-GFP } \\
\hline \multicolumn{3}{|c|}{ Protein Location $\quad$ Function } \\
\hline Swd3 & Nuc & Set1C complex \\
\hline $\begin{array}{l}\text { Myo52 } \\
543.02\end{array}$ & $\begin{array}{l}\text { Cyto } \\
\text { Cyto }\end{array}$ & $\begin{array}{l}\text { Myosin type } V \\
\text { DNAJC7/Hsp40 family }\end{array}$ \\
\hline Adh8 & Cyto & Alcohol Dehydrogenase \\
\hline Sec18 & Cyto & Secretion \\
\hline Plo1 & Nuc & Polo Kinase \\
\hline Sec28 & Cyto & Coatomer \\
\hline Ssa1 & Cyto & Hsp70 family \\
\hline Sal3 & Nuc & Nuclear import \\
\hline Ctt1 & Nuc + Cyto & Catalase \\
\hline $30 \mathrm{C} 2.08$ & Nuc + Cyto & Fungal protein \\
\hline Hht1 & Nuc & Histone $\mathrm{H} 3$ \\
\hline Ntp1 & Cyto & Trehalase \\
\hline Gpd3 & Cyto & GAPDH \\
\hline Sit1 & Nuc + Cyto & Unknown \\
\hline C9.07 & Nuc + Cyto & Rbg1/Translation \\
\hline Vid21 & Nuc & Nua4 HAT complex \\
\hline Eaf6 & Nuc & Nua4 HAT complex \\
\hline Lsd90 & Cyto & Fatty acid metabolism \\
\hline Hhf1 & Nuc & Histone $\mathrm{H} 4$ \\
\hline $\operatorname{Slh} 1$ & Cyto & RNA helicase \\
\hline 12B10.01 & Nuc + Cyto & E3 Ub Ligase \\
\hline Alp5 & Nuc & Chromatin remodelling \\
\hline Csn2 & Nuc + Cyto & COP9/signalosome \\
\hline Gen1 & Cyto & Translation initiation \\
\hline Mcs4 & Cyto & Kinase regulator \\
\hline 1347.09 & Cyto & Ubiquitone biosynthesis \\
\hline Swc4 & Nuc & Swric chromatin remodelling \\
\hline Vgl1 & Cyto & RNA binding \\
\hline Cwf4 & Nuc & Splicing \\
\hline Bdf2 & Nuc & Chromatin binding \\
\hline $\begin{array}{l}\text { Lrs1 } \\
\text { Mcm7 }\end{array}$ & $\begin{array}{l}\text { Cyto } \\
\text { Nuc }\end{array}$ & $\begin{array}{l}\text { Leu-tRNA Ligase } \\
\text { MCM Complex }\end{array}$ \\
\hline Hsp16 & $\mathrm{Nuc}+$ Cyto & Heat shock protein chaperone \\
\hline Swi6 & Nuc & Chromatin binding \\
\hline Abp2 & Nuc & DNA/chromatin-associated \\
\hline Cut3 & Nuc & Condensin subunit \\
\hline Bdc1 & Nuc & Chromatin binding \\
\hline Rpn1301 & Nuc + Cyto & 19S Proteasome RP subunit \\
\hline Sec71 & Cyto & ER/Golgi function \\
\hline Rad21 & Nuc & Cohesin subunit \\
\hline Png1 & Nuc & NuA4 HAT complex \\
\hline Mrd1 & Nuc & $\begin{array}{l}\text { Ribosome biogenesis } \\
\text { DNA Topoisomerse II }\end{array}$ \\
\hline $\begin{array}{l}\text { Top2 } \\
\text { Tpp1 }\end{array}$ & $\begin{array}{l}\text { Nuc } \\
\text { Cyto }\end{array}$ & $\begin{array}{l}\text { DNA Topoisomerse II } \\
\text { Trehalose-6-phosphate PPase }\end{array}$ \\
\hline Cut15 & Nuc & Importin alpha; nuclear pore \\
\hline Trr1 & Nuc + Cyto & Thioredoxin reductase \\
\hline Sec21 & Cyto & Coatomer subunit \\
\hline Gen20 & Cyto & AAA ATPase \\
\hline $\mathrm{Hmo1}$ & Nuc & RNAPI HMG transcription factor \\
\hline Hsp104 & Nuc + Cyto & Heat shock protein, disaggregase \\
\hline $4 \mathrm{~F} 6.17$ & Cyto & Mitochrondrial HSP. \\
\hline - Order: T & -Bottom of Volc & - Epe1-GFP bait \\
\hline
\end{tabular}

b

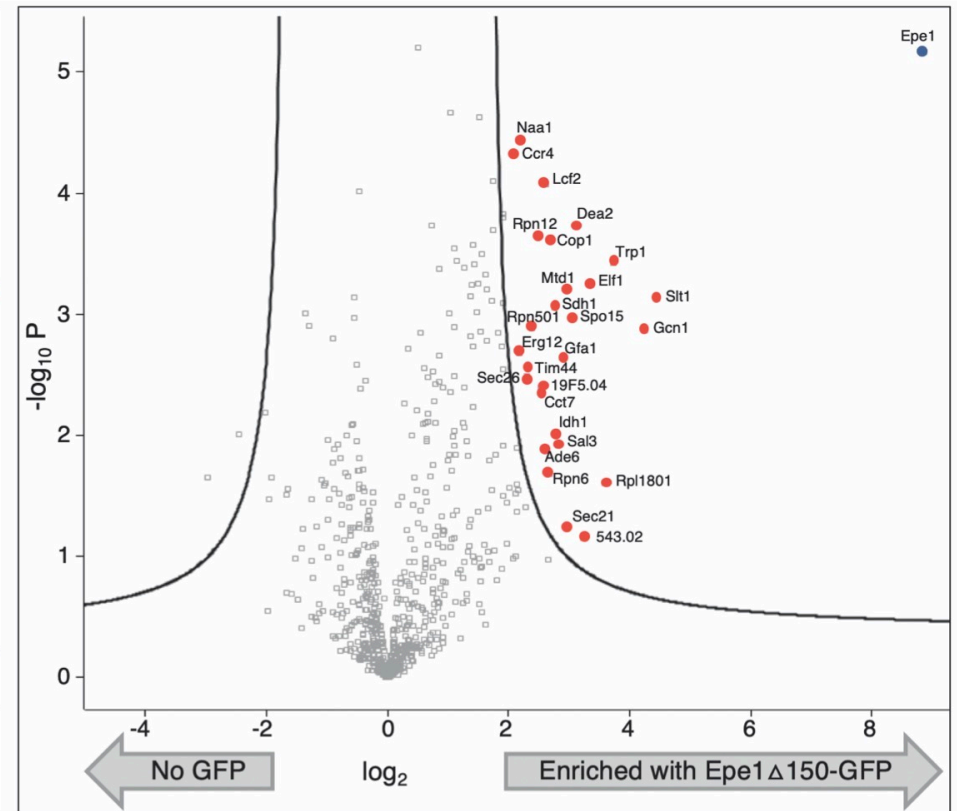

\begin{tabular}{|c|c|c|}
\hline \\
\hline Protein & Location & Proteins enriched with Epe $1 \Delta 150$-GFP \\
\hline Naa15 & Cyto & NatA N-terminal Acetyltransferase \\
\hline Ccr4 & Nuc + Cyto & $3^{\prime}-5^{\prime}-\operatorname{exo}$ \\
\hline Lcf2 & Cyto & Fatty acid CoA ligase \\
\hline Dea2 & Nuc + Cyto & Adenine deaminase \\
\hline Rpn12 & Nuc + Cyto & 19S Proteasome RP subunit \\
\hline Cop1 & Cyto & Coatomer a subunit \\
\hline Trp1 & Cyto & Anthranilate synthase \\
\hline Elf1 & Cyto & AAA ATPase \\
\hline Mtd1 & Nuc + Cyto & $\begin{array}{l}\text { Methylene } \\
\text { tetrahydrofolate reductase }\end{array}$ \\
\hline Slt1 & Cyto & Unknown \\
\hline Sdh1 & Cyto & Succinate dehydrogenase \\
\hline $\begin{array}{l}\text { Spo15 } \\
\text { Rpn501 }\end{array}$ & $\begin{array}{l}\text { SPB } \\
\text { Nuc }+ \text { Cyto }\end{array}$ & $\begin{array}{l}\text { SPB Unknown } \\
\text { 19S Proteasome RP subunit }\end{array}$ \\
\hline Gen1 & Cyto & Translation initiation \\
\hline Erg12 & Nuc + Cyto & Mevalonate Kinase \\
\hline Gfa1 & Cyto & $\begin{array}{l}\text { Glutamine-fructose } \\
\text { 6-phosphate transaminase }\end{array}$ \\
\hline Tim44 & Cyto & Tim23 translocase \\
\hline Sec26 & Cyto & Coatomer subunit \\
\hline $19 F 5.04$ & Cyto & Aspartate Kinase \\
\hline Cct7 & $\mathrm{Nuc}+$ Cyto & Chaperonin T-complex \\
\hline Idh1 & Cyto & Isocitrate dehydrogenase \\
\hline Sal3 & Nuc & Nuclear import \\
\hline Ade6 & Cyto & $\begin{array}{l}\text { Phosphoribosylaminoimidazole } \\
\text { carboxylase }\end{array}$ \\
\hline Rpn6 & Nuc + Cyto & 19S proteasome \\
\hline Rpl1801 & Cyto & Ribosomal protein \\
\hline Sec21 & Cyto & Coatomer subunit \\
\hline 543.02 & Cyto & DNAJC7/Hsp40 family \\
\hline Order: & -Bottom of Volc & - Epe1D150-GFP bait \\
\hline
\end{tabular}




\section{Supplemental Fig. 4. Chromatin-associated nuclear proteins are enriched with full length Epe1 whereas more cytoplasmic proteins are enriched with constitutively truncated Epe1 $\Delta$ N150-GFP}

a. Volcano plot of proteins enriched with full-length Epe1-GFP extracted from cells detected by proteomic analysis (top), specific proteins labelled (red dots). Table with names and functions of proteins enriched (bottom). Full data, Supplementary Table 6.

b. Volcano plot of proteins enriched with constitutively processed Epe1 $\Delta$ N150-GFP extracted from cells and detected by proteomic analysis (top), specific proteins labelled (red dots). Table with names and functions of proteins enriched (bottom). Full data, Supplementary Table 7. 
bioRxiv preprint doi: https://doi.org/10.1101/2021.12.20.473483; this version posted December 20, 2021. The copyright holder for this

preprint (which was not certified by peer review) is the author/funder, who has granted bioRxiv a license to display the preprint in perpetuity. It is made available under aCC-BY 4.0 International license.

a
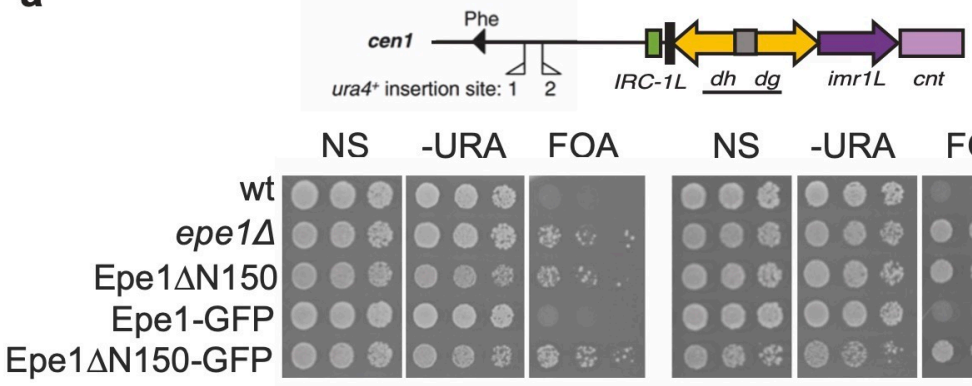

site 1

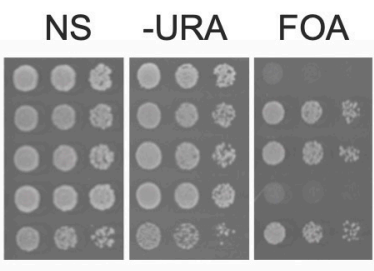

site 2

b

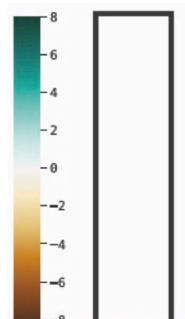
-SPNCRNA.70 -SPAC212.08C -SPAC212.06c -ght3

-SPAC1F8.02c SPAPB1A11.03 SPNCRNA. 231 SPNCRNA. 232 SPNCRNA. 234 SPNCRNA. SPAC869.09 - $\mathrm{pcm} 2$

- mel1 SPAC869.06 SPAC186.01 SPAC186.03 SPAC186.03 SPAC186.04C SPAC186.05C SPAC186.06 SPAC186.07 PAC186.08C PPAC186.09 SPAC750.05 SPAC750.06c SPAC750.07c (SPAC750.08 SPBC1348.01 PBC1348.02 nol02

PBPB21E7.02C SPBPB21E7.10 SPBPB2157.11 SPBPB21E7.04C mug14

fbp1

SPNCRNA. 371

-SPNCRNA. 389

-SPBC1289.14

SPBP 463.03

PBPB2 B2.06C -SPBPB2B2 . 19C SPBCPT2R1.04 -SPBCPT2R1.06 -SPBCPT 2R1.07C -meu3 PNCRNA. 482 (PPNCRNA.48

Chr I

Chr II

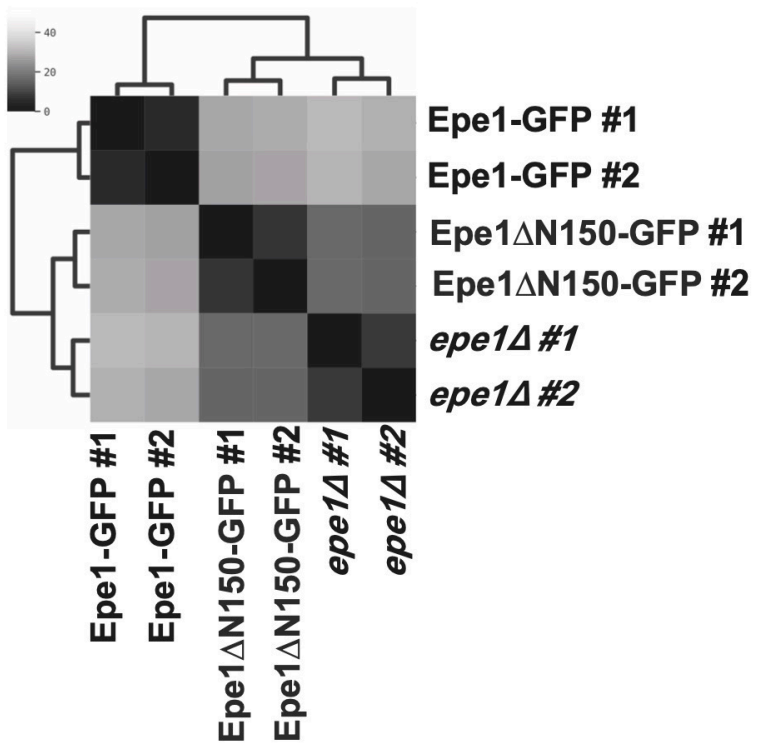

Supplementary Figure 5. Yaseen et al., 


\section{Supplemental Fig. 5. Altered silencing and gene expression in epe1 $\Delta$ and Epe1- $\triangle$ N150-GFP cells}

a. Wild-type, epe1 $\Delta$, Epe1- $\Delta$ N150, Epe1-GFP/wt and Epe1- $\Delta$ N150-GFP cells harbouring ura $4^{+}$marker gene insertions at either site 1 or site 2 as indicated (top) were serially diluted and plated on non-selective (N/S), selective (-URA) or counter-selective (FOA) plates.

b. Heat-map generated from processed data of RNA-seq two biological replicates from Epe $1 \Delta$ N150-GFP or epe $1 \Delta$ cells compared with that of wild-type Epe1-GFP cells. Genes with higher (turquoise) or lower (brown) expression relative to wild-type Epe1-GFP cells are shown as a $\log _{2}$ scale. The position of specific affected genes along $S$. pombe chromosomes $\mathrm{Chr}$ I, II, III are shown with arrowheads indicating telomeres on $\mathrm{Chr}$ I and Chrll. The annotated S. pombe genome shows only rDNA arrays (rectangles) at both ends of Chr III.

c. Heat-map showing that RNA-seq data (used in b.) resulting from two Epe $1 \Delta$ N150-GFP and epe $1 \Delta$ biological replicates are more similar to each other than they are to wild-type Epe1-GFP cells. 
bioRxiv preprint doi: https://doi.org/10.1101/2021.12.20.473483; this version posted December 20, 2021. The copyright holder for this preprint (which was not certified by peer review) is the author/funder, who has granted bioRxiv a license to display the preprint in perpetuity. It is made available under aCC-BY 4.0 International license.

a

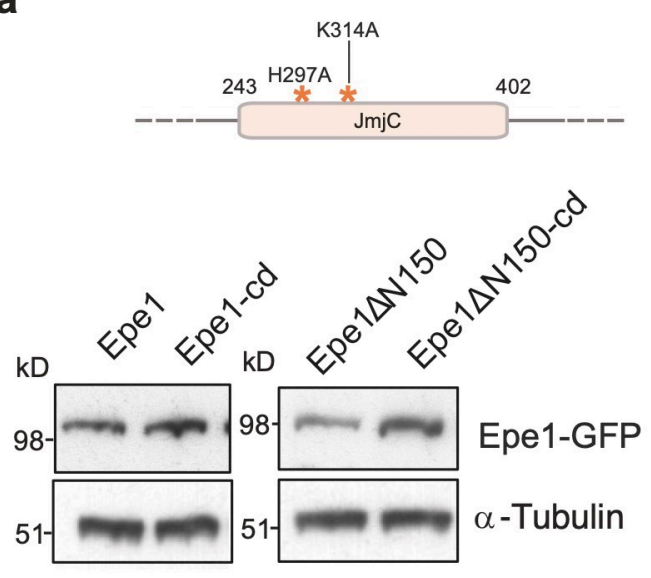

b

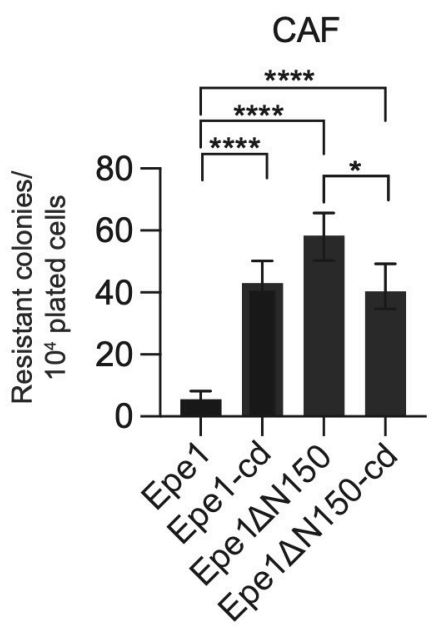

FLC

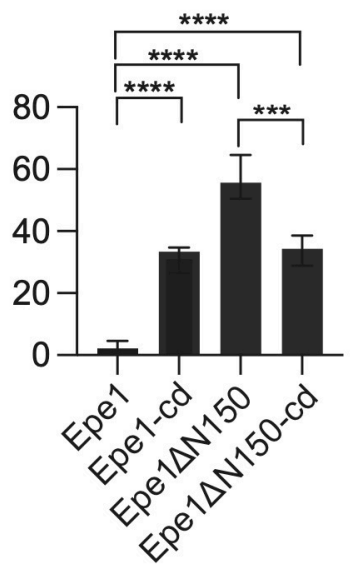

Supplementary Figure 6. Yaseen et al., 


\section{Supplemental Fig. 6. Cells expressing predicted catalytically inactive Epe1-GFP and} Epe1- $\triangle$ N150-GFP exhibit decreased resistance

a. Schematic showing position of $\mathrm{H} 297 \mathrm{~A}$ and K314A mutations predicted to reduce association of the essential iron/Fe(2) and 2-Oxoglutarate ( $\alpha$-ketoglutarate) cofactors, respectively, with the JmjC demethylase domain of Epe1 (Top). Westerns detecting Epe1GFP, Epe1-cd-GFP, Epe1 $\Delta$ N150-GFP and Epe1 $\Delta$ N150-cd-GFP (cd; catalytically dead) or $\alpha-$ tubulin (bottom).

b. Number of resistant colonies formed/1 $\times 10^{4}$ viable cells by Epe1-GFP, Epe1-cd-GFP, Epe1 $1 \Delta$ N150-GFP and Epe1 $\Delta$ N150-cd-GFP cells plated on caffeine or fluconazole plates. 
a

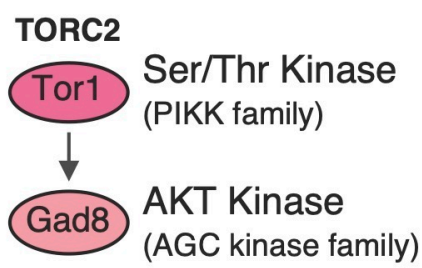

b

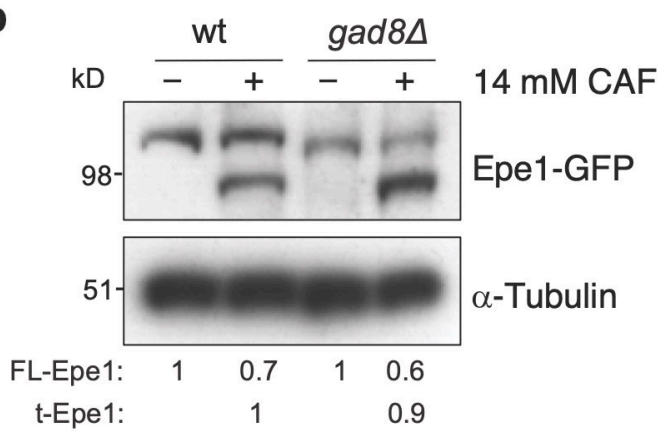

C

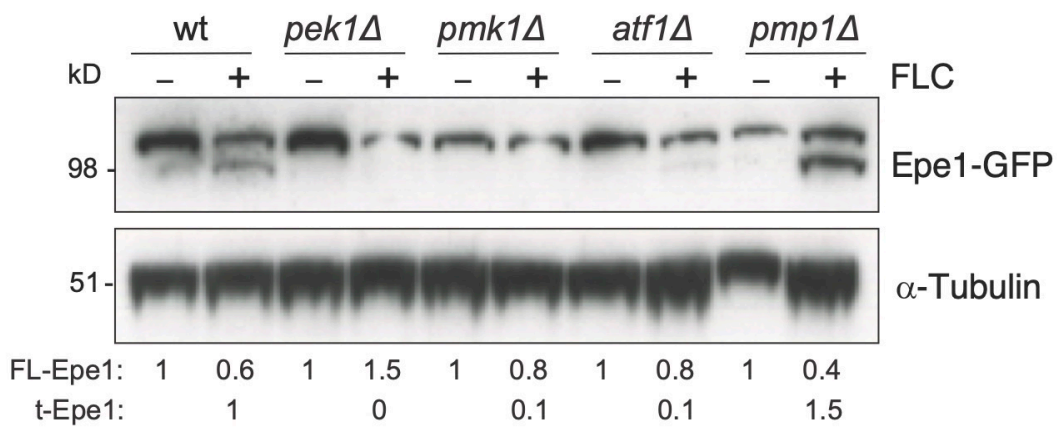

d

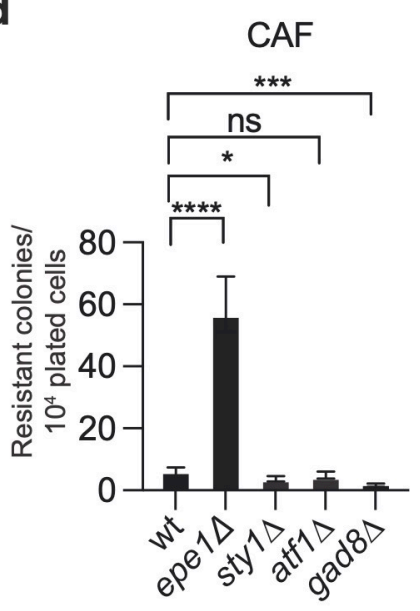

e

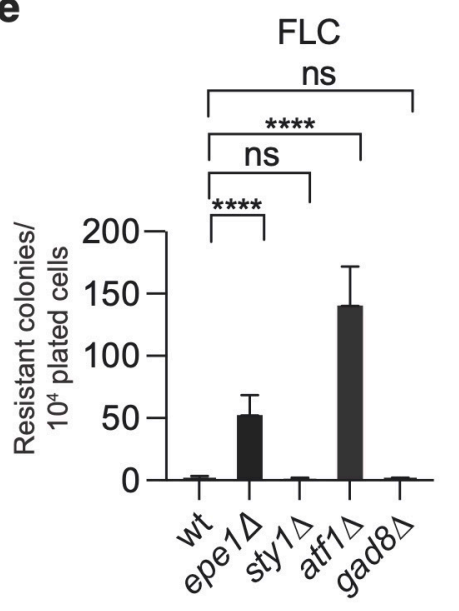




\section{Supplemental Fig. 7. The cell integrity/Pmk1 but not the TORC2/Gad8 stress signalling pathway regulates Epe1 processing and resistance}

a. Diagram of part the S. pombe TORC2/Tor1-dependent signalling pathway.

b. Western detecting Epe1-GFP or $\alpha$-tubulin from wild-type, or gad8 $\Delta$ cells untreated $(-) /$ treated $(+)$ with $14 \mathrm{mM} / 16 \mathrm{~h}$ caffeine.

c. Western detecting Epe1-Myc or $\alpha$-tubulin from wild-type, pek1 $\Delta, p m k 1 \Delta$, atf1 $\Delta$ or pmp1 $\Delta$ cells untreated (-)/treated $(+)$ with $0.5 \mathrm{mM} / 16 \mathrm{~h}$ fluconazole (FLC).

d. Number of resistant colonies formed $/ 1 \times 10^{4}$ viable cells plated by wild-type, epe $1 \Delta$, sty $1 \Delta$, atf $1 \Delta$ and gad $8 \Delta$ on plates containing $16 \mathrm{mM}$ caffeine (CAF).

e. Number of resistant colonies formed $/ 1 \times 10^{4}$ viable cells plated by wild-type, epe $1 \Delta$, sty $1 \Delta$, atf1 $\Delta$ and gad $8 \Delta$ on plates containing $0.5 \mathrm{mM}$ fluconazole (FLC).

Statistical analysis of three biological replicates performed as in Materials and Methods.

\section{Supplemental Data References}

1. Borek, W. E. et al. Mto2 multisite phosphorylation inactivates non-spindle microtubule nucleation complexes during mitosis. Nat. Commun. 6, (2015). 